\title{
Mechanistic Studies Lead to Dramatically Improved Reaction Conditions for the Cu-Catalyzed Asymmetric Hydroamination of Olefins
}

\author{
Jeffrey S. Bandar ${ }^{\ddagger}$, Michael T. Pirnot ${ }^{\ddagger}$, and Stephen L. Buchwald* \\ Department of Chemistry, Massachusetts Institute of Technology \\ Cambridge, Massachusetts 02139, United States
}

\section{Contents}

I. General information S1

II. Initial-rate kinetic measurements $\quad$ S2

III. Nonlinear effect studies $\quad \mathrm{S} 12$

IV. Kinetic isotope effect studies with diphenylsilane $\quad$ S13

V. Reaction Progress Kinetic Analysis (RPKA) by ${ }^{19}$ F-NMR $\quad$ S13

VI. Reaction optimization $\quad \mathrm{S} 15$

VII. Linear free energy relationship studies $\quad \mathrm{S} 18$

VIII. Isotope labeling studies $\quad$ S20

IX. Preparation of ligated copper precomplex (CuCatMix) S21

X. Optimized hydroamination procedure $\quad$ S22

XI. Hydroamination with low loadings of DTBM-SEGPHOS S25

XII. Preparation of amine electrophiles $\quad$ S26

XIII. ${ }^{31}$ P-NMR Studies $\quad$ S28

XIV. Electrospray ionization studies $\quad$ S33

XV. References $\quad$ S37

XVI. Chiral HPLC traces $\quad$ S38

XVII. NMR spectra $\quad$ S46

\section{General Information.}

General reagent information. All reactions for kinetic analysis were set up in a nitrogen-filled glove box. Tetrahydrofuran (THF) was dried and deoxygenated by passage through two packed columns of neutral alumina and copper(II) oxide under a positive pressure of argon. $(R)$ - and $(S)$-DTBM-SEGPHOS ligands were purchased from Strem Chemicals Inc. and Takasago International Co. and used as received. Diethoxy(methyl)silane and dimethoxy(methyl)silane were purchased from Tokyo Chemical Industry Co. (TCI) and stored in a nitrogen-glove box at $-20{ }^{\circ} \mathrm{C}$ for long term storage. Diethoxy(methyl)silane and dimethoxy(methyl)silane were also transferred to vials that were stored under nitrogen in a freezer at $-5{ }^{\circ} \mathrm{C}$ for reaction set-up outside of the glove box. All other solvents and commercial reagents were used as received from Sigma Aldrich, Alfa Aesar, Acros Organics and TCI unless otherwise noted. Flash column chromatography was performed using $40-63 \mu \mathrm{m}$ silica gel (SiliaFlash ${ }^{\circledR}$ F60 from 
Silicycle). Organic solutions were concentrated using a Buchi rotary evaporator.

General analytical information. All new compounds were characterized by NMR spectroscopy, IR spectroscopy, elemental analysis and melting point analysis (if solids). ${ }^{1} \mathrm{H}$ and ${ }^{13} \mathrm{C}$ NMR spectra were recorded in $\mathrm{CDCl}_{3}$ (except where noted) on a Bruker AMX-400 spectrometer. Data for ${ }^{1} \mathrm{H}$ NMR are reported as follows: chemical shift in reference to residual $\mathrm{CHCl}_{3}$ at $7.26 \mathrm{ppm}(\delta \mathrm{ppm})$, multiplicity $(\mathrm{s}=$ singlet, br $\mathrm{s}=$ broad singlet, $\mathrm{d}=$ doublet, $\mathrm{t}=$ triplet, $\mathrm{q}=$ quartet, $\mathrm{dd}=$ doublet of doublets, $\mathrm{td}=$ triplet of doublets, $\mathrm{m}=$ multiplet), coupling constant $(\mathrm{Hz})$, and integration. Data for ${ }^{13} \mathrm{C} \mathrm{NMR}$ are reported in terms of chemical shift in reference to the $\mathrm{CDCl}_{3}$ solvent signal $(77.16 \mathrm{ppm})$. ${ }^{31} \mathrm{P}$ NMR and ${ }^{19} \mathrm{~F}-\mathrm{NMR}$ spectroscopy were performed on a Varian Inova $500 \mathrm{MHz}$ spectrometer and all spectra are referenced to an external standard $(\alpha, \alpha, \alpha$-trifluorotoluene set to $\delta-63.7 \mathrm{ppm}$ for ${ }^{19} \mathrm{~F}-\mathrm{NMR}$; $a q . \mathrm{H}_{3} \mathrm{PO}_{4}$ set to $\delta 0.0 \mathrm{ppm}$ for $\left.{ }^{31} \mathrm{P}-\mathrm{NMR}\right)$. IR spectra were recorded on a Thermo Scientific Nicolet iS5 spectrometer (iD5 ATR, diamond) and are reported in terms of frequency of absorption $\left(\mathrm{cm}^{-1}\right)$. Melting points were measured on a Mel-Temp capillary melting point apparatus. Optical rotations were measured using a Jasco P-1010 digital polarimeter. Elemental analyses were performed by Atlantic Microlabs Inc., Norcross, GA. Electrospray ionization mass spectrometry (ESI-MS) studies were conducted on a Bruker Daltonics APEX IV 4.7T FT-ICR spectrometer while operating in positive ion mode. HPLC analysis was performed on an Agilent Technologies 1200 series instrument with Daicel Chiralpak and Chiralcel chiral columns $(25 \mathrm{~cm})$ using the given conditions. Achiral gas chromatography (GC) analyses were performed on an Agilent 7890A gas chromatograph with an FID detector using a J\&W DB-1 column (10 m, $0.1 \mathrm{~mm}$ I.D.). Thin-layer chromatography (TLC) was performed on silica gel $60 \AA \mathrm{F}_{254}$ plates (SiliaPlate from Silicycle) and visualized with UV light or potassium permanganate stain. Preparatory thin-layer chromatography (PrepTLC) was performed on silica gel GF with UV $254(20$ x $20 \mathrm{~cm}, 1000$ microns, catalog \# 02013 from Analtech) and visualized with UV light.

\section{Initial-rate kinetic measurements}

\section{IIA. General Procedure for Kinetic Experiments}

Reactions used for kinetic analysis were set up in a nitrogen-filled glove box using the following general sequence:

1) A $(S)$-DTBM-SEGPHOS, $\mathrm{Cu}(\mathrm{OAc})_{2}$, and silane stock solution in THF was prepared.

2) Styrene, amine electrophile, and $n$-dodecane standard were measured into a separate reaction vial.

3) The desired amount of stock solution prepared in step 1) was transferred to the reaction vial prepared in step 2).

4) The reaction vial was quickly capped with a screw top septum, removed from the glove box, placed under a positive pressure of argon, and inserted into an oil bath preheated to $40{ }^{\circ} \mathrm{C}$.

5) Reaction progress was monitored by GC analysis of reaction aliquots taken at $10 \mathrm{~min}$ intervals for approximately $2 \mathrm{~h}$. 
6) The initial reaction rate was determined by plotting product formation over time (up to $20 \%$ conversion).

7) This process was repeated 2 or 3 times for each experiment in order to arrive at an average value of $\mathrm{d}[\mathrm{P}] / \mathrm{dt}$.

\section{IIB. Representative process for the determination of $\mathrm{Cu}(\mathrm{OAc})_{2}+(S)$-DTBM- SEGPHOS rate order.}

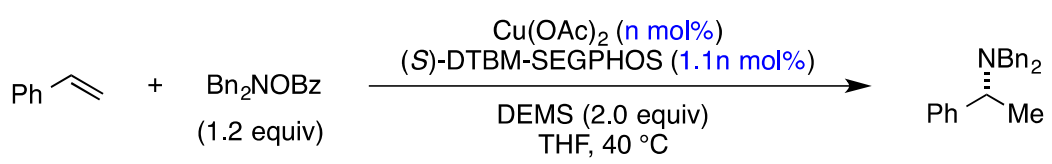

Note: The rate order of $\mathrm{Cu}(\mathrm{OAc})_{2}+(S)$-DTBM-SEGPHOS was first determined as a single unit always using a 1:1.1 ratio, respectively. For rate orders of the individual components of this mixture see section SIIC-E, SIIG, and SIIH.

Detailed prototypical example procedure: In a nitrogen-filled glove box, a catalyst stock solution was prepared by adding $\mathrm{Cu}(\mathrm{OAc})_{2}(3.6 \mathrm{mg}, 0.02 \mathrm{mmol}, 0.08$ equiv), $(S)$ DTBM-SEGPHOS (26 mg, $0.022 \mathrm{mmol}, 0.088$ equiv), and THF (2.0 mL) to an ovendried $4 \mathrm{~mL}$ vial containing a magnetic stir bar. This mixture was stirred for $10 \mathrm{~min}$ as a homogenous blue solution formed. At this time, diethoxy(methyl)silane (320 $\mu \mathrm{L}, 2.00$ mmol, 8.0 equiv) was added and the solution was stirred for another $10 \mathrm{~min}$, during which time the solution developed a bright orange color. An aliquot of this solution (580 $\mu \mathrm{L}$ ) was then transferred to a reaction tube (Fisherbrand, 13 x $100 \mathrm{~mm}$, catalog no. $1495925 \mathrm{~A})$ containing styrene $(29 \mu \mathrm{L}, 26.0 \mathrm{mg}, 0.25 \mathrm{mmol}, 1.0$ equiv), $O$-benzoyl- $N, N$ dibenzylhydroxylamine ( $95.2 \mathrm{mg}, 0.30 \mathrm{mmol}, 1.2$ equiv), $n$-dodecane (57 $\mu \mathrm{L}, 42.6 \mathrm{mg}$, $0.25 \mathrm{mmol}, 1.0$ equiv), and a magnetic stir bar. The reaction tube was quickly capped (Thermo Scientific $13 \mathrm{~mm}$ screw cap with TEF/SIL septa, catalog no. C4015-66A) and removed from the glove box. A needle line under positive pressure of argon was inserted into the septum and the reaction tube was placed in an oil bath preheated to $40{ }^{\circ} \mathrm{C}$. Aliquots were taken at 10 min intervals by removing a small amount (ca. $30 \mu \mathrm{L}$ ) of the reaction solution and passing it through a small silica gel plug, eluting with EtOAc. GC analysis was used to quantitate product formation using $n$-dodecane as the internal standard. The reaction progress plot used to determine $\mathrm{d}[\mathrm{P}] / \mathrm{dt}$ for this reaction is provided below for example. This process was repeated to calculate an average rate value and its standard deviation. 


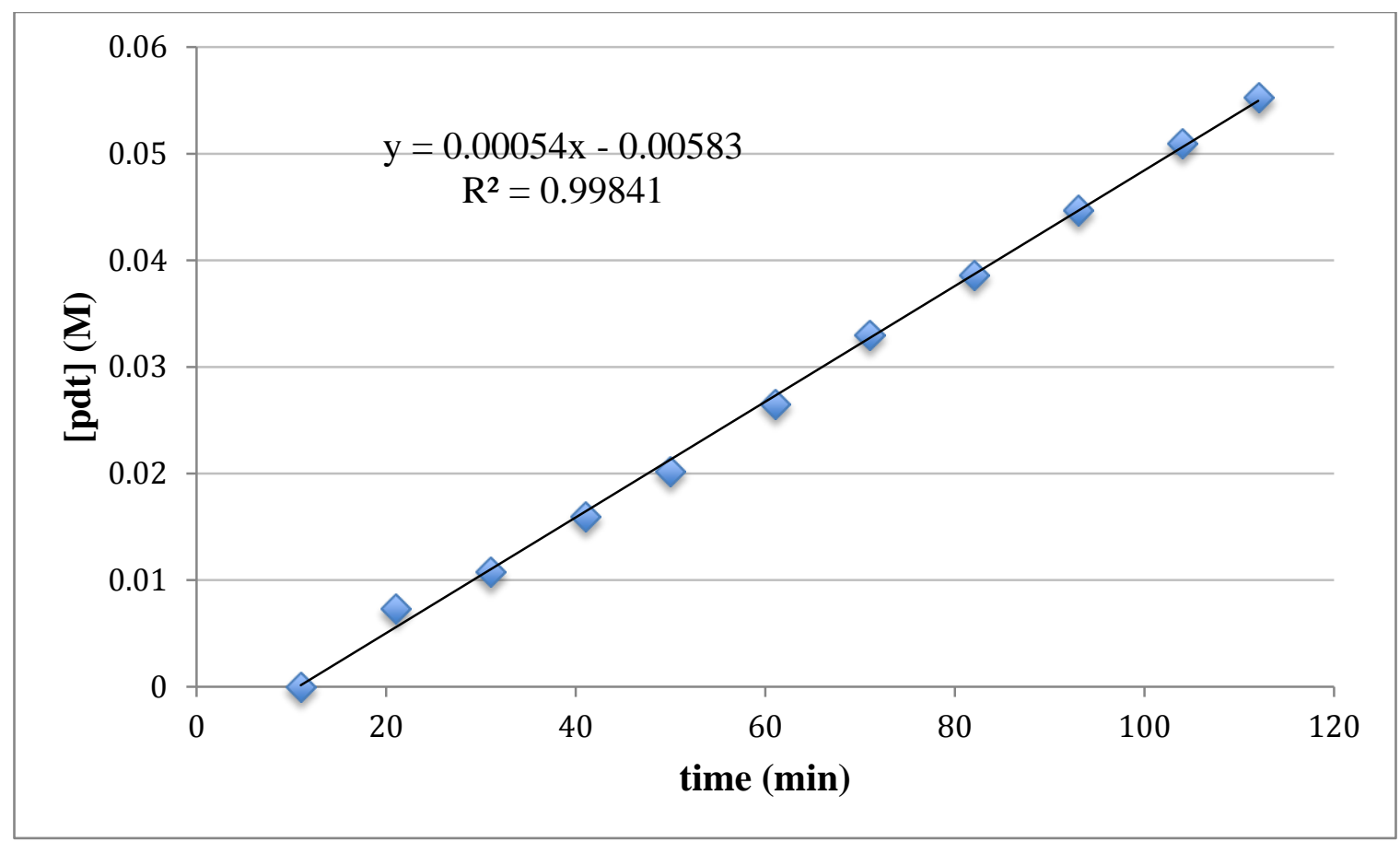

Figure S1. Sample reaction profile used for initial rate calculation using $\mathrm{Cu}(\mathrm{OAc})_{2}(2 \mathrm{~mol} \%)$ with $(S)$-DTBM-SEGPHOS (2.2 mol\%)

The overall procedure described above was repeated for various amounts of $\mathrm{Cu}(\mathrm{OAc})_{2}$ and $(S)$-DTBM-SEGPHOS (at a 1:1.1 ratio), always using a total reaction volume of approximately $760 \mu \mathrm{L}$. Similar reaction progress plots were prepared to determine the rates of these reactions and the results are compiled in the chart and graph below.

\begin{tabular}{|c|c|c|}
\hline$\left[\mathrm{Cu}(\mathrm{OAc})_{2}\right](\mathrm{M})$ & $\begin{array}{c}\text { Avg Rate } \\
(\mathrm{M} / \mathrm{min})\end{array}$ & $\begin{array}{c}\text { Standard } \\
\text { deviation }\end{array}$ \\
\hline $3.29 \times 10^{-3}$ & $1.61 \times 10^{-4}$ & $3.7 \times 10^{-5}$ \\
\hline $6.57 \times 10^{-3}$ & $4.61 \times 10^{-4}$ & $7.3 \times 10^{-5}$ \\
\hline $1.15 \times 10^{-2}$ & $6.67 \times 10^{-4}$ & $5.6 \times 10^{-5}$ \\
\hline $1.64 \times 10^{-2}$ & $8.69 \times 10^{-4}$ & $2.1 \times 10^{-5}$ \\
\hline $2.46 \times 10^{-2}$ & $9.27 \times 10^{-4}$ & $5.2 \times 10^{-5}$ \\
\hline $3.29 \times 10^{-2}$ & $9.53 \times 10^{-4}$ & $6.3 \times 10^{-5}$ \\
\hline
\end{tabular}

Table S1. Rates determined while varying $\left[\mathrm{Cu}(\mathrm{OAc})_{2}\right]$ and $[(S)$-DTBM-SEGPHOS] together (1:1.1 ratio); rate plotted against $\left[\mathrm{Cu}(\mathrm{OAc})_{2}\right]$ 


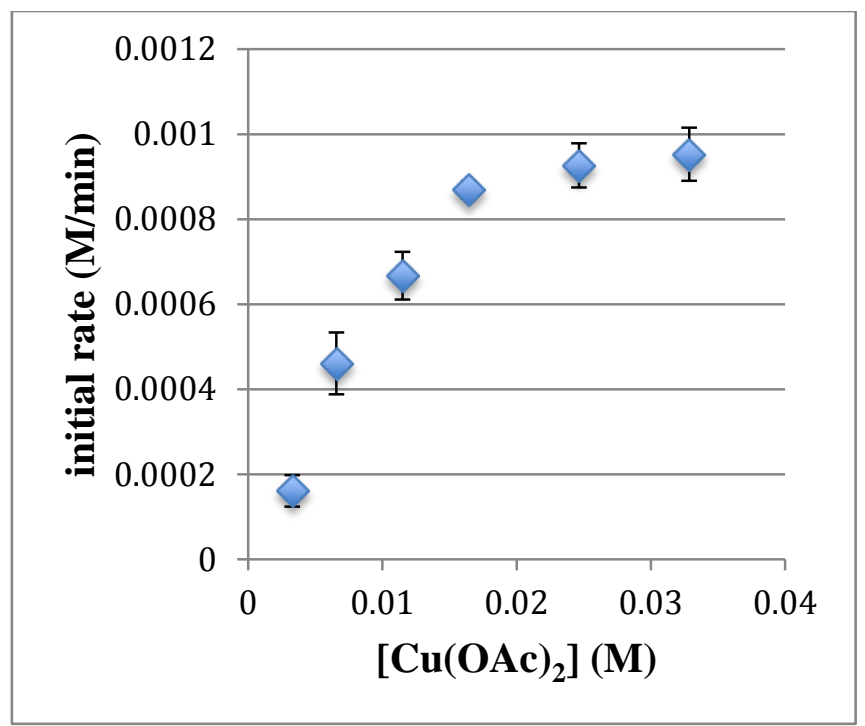

Figure $\mathrm{S} 2$. Rates determined while varying $\left[\mathrm{Cu}(\mathrm{OAc})_{2}\right]$ and $[(S)$-DTBM-SEGPHOS] together (1:1.1 ratio); rate plotted against $\left[\mathrm{Cu}(\mathrm{OAc})_{2}\right]$

\section{IIC. Styrene rate order}

$$
\begin{aligned}
& \mathrm{Cu}(\mathrm{OAc})_{2}(2 \mathrm{~mol} \%)
\end{aligned}
$$

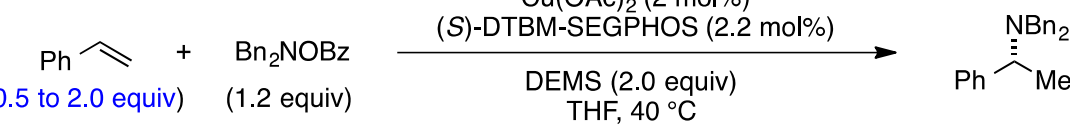

The overall process described above for the determination of $\mathrm{Cu}(\mathrm{OAc})_{2}+(S)$-DTBMSEGPHOS rate order was repeated for styrene at the indicated concentrations. The quantitative results and graphs of these experiments are provided below.

\begin{tabular}{|c|c|c|}
\hline $\begin{array}{c}\text { [styrene] } \\
(\mathrm{M})\end{array}$ & $\begin{array}{c}\text { Rate } \\
(\mathrm{M} / \mathrm{min})\end{array}$ & $\begin{array}{c}\text { Standard } \\
\text { deviation }\end{array}$ \\
\hline 0.164 & $5.7 \times 10^{-4}$ & $2.2 \times 10^{-5}$ \\
\hline 0.246 & $5.9 \times 10^{-4}$ & $2.2 \times 10^{-5}$ \\
\hline 0.411 & $5.6 \times 10^{-4}$ & $2.4 \times 10^{-5}$ \\
\hline
\end{tabular}

Table S2. Rates determined from varying [styrene] 


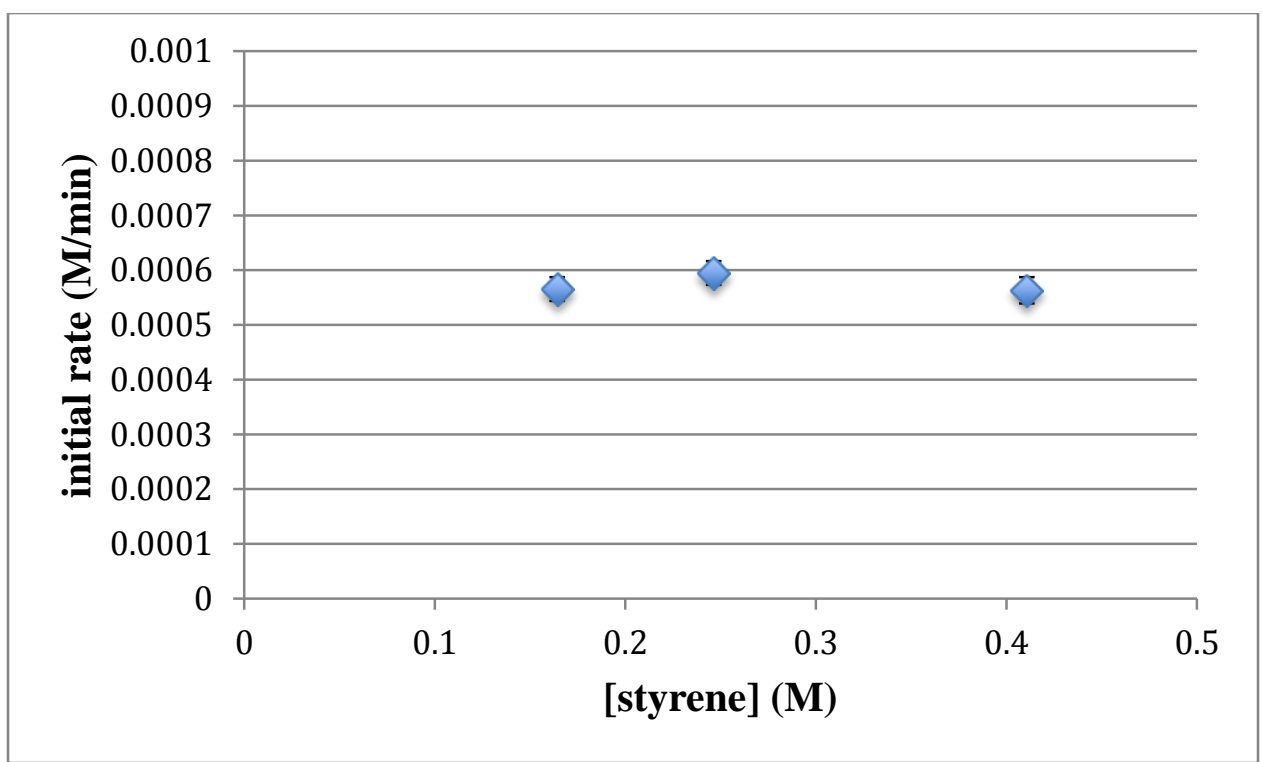

Figure S3. Rates determined while varying [styrene]

\section{IID. $\mathrm{Bn}_{2} \mathrm{NOBz}$ rate order}

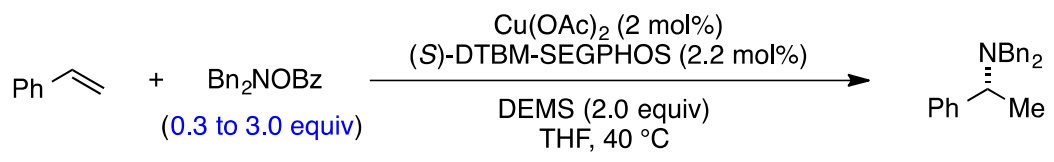

The overall process described above for the determination of $\mathrm{Cu}(\mathrm{OAc})_{2}+(S)$-DTBMSEGPHOS rate order was repeated for $\mathrm{Bn}_{2} \mathrm{NOBz}$ at the indicated concentrations. The quantitative results and graphs of these experiments are provided below.

\begin{tabular}{|c|c|c|}
\hline $\begin{array}{c}{\left[\mathbf{B n}_{2} \mathbf{N O B z}\right]} \\
(\mathrm{M})\end{array}$ & $\begin{array}{c}\text { Rate } \\
(\mathrm{M} / \mathrm{min})\end{array}$ & $\begin{array}{c}\text { Standard } \\
\text { deviation }\end{array}$ \\
\hline 0.164 & $6.4 \times 10^{-4}$ & $8.7 \times 10^{-6}$ \\
\hline 0.246 & $5.9 \times 10^{-4}$ & $3.6 \times 10^{-5}$ \\
\hline 0.328 & $5.6 \times 10^{-4}$ & $6.5 \times 10^{-5}$ \\
\hline 0.410 & $5.7 \times 10^{-4}$ & $2.1 \times 10^{-5}$ \\
\hline
\end{tabular}

Table S3. Rates determined while varying $\left[\mathrm{Bn}_{2} \mathrm{NOBz}\right]$ 


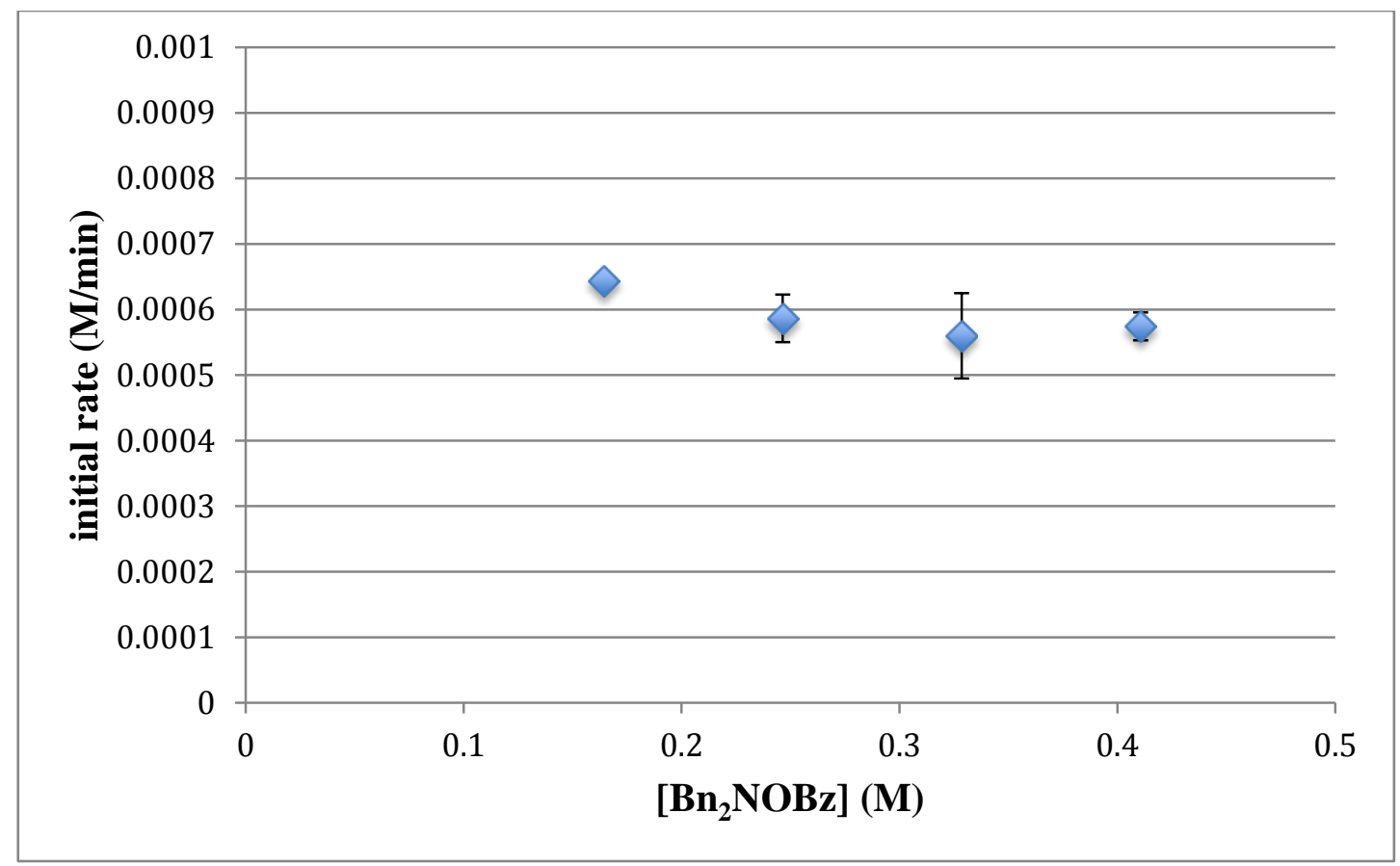

Figure S4. Rates determined while varying $\left[\mathrm{Bn}_{2} \mathrm{NOBz}\right]$

IIE. Diethoxy(methyl)silane rate order

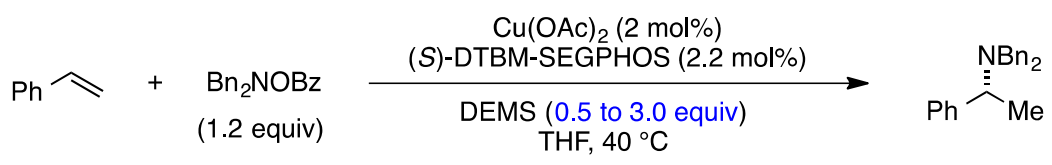

The overall process described above for the determination of $\mathrm{Cu}(\mathrm{OAc})_{2}+(S)$-DTBMSEGPHOS rate order was repeated for diethoxy(methyl)silane at the indicated concentrations. The quantitative results and graphs of these experiments are provided below.

\begin{tabular}{|c|c|c|}
\hline $\begin{array}{c}\text { [DEMS } \\
(\mathrm{M})\end{array}$ & $\begin{array}{c}\text { Rate } \\
(\mathrm{M} / \mathrm{min})\end{array}$ & $\begin{array}{c}\text { Standard } \\
\text { deviation }\end{array}$ \\
\hline 0.18 & $2.2 \times 10^{-4}$ & $3.1 \times 10^{-5}$ \\
\hline 0.35 & $3.8 \times 10^{-4}$ & $5.7 \times 10^{-5}$ \\
\hline 0.51 & $5.6 \times 10^{-4}$ & $6.5 \times 10^{-5}$ \\
\hline 0.66 & $6.5 \times 10^{-4}$ & $4.9 \times 10^{-5}$ \\
\hline 0.94 & $9.7 \times 10^{-4}$ & $3.1 \times 10^{-5}$ \\
\hline
\end{tabular}

Table S4. Rates determined while varying [DEMS] 


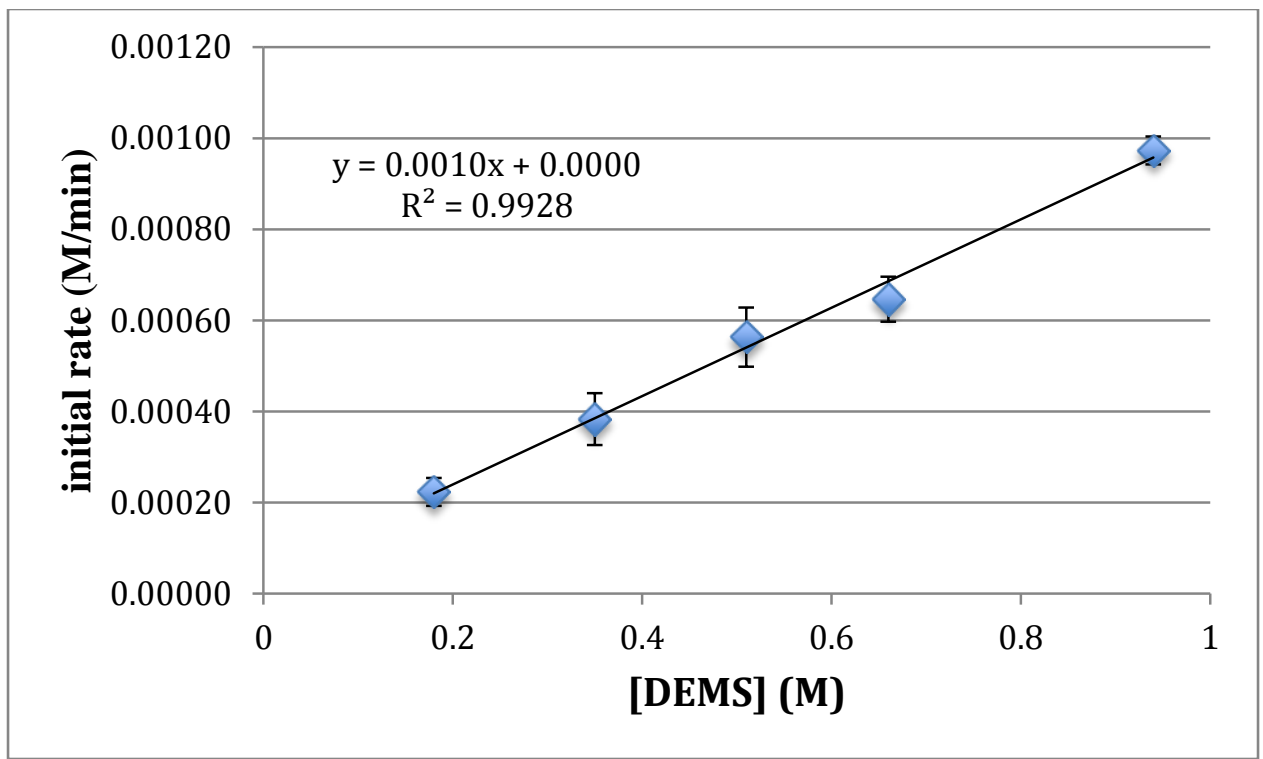

Figure S5. Rates determined while varying [DEMS]

\section{IIF. Hammett plots of styrene derivatives and $O$-benzoyl- $N, N$-dibenzylhydroxyl- amine derivatives}

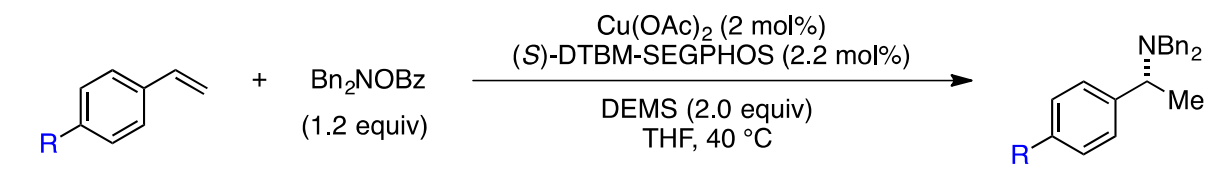

$\mathrm{R}=\mathrm{OMe}, \mathrm{H}, \mathrm{F}, \mathrm{CF}_{3}$

The general procedure for rate determination was followed using 4-methoxystyrene (33.5 $\mathrm{mg}, 0.25 \mathrm{mmol}, 1.0$ equiv), 4-fluorostyrene (30.5 mg, $0.25 \mathrm{mmol}, 1.0$ equiv) and 4(trifluoromethyl)styrene ( $43.0 \mathrm{mg}, 0.25 \mathrm{mmol}, 1.0$ equiv). Each experiment was repeated in duplicate. Characterization of the antipodes of these hydroamination products is provided in a previous report. ${ }^{1}$ The quantitative rates of hydroamination of these substrates are provided below with a corresponding Hammett plot.

\begin{tabular}{|c|c|c|}
\hline $\mathbf{R}$ & $\begin{array}{c}\text { Rate } \\
(\mathrm{M} / \mathrm{min})\end{array}$ & $\begin{array}{c}\text { Standard } \\
\text { deviation }\end{array}$ \\
\hline $\mathrm{H}$ & $5.4 \times 10^{-4}$ & $2.7 \times 10^{-5}$ \\
\hline $\mathrm{OMe}$ & $4.0 \times 10^{-4}$ & $7.1 \times 10^{-6}$ \\
\hline $\mathrm{F}$ & $5.8 \times 10^{-4}$ & $4.5 \times 10^{-5}$ \\
\hline $\mathrm{CF}_{3}$ & $5.0 \times 10^{-4}$ & $2.9 \times 10^{-5}$ \\
\hline
\end{tabular}

Table S5. Rates determined for Hammett study of styrene derivatives 


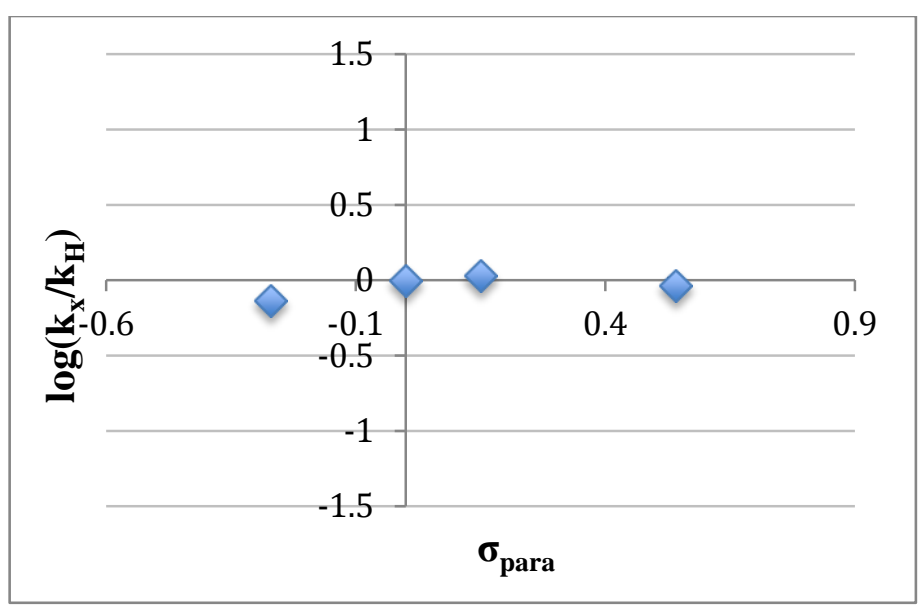

Figure S6. Hammett study with styrene derivatives

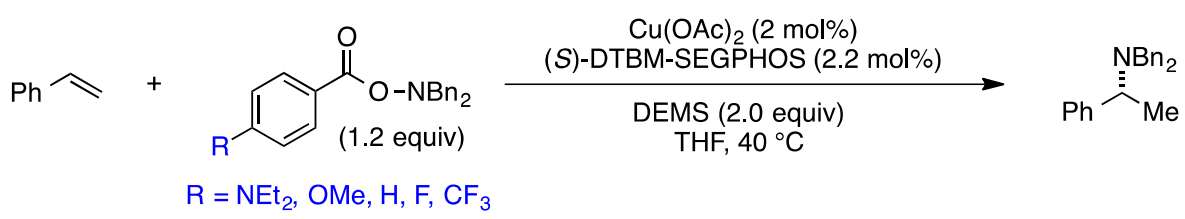

The general procedure for rate determination was followed using the following amine electrophiles: $O$-benzoyl- $N, N$-dibenzylhydroxylamine $(\mathbf{3}, 95 \mathrm{mg}, 0.30 \mathrm{mmol}, 1.2$ equiv); 4-(((dibenzylamino)oxy)carbonyl)- $N, N$-diethylaniline $(\mathbf{1 1}, 117 \mathrm{mg}, 0.30 \mathrm{mmol}, 1.2$ equiv); $N, N$-dibenzyl- $O$-(4-methoxybenzoyl)hydroxylamine $(104 \mathrm{mg}, 0.30 \mathrm{mmol}, 1.2$ equiv); $N, N$-dibenzyl- $O$-(4-fluorobenzoyl)hydroxylamine $(101 \mathrm{mg}, 0.30 \mathrm{mmol}, 1.2$ equiv); $\quad N, N$-dibenzyl- $O$-(4-(trifluoromethyl)benzoyl)hydroxylamine (116 $\mathrm{mg}, \quad 0.30$ mmol, 1.2 equiv). Each experiment was repeated in duplicate. The quantitative rates of hydroamination using these oxidants are provided below with a corresponding Hammett plot.

\begin{tabular}{|c|c|c|}
\hline $\mathbf{R}$ & $\begin{array}{c}\text { Avg Rate } \\
(\mathrm{M} / \mathrm{min})\end{array}$ & $\begin{array}{c}\text { Standard } \\
\text { deviation }\end{array}$ \\
\hline $\mathrm{H}$ & $5.6 \times 10^{-4}$ & $2.7 \times 10^{-5}$ \\
\hline $\mathrm{NEt}_{2}$ & $1.6 \times 10^{-3}$ & $1.6 \times 10^{-5}$ \\
\hline $\mathrm{OMe}$ & $1.0 \times 10^{-3}$ & $5.1 \times 10^{-5}$ \\
\hline $\mathrm{F}$ & $3.5 \times 10^{-4}$ & $2.7 \times 10^{-5}$ \\
\hline $\mathrm{CF}_{3}$ & $2.4 \times 10^{-4}$ & $3.6 \times 10^{-5}$ \\
\hline
\end{tabular}

Table S6. Rates determined for Hammett study of $O$-benzoyl- $N, N$ dibenzylhydroxylamine derivatives 


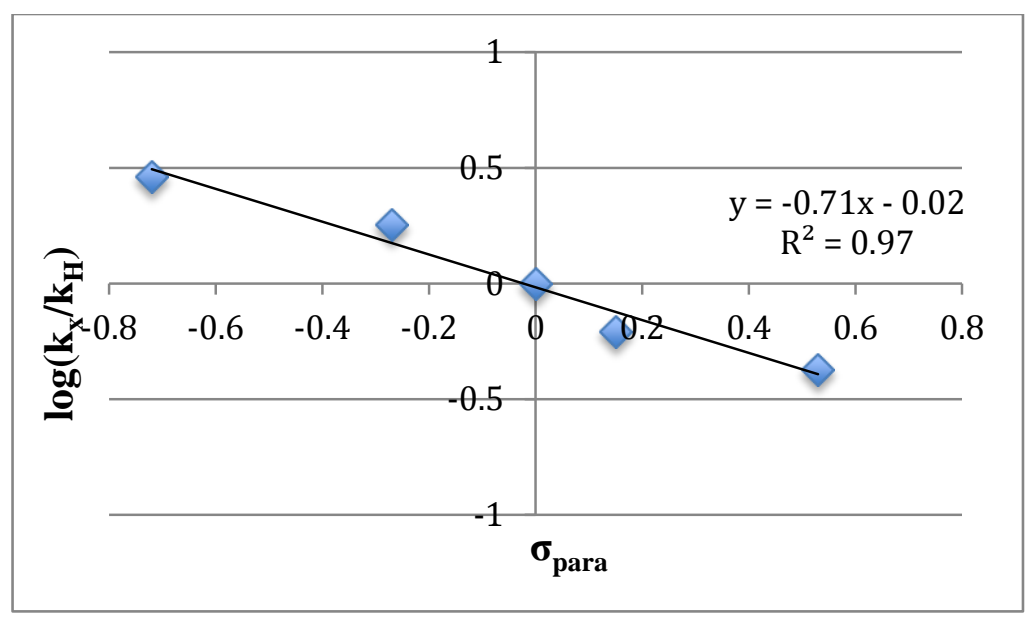

Figure S7. Hammett study with $O$-benzoyl- $N, N$-dibenzylhydroxylamine derivatives

\section{IIG. Rate dependence on $\left[\mathrm{Cu}(\mathrm{OAc})_{2}\right]$ with constant [(S)-DTBM-SEGPHOS]}

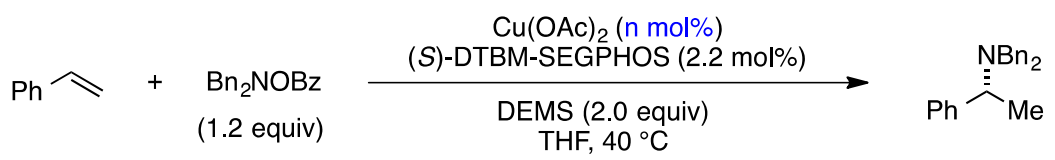

The general procedure for rate determination was followed by varying only the amount of $\mathrm{Cu}(\mathrm{OAc})_{2}$. For these experiments, [(S)-DTBM-SEGPHOS] was held constant at $7.2 \times 10^{-}$

${ }^{3} \mathrm{M}$, corresponding to $2.2 \mathrm{~mol} \%$ compared to styrene. The quantitative results and graphs of these experiments are provided below.

\begin{tabular}{|c|c|c|}
\hline $\begin{array}{c}{\left[\mathrm{Cu}(\mathrm{OAc})_{2}\right]} \\
(\mathrm{M})\end{array}$ & $\begin{array}{c}\text { Rate } \\
(\mathrm{M} / \mathrm{min})\end{array}$ & $\begin{array}{c}\text { Standard } \\
\text { deviation }\end{array}$ \\
\hline 0.0033 & $3.3 \times 10^{-4}$ & $6.4 \times 10^{-5}$ \\
\hline 0.0066 & $5.9 \times 10^{-4}$ & $5.7 \times 10^{-5}$ \\
\hline 0.0099 & $9.4 \times 10^{-4}$ & $9.2 \times 10^{-5}$ \\
\hline 0.0132 & $8.4 \times 10^{-4}$ & $4.2 \times 10^{-5}$ \\
\hline 0.0197 & $8.6 \times 10^{-4}$ & $4.9 \times 10^{-5}$ \\
\hline 0.0263 & $1.0 \times 10^{-3}$ & $7.1 \times 10^{-6}$ \\
\hline
\end{tabular}

Table S7. Rates determined while varying $\left[\mathrm{Cu}(\mathrm{OAc})_{2}\right]$ only 


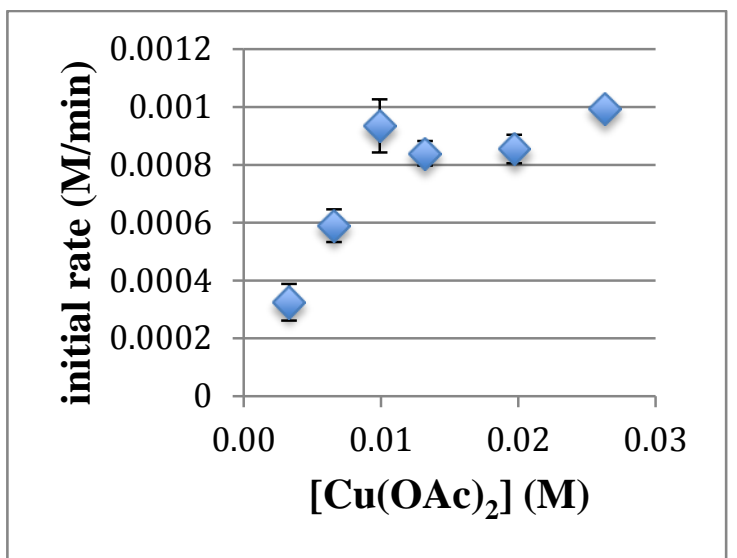

Figure S8. Plot of rate while only varying $\left[\mathrm{Cu}(\mathrm{OAc})_{2}\right]$

\section{IIH. Rate dependence on [(S)-DTBM-SEGPHOS] with constant [Cu(OAc) $\left.)_{2}\right]$}

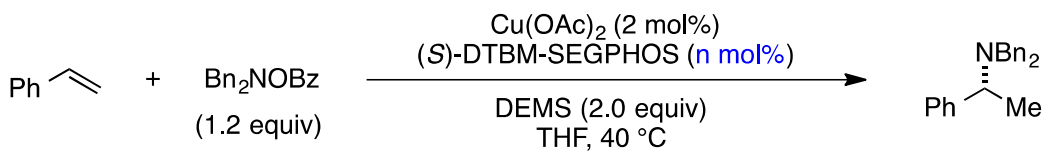

The general procedure for rate determination was followed by varying only the amount of $(S)$-DTBM-SEGPHOS. For these experiments, $\left[\mathrm{Cu}(\mathrm{OAc})_{2}\right]$ was held constant at $6.6 \times 10^{-}$ ${ }^{3} \mathrm{M}$, corresponding to $2.0 \mathrm{~mol} \%$ compared to styrene. The quantitative results and graphs of these experiments are provided below.

\begin{tabular}{|c|c|c|}
\hline $\begin{array}{c}\text { [(S)-DTBM- } \\
\text { SEGPHOS }] \\
(\mathrm{M})\end{array}$ & $\begin{array}{c}\text { Rate } \\
(\mathrm{M} / \mathrm{min})\end{array}$ & $\begin{array}{c}\text { Standard } \\
\text { deivation }\end{array}$ \\
\hline 0.0036 & $4.4 \times 10^{-4}$ & $1.9 \times 10^{-4}$ \\
\hline 0.0145 & $5.9 \times 10^{-4}$ & $2.1 \times 10^{-5}$ \\
\hline 0.0217 & $6.2 \times 10^{-4}$ & $2.8 \times 10^{-5}$ \\
\hline 0.0109 & $6.2 \times 10^{-4}$ & $5.7 \times 10^{-5}$ \\
\hline 0.0289 & $4.3 \times 10^{-4}$ & $2.8 \times 10^{-5}$ \\
\hline 0.0072 & $6.5 \times 10^{-4}$ & $4.9 \times 10^{-5}$ \\
\hline
\end{tabular}

Table S8. Rates determined while varying [(S)-DTBM-SEGPHOS] only 


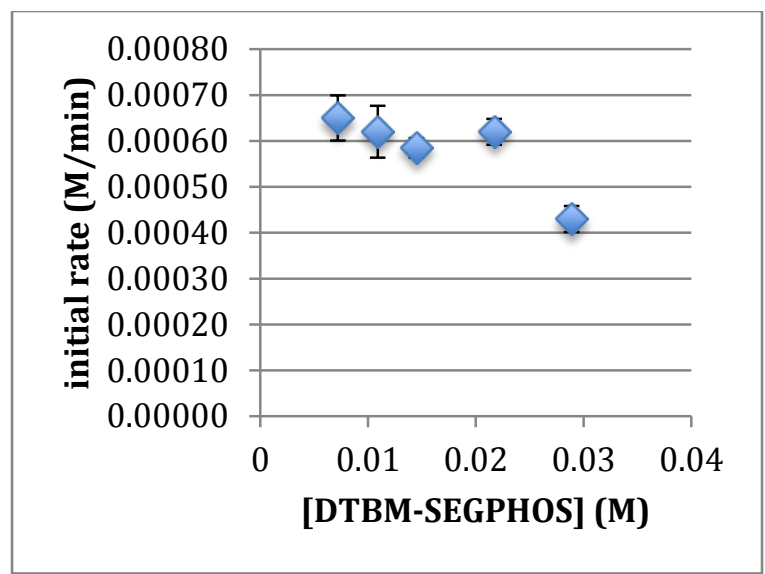

Figure S9. Plot of rate while only varying [(S)-DTBM-SEGPHOS]

\section{Nonlinear effect studies}

In a nitrogen-filled glove box, four 8-mL scintillation vials were charged with the specified amount of $(S)$-DTBM-SEGPHOS and $(R)$-DTBM-SEGPHOS to provide the enantiomeric composition of DTBM-SEGPHOS as specified in Table S9. To each of these vials, $\mathrm{Cu}(\mathrm{OAc})_{2}(3.6 \mathrm{mg}, 0.02 \mathrm{mmol}, 0.08$ equiv) and $\mathrm{THF}(2.0 \mathrm{~mL})$ was added and these vials were stirred to homogeneity. Once homogeneity was reached, diethoxy(methyl)silane ( $320 \mu \mathrm{L}, 2.0 \mathrm{mmol}, 8.0$ equiv) was added to each vial for $15 \mathrm{~min}$ until a color change to orange occurred. An aliquot of each solution $(580 \mu \mathrm{L})$ was added to a reaction tube (Fisherbrand, $16 \times 125 \mathrm{~mm}$, catalog no. 1495925C) containing a stir bar with styrene ( $29 \mu \mathrm{L}, 0.25 \mathrm{mmol}, 1.0$ equiv) and $O$-benzoyl- $N, N$-dibenzylhydroxylamine (95 $\mathrm{mg}, 0.30 \mathrm{mmol}, 1.2$ equiv). Caps were tightened on the reaction vial, the reaction vials were brought outside of the glove box, and placed into an oil bath preheated to 40 ${ }^{\circ} \mathrm{C}$ and stirred for $24 \mathrm{~h}$. The reaction mixture was then cooled to ambient temperature and $n$-dodecane ( $57 \mu \mathrm{L}, 0.25 \mathrm{mmol}, 1.0$ equiv) was added to the crude reaction mixture. The reaction mixture was then quenched with a saturated solution of $\mathrm{NaHCO}_{3}(2 \mathrm{~mL})$ and extracted with EtOAc $(3 \times 2 \mathrm{~mL})$.

An aliquot of the collected organic layers was then analyzed by GC to determine if the reaction went to completion and the combined organic layers for each experiment were then concentrated in vacuo. Preparatory thin-layer chromatography (TLC) was used (5\% EtOAc/hexanes) to isolate the desired product. Enantiomeric excess (ee) of the desired product from each experiment was determined by chiral HPLC (OD-H column, 98:2 hexanes/IPA, $0.6 \mathrm{~mL} / \mathrm{min}, 6.8 \mathrm{~min}$ (minor) and $7.9 \mathrm{~min}$ (major)). 


\begin{tabular}{|c|c|c|c|}
\hline $\begin{array}{c}\text { ee, } \\
\text { ligand }\end{array}$ & $\begin{array}{c}(\boldsymbol{S})-D T B M- \\
\text { SEGPHOS, mg }\end{array}$ & $\begin{array}{c}(\boldsymbol{R})-D T B M- \\
\text { SEGPHOS, mg }\end{array}$ & $\begin{array}{c}\text { ee, } \\
\text { product }\end{array}$ \\
\hline 20 & 60 & 40 & 18.9 \\
\hline 40 & 70 & 30 & 37.4 \\
\hline 60 & 80 & 20 & 55 \\
\hline 80 & 90 & 10 & 75.3 \\
\hline
\end{tabular}

Table S9. Nonlinear effect studies - setup of experiment and results.

\section{Kinetic isotope effect studies with diphenylsilane}

A series of independent kinetic isotope effect (KIE) experiments were performed with the standard reaction and protio- and deutero-diphenylsilane $\left(\mathrm{SiPh}_{2} \mathrm{D}_{2}\right)$.

In a nitrogen-filled glove box, an $8 \mathrm{~mL}$ scintillation vial was charged with $\mathrm{Cu}(\mathrm{OAc})_{2}(3.6$ $\mathrm{mg}, 0.02 \mathrm{mmol}, 0.08$ equiv), $(S)$-DTBM-SEGPHOS (26.0 mg, $0.022 \mathrm{mmol}, 0.088$ equiv) and THF $(2.0 \mathrm{~mL})$, and this vial was stirred to homogeneity. Once homogeneity was reached, diphenylsilane ( $370 \mu \mathrm{L}, 2.0 \mathrm{mmol}, 8.0$ equiv) was added to the vial and stirred until a color change to orange occurred $(15 \mathrm{~min})$. An aliquot of each solution $(590 \mu \mathrm{L})$ was added to three separate reaction tubes (Fisherbrand, 16 x $125 \mathrm{~mm}$, catalog no. $1495925 \mathrm{C})$ each containing a stir bar with styrene $(29 \mu \mathrm{L}, 0.25 \mathrm{mmol}, 1.0$ equiv), $n$ dodecane ( $57 \mu \mathrm{L}, 0.25 \mathrm{mmol}, 1.0$ equiv), and $O$-benzoyl- $N, N$-dibenzylhydroxylamine (95 $\mathrm{mg}, 0.30 \mathrm{mmol}, 1.2$ equiv). Caps were tightened on the reaction vial, the reaction vials were brought outside of the glove box, placed into an oil bath preheated to $40{ }^{\circ} \mathrm{C}$, and put under a positive pressure of argon. The reaction rate was monitored for the first $20 \%$ of the reaction using the method described in the general procedure (section IA in the SI) for the acquisition of initial rate measurements. A separate set of experiments was set-up in an identical manner with deutero-diphenylsilane $(372 \mu \mathrm{L}, 2.0 \mathrm{mmol}, 8.0$ equiv) instead of protio-diphenylsilane. A KIE $\left(\mathrm{k}_{\mathrm{H}} / \mathrm{k}_{\mathrm{D}}\right)$ of $1.06 \pm 0.10$ was determined. The initial rate data is presented in Table S10.

\begin{tabular}{|c|c|c|c|}
\hline Trial \#: & $\begin{array}{c}\text { initial rate }\left(\mathbf{P h}_{2} \mathbf{S i H}_{2}\right), \\
\mathbf{M} / \mathbf{m i n}\end{array}$ & $\begin{array}{c}\text { initial } \mathbf{~ r a t e ~}\left(\mathbf{P h}_{2} \mathbf{S i D}_{2}\right), \\
\mathbf{M} / \mathbf{m i n}\end{array}$ & KIE \\
\hline $\mathbf{1}$ & 0.00138 & 0.00125 & 1.1 \\
\hline $\mathbf{2}$ & 0.00143 & 0.00126 & 1.13 \\
\hline $\mathbf{3}$ & 0.00115 & 0.00121 & 0.95 \\
\hline Avg. KIE & 1.06 & \multicolumn{2}{|}{} \\
\cline { 1 - 2 } standard dev. & 0.10 & &
\end{tabular}

Table S10. Kinetic Isotope Effect Studies

\section{Reaction Progress Kinetic Analysis (RPKA) by ${ }^{19}$ F-NMR}

In a nitrogen-filled glove box, an $8 \mathrm{~mL}$ scintillation vial was charged with $\mathrm{Cu}(\mathrm{OAc})_{2}(3.6$ mg, 0.02 mmol, 0.08 equiv), (S)-DTBM-SEGPHOS (26.0 mg, $0.022 \mathrm{mmol}, 0.088$ equiv), 
and THF $(2.0 \mathrm{~mL})$, and this vial was stirred to homogeneity. Once homogeneity was reached, diethoxymethylsilane $(320 \mu \mathrm{L}, 2.0 \mathrm{mmol}, 8.0$ equiv) was added to the vial and stirred until a color change to orange occurred $(15 \mathrm{~min})$. An aliquot of this solution (580 $\mu \mathrm{L})$ was added to a separate $8 \mathrm{~mL}$ scintillation vial containing 4-fluorostyrene $(30 \mu \mathrm{L}$, $0.25 \mathrm{mmol}, 1.0$ equiv), 1-fluoronaphthalene (32 $\mu \mathrm{L}, 0.25 \mathrm{mmol}, 1.0$ equiv), and $O$ benzoyl- $N, N$-dibenzylhydroxylamine ( $95 \mathrm{mg}, 0.30 \mathrm{mmol}, 1.2$ equiv). The contents of this vial were transferred to a NMR tube, and the NMR tube was capped and sealed with parafilm (experiment A).

In situ ${ }^{19} \mathrm{~F}-\mathrm{NMR}$ studies were conducted at $40{ }^{\circ} \mathrm{C}$, which was established before the sample was inserted into the spectrometer. A pad array experiment was used to collect the data. A total number of 75 experiments were collected with a relaxation delay of $5 \mathrm{~s}$, an acquisition time of $3 \mathrm{~s}$, and 24 scans for each individual experiment in the pad array. Data was collected for an experiment every $628 \mathrm{~s}$. The yield of the product was determined with respect to the internal standard, 1-fluoronaphthalene.

Same excess experiments were conducted by running an additional experiment that mimics $50 \%$ completion (experiment B). In a nitrogen-filled glove box, an $8 \mathrm{~mL}$ scintillation vial was charged with $\mathrm{Cu}(\mathrm{OAc})_{2}(3.6 \mathrm{mg}, 0.02 \mathrm{mmol}, 0.08$ equiv), $(S)$ DTBM-SEGPHOS (26.0 mg, $0.022 \mathrm{mmol}, 0.088$ equiv), and THF (2.0 mL), and this vial was stirred to homogeneity. Once homogeneity was reached, diethoxymethylsilane (240 $\mu \mathrm{L}, 1.5 \mathrm{mmol}, 6.0$ equiv) was added and stirred until a color change to orange occurred $(15 \mathrm{~min})$. An aliquot of this solution $(580 \mu \mathrm{L})$ was added to another 8 -mL scintillation vial containing 4-fluorostyrene ( $15 \mu \mathrm{L}, 0.125 \mathrm{mmol}, 0.5$ equiv), 1-fluoronaphthalene (32 $\mu \mathrm{L}, 0.25 \mathrm{mmol}, 1.0$ equiv), $O$-benzoyl- $N, N$-dibenzylhydroxylamine $(56 \mathrm{mg}, 0.175 \mathrm{mmol}$, 0.7 equiv), and THF ( $75 \mu \mathrm{L}$ to account for a volume difference with the previous experiment). The contents of this vial were transferred to a NMR tube, and the NMR tube was capped and sealed with parafilm, and run in the Varian Inova $500 \mathrm{MHz}$ spectrometer as explained above. The two experiments are plotted together on Figure S10. Generally, similar trends are observed (experiment B is slightly faster), and both appear to be zero order in substrate. 


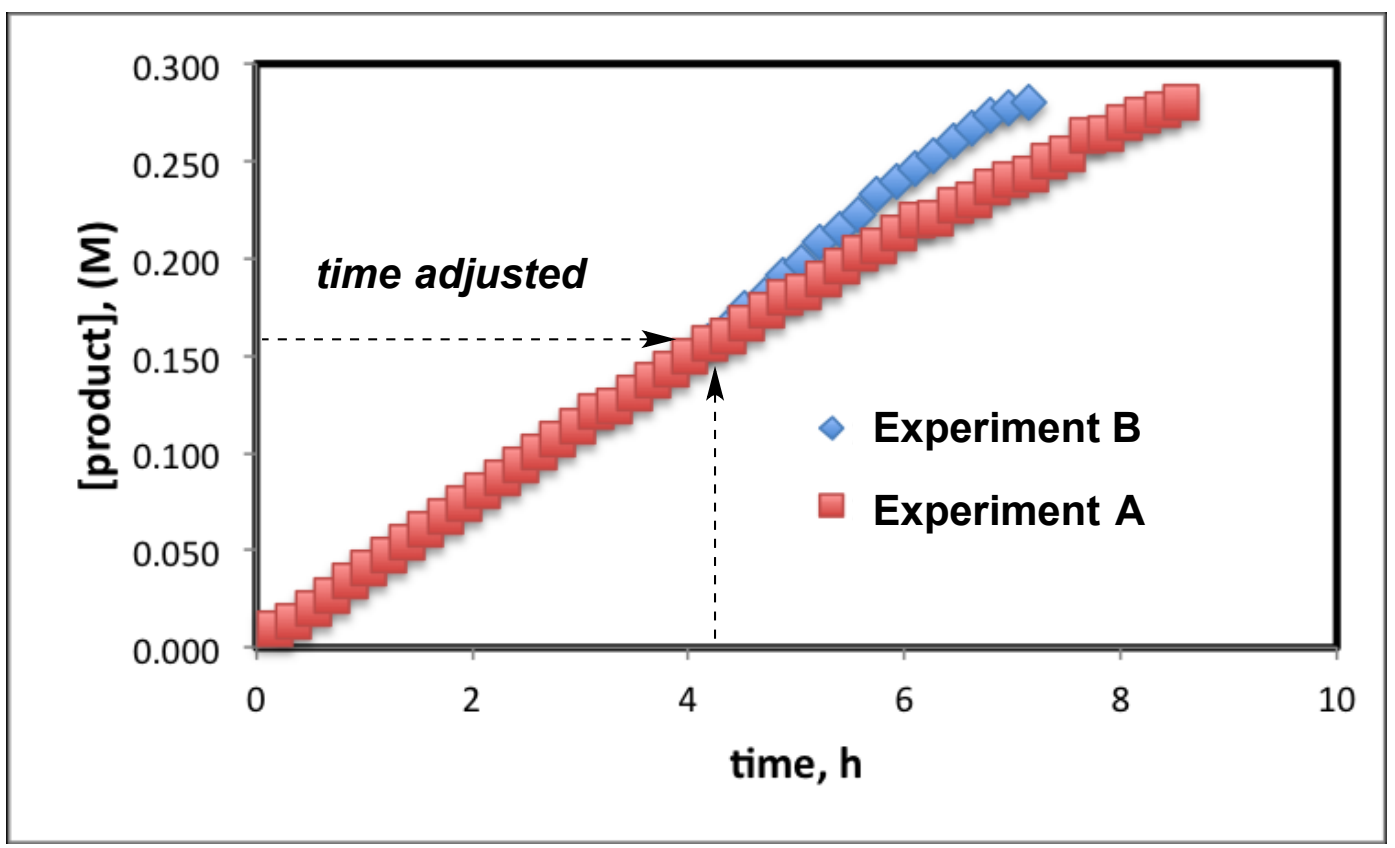

Figure S10. Same-excess experiments.

VI. Reaction optimization: hydroamination kinetics using various silanes, amine electrophiles, and phosphine additives

VIA. Silane optimization

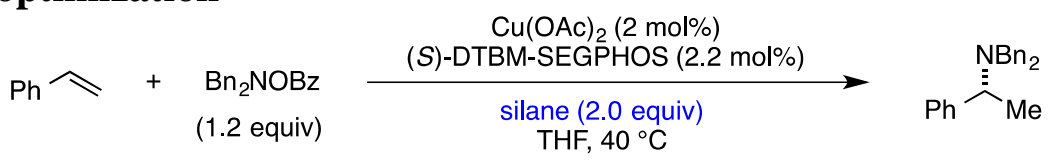

General procedure. In a nitrogen-filled glove box, a catalyst stock solution was prepared by adding $\mathrm{Cu}(\mathrm{OAc})_{2}(3.6 \mathrm{mg}, 0.02 \mathrm{mmol}, 0.08$ equiv), (S)-DTBM-SEGPHOS (26 mg, $0.022 \mathrm{mmol}, 0.088$ equiv), and THF $(2.0 \mathrm{~mL})$ to an oven-dried $4 \mathrm{~mL}$ vial containing a magnetic stir bar. This mixture was stirred for $10 \mathrm{~min}$ as a homogenous blue solution formed. At this time, silane $(2.0 \mathrm{mmol}, 8.0$ equiv) was added and the solution was stirred for another $10 \mathrm{~min}$, during which time the solution developed a bright orange color. An aliquot of this solution ( $1 / 4$ total volume) was then transferred to a reaction vial containing styrene ( $29 \mu \mathrm{L}, 26.0 \mathrm{mg}, 0.25 \mathrm{mmol}, 1.0$ equiv), $O$-benzoyl- $N, N$-dibenzylhydroxylamine (95.2 $\mathrm{mg}, 0.30 \mathrm{mmol}, 1.2$ equiv), and $n$-dodecane $(57 \mu \mathrm{L}, 42.6 \mathrm{mg}, 0.25 \mathrm{mmol}, 1.0$ equiv). The reaction vial was quickly capped and removed from the glove box. The reaction vial was placed under a positive pressure of argon and was then placed into an oil bath preheated to $40{ }^{\circ} \mathrm{C}$. Aliquots were taken at 10 min intervals by removing a small amount (ca. $30 \mu \mathrm{L}$ ) of the reaction solution and washing it through a small silica gel plug with EtOAc. The reaction was followed for approximately $2 \mathrm{~h}$. GC analysis was used to quantitate product formation using $n$-dodecane as the internal standard and $\mathrm{d}[\mathrm{P}] / \mathrm{dt}$ was then calculated. 
Silanes used in this general procedure: 1,1,3,3-tetramethyldisiloxane (TMDS, $353 \mu$, $2.00 \mathrm{mmol}, 8.0$ equiv), dimethoxy(methyl)silane (DMMS, $320 \mu \mathrm{l}, 2.00 \mathrm{mmol}, 8.0$ equiv), and polymethylhydrosiloxane (PMHS, $112 \mu \mathrm{l}, 8.0$ equiv of $\mathrm{Si}-\mathrm{H}$ ) were used for the preparation of the $\mathrm{CuH}$ solution.

\begin{tabular}{|c|c|c|}
\hline Silane & $\begin{array}{c}\text { Rate } \\
(\mathrm{M} / \mathrm{min})\end{array}$ & $\begin{array}{c}\text { Standard } \\
\text { deviation }\end{array}$ \\
\hline DEMS & $5.4 \times 10^{-4}$ & $2.7 \times 10^{-5}$ \\
\hline DMMS & $1.7 \times 10^{-3}$ & $1.3 \times 10^{-4}$ \\
\hline TMDS & $3.1 \times 10^{-4}$ & $3.7 \times 10^{-5}$ \\
\hline PMHS & $1.9 \times 10^{-4}$ & $9.8 \times 10^{-6}$ \\
\hline
\end{tabular}

Table S11. Study of rate with various silanes

VIB. Amine electrophile optimization

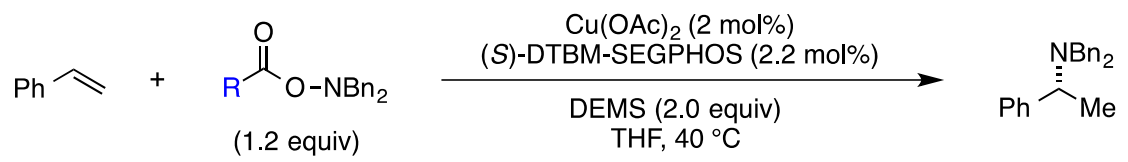

General procedure. In a nitrogen-filled glove box, a catalyst stock solution was prepared by adding $\mathrm{Cu}(\mathrm{OAc})_{2}(3.6 \mathrm{mg}, 0.02 \mathrm{mmol}, 0.08$ equiv), $(S)$-DTBM-SEGPHOS (26 mg, $0.022 \mathrm{mmol}, 0.088$ equiv), and THF $(2.0 \mathrm{~mL})$ to an oven-dried $4 \mathrm{~mL}$ vial containing a magnetic stir bar. This mixture was stirred for $10 \mathrm{~min}$ as a homogenous blue solution formed. At this time, diethoxy(methyl)silane $(320 \mu \mathrm{L}, 2.00 \mathrm{mmol}, 8.0$ equiv) was added and the solution was stirred for another $10 \mathrm{~min}$, during which time the solution developed a bright orange color. An aliquot of this solution $(580 \mu \mathrm{L})$ was then transferred to a reaction vial containing styrene $(29 \mu \mathrm{L}, 26.0 \mathrm{mg}, 0.25 \mathrm{mmol}, 1.0$ equiv), amine electrophile ( $0.30 \mathrm{mmol}, 1.2$ equiv) and $n$-dodecane $(57 \mu \mathrm{L}, 42.6 \mathrm{mg}, 0.25 \mathrm{mmol}, 1.0$ equiv). The reaction vial was quickly capped and removed from the glove box. The reaction vial was then placed under a positive pressure of argon, and placed into an oil bath preheated to $40{ }^{\circ} \mathrm{C}$. Aliquots were taken at $10 \mathrm{~min}$ intervals by removing a small amount (ca. $30 \mu \mathrm{L}$ ) of the reaction solution and filtering it through a small silica gel plug eluting with EtOAc. The reaction was followed for approximately $2 \mathrm{~h}$. GC analysis was used to quantitate product formation using $n$-dodecane as the internal standard and $\mathrm{d}[\mathrm{P}] / \mathrm{dt}$ was then calculated.

Amine oxidants used in this general procedure: $N, N$-dibenzyl- $O-(2,4,6-$ trimethoxybenzoyl)hydroxylamine $\quad(\mathbf{1 2}, 122 \mathrm{mg}, \quad 0.30 \mathrm{mmol}, \quad 1.2$ equiv); 4(((dibenzylamino)oxy)carbonyl)- $N, N$-diethylaniline (11, $117 \mathrm{mg}, 0.30 \mathrm{mmol}, 1.2$ equiv); $N, N$-dibenzyl- $O$-pivaloylhydroxylamine $(14,89.2 \mathrm{mg}, 0.30 \mathrm{mmol}, 1.2$ equiv), $O$-acetyl$\mathrm{N}, \mathrm{N}$-dibenzylhydroxylamine $(\mathbf{1 3}, 76.6 \mathrm{mg}, 0.30 \mathrm{mmol}, 1.2$ equiv); $\mathrm{N}, \mathrm{N}$-dibenzyl- $\mathrm{O}$ (ethoxycarbonyl)hydroxylamine $(\mathbf{1 5}, 85.6 \mathrm{mg}, 0.30 \mathrm{mmol}, 1.2$ equiv). 


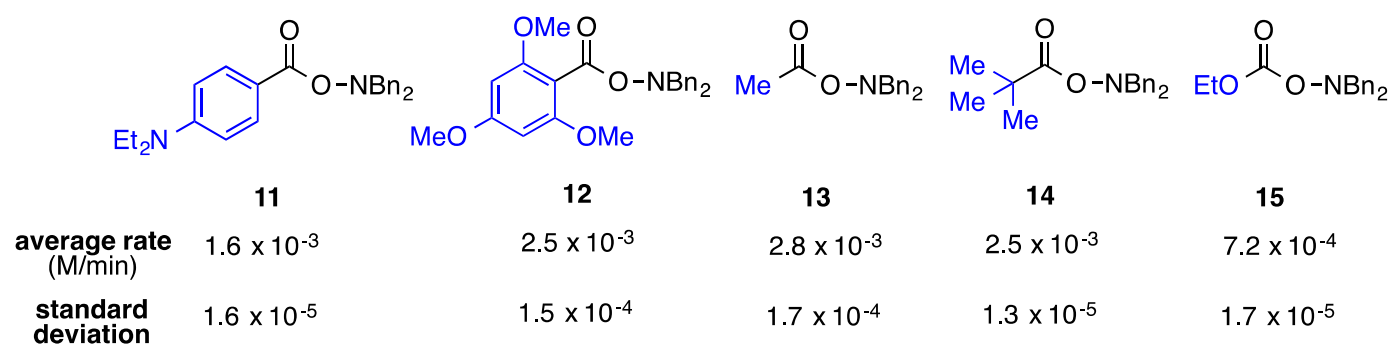

Scheme S1. Rate with various amine oxidants

VIC. Phosphine additive optimization

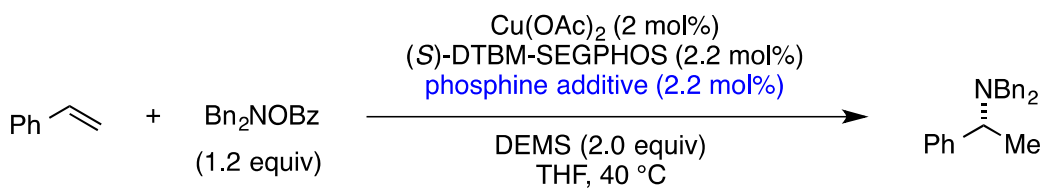

In a nitrogen-filled glove box, a catalyst stock solution was prepared by adding $\mathrm{Cu}(\mathrm{OAc})_{2}$ (3.6 mg, $0.02 \mathrm{mmol}, 0.08$ equiv), (S)-DTBM-SEGPHOS (26 mg, $0.022 \mathrm{mmol}, 0.088$ equiv), phosphine additive $(0.022 \mathrm{mmol}, 0.088 \mathrm{mmol})$ and THF $(2.0 \mathrm{~mL})$ to an ovendried $4 \mathrm{~mL}$ vial containing a magnetic stir bar. This mixture was stirred for $10 \mathrm{~min}$ as a homogenous blue solution formed. At this time, diethoxy(methyl)silane $(320 \mu \mathrm{L}, 2.00$ mmol, 8.0 equiv) was added and the solution was stirred for another $10 \mathrm{~min}$, during which time the solution developed a bright orange color. An aliquot of this solution (580 $\mu \mathrm{L})$ was then transferred to a reaction vial containing styrene $(29 \mu \mathrm{L}, 26.0 \mathrm{mg}, 0.25$ mmol, 1.0 equiv), $O$-benzoyl- $N, N$-dibenzylhydroxylamine $(95.2 \mathrm{mg}, 0.30 \mathrm{mmol}, 1.2$ equiv) and $n$-dodecane (57 $\mu \mathrm{L}, 42.6 \mathrm{mg}, 0.25 \mathrm{mmol}, 1.0$ equiv). The reaction vial was quickly capped and removed from the glove box. A needle line under positive pressure of argon was inserted into the septum and the reaction vial was placed into a $40{ }^{\circ} \mathrm{C}$ oil bath. Aliquots were taken at 10 min intervals by removing a small amount (ca. $30 \mu \mathrm{L}$ ) of the reaction solution and filtering it through a small silica gel plug eluting with EtOAc. The reaction was followed for approximately $2 \mathrm{~h}$. GC analysis was used to quantitate product formation using $n$-dodecane as the internal standard and $\mathrm{d}[\mathrm{P}] / \mathrm{dt}$ was then calculated.

\begin{tabular}{|c|c|}
\hline $\begin{array}{c}\text { Phosphine } \\
\text { additive }\end{array}$ & $\begin{array}{c}\text { Rate } \\
(\mathrm{M} / \mathrm{min})\end{array}$ \\
\hline $\mathrm{PPh}_{3}$ & $8.8 \times 10^{-4}$ \\
\hline $\mathrm{P}\left(4-\mathrm{OMeC}_{6} \mathrm{H}_{4}\right)_{3}$ & $1.0 \times 10^{-3}$ \\
\hline $\mathrm{PPh}_{2} t-\mathrm{Bu}$ & $1.2 \times 10^{-3}$ \\
\hline $\mathrm{PPh}$ - $\mathrm{Bu}_{2}$ & $8.2 \times 10^{-4}$ \\
\hline $\mathrm{P} t-\mathrm{Bu}_{3}$ & $7.8 \times 10^{-4}$ \\
\hline $\mathrm{PPhMe}_{2}$ & $6.0 \times 10^{-4}$ \\
\hline $\mathrm{PCy}_{3}$ & $3.4 \times 10^{-4}$ \\
\hline
\end{tabular}

Table S12. Study of rate with various phosphine additives 
VID. Rate order of $\mathrm{PPh}_{3}$ additive

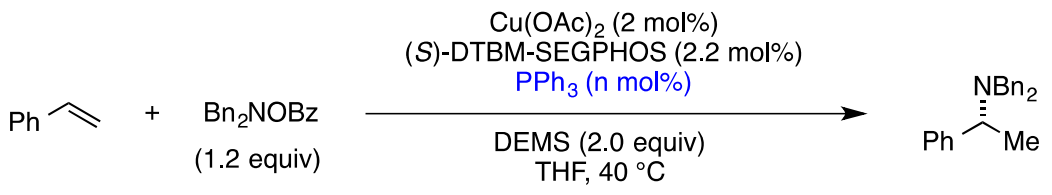

The general procedure for kinetic analysis (see section IA in SI) was followed using varying amounts of $\mathrm{PPh}_{3}$ in the catalyst stock solution preparation. The average values obtained from duplicate experiments are included below.

\begin{tabular}{|c|c|c|}
\hline $\begin{array}{c}{\left[\mathbf{P P h}_{3}\right]} \\
(\mathrm{M})\end{array}$ & $\begin{array}{c}\text { Rate } \\
(\mathrm{M} / \mathrm{min})\end{array}$ & $\begin{array}{c}\text { Standard } \\
\text { deviation }\end{array}$ \\
\hline $3.6 \times 10^{-3}$ & $6.4 \times 10^{-4}$ & $1.4 \times 10^{-5}$ \\
\hline $7.1 \times 10^{-3}$ & $9.0 \times 10^{-4}$ & $4.7 \times 10^{-5}$ \\
\hline $1.4 \times 10^{-2}$ & $8.2 \times 10^{-4}$ & $7.3 \times 10^{-5}$ \\
\hline $2.9 \times 10^{-2}$ & $1.2 \times 10^{-3}$ & $2.4 \times 10^{-5}$ \\
\hline
\end{tabular}

Table S13. Study of rate while varying $\left[\mathrm{PPh}_{3}\right]$

\section{Linear free energy relationship studies}

\section{VIIA. Hammett plot for styrene series}

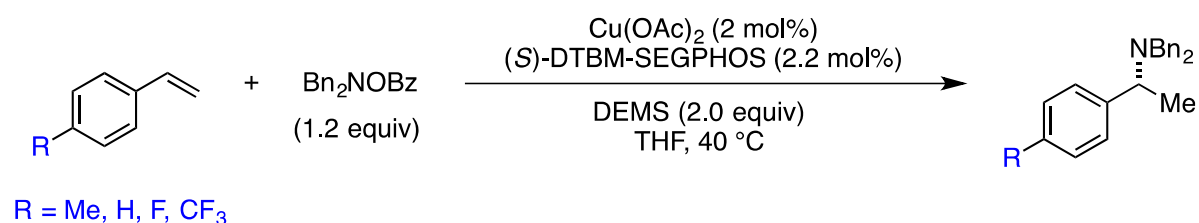

Enantiomeric ratios were compiled for the amine products shown above. For the amine products derived from styrene, 4-fluorostyrene and 4-(trifluoromethyl)styrene, values were obtained from our previous report. ${ }^{1}$ For the reaction with 4-methylstyrene, see below. The average er of two experiments for each substrate is shown below with the $\log (\mathrm{er})$, standard deviation and a Hammett plot. Note: 4-methoxystyrene was not included in this study because an accurate determination of the product er was not possible using chiral HPLC as the minor enantiomer eluted over a $7 \mathrm{~min}$ period.<smiles>Cc1ccc(C(C)(C)N)cc1</smiles>

$(\boldsymbol{R})$ - $N, N$-Dibenzyl-1-( $\boldsymbol{p}$-tolyl)ethan-1-amine. In a nitrogen-filled glovebox, a catalyst solution was prepared with $\mathrm{Cu}(\mathrm{OAc})_{2}(3.6 \mathrm{mg}, 0.02$ mmol, 0.04 equiv) and (S)-DTBM-SEGPHOS $(26 \mathrm{mg}, 0.022 \mathrm{mmol}$, 0.044 equiv) in THF $(2.0 \mathrm{~mL})$. This mixture was stirred for $10 \mathrm{~min}$ as a homogenous blue solution formed. At this time, diethoxy(methyl)silane $(320 \mu \mathrm{L}, 2.00$ mmol, 4.0 equiv) was added and the solution was stirred for another $10 \mathrm{~min}$, during which time the solution developed a bright orange color. An aliquot of this solution (1.16 $\mathrm{mL}$ ) was then transferred to a reaction vial containing 4-methylstyrene $(66 \mu 1,0.50 \mathrm{mmol}$, 1.0 equiv) and $O$-benzoyl- $N, N$-dibenzylhydroxylamine (95.2 $\mathrm{mg}, 0.30 \mathrm{mmol}, 1.2$ equiv). 
The reaction vial was capped, removed from the glove box and inserted into an oil bath preheated to $40{ }^{\circ} \mathrm{C}$. After $20 \mathrm{~h}$, the reaction mixture was allowed to cool to ambient temperature and then quenched with sat. $\mathrm{NaHCO}_{3}(2 \mathrm{~mL})$ and extracted with EtOAc $(3 \mathrm{x}$ $2 \mathrm{~mL}$ ). The combined organic layers were dried with $\mathrm{Na}_{2} \mathrm{SO}_{4}$, filtered, concentrated in vacuo and the crude material was purified by silica gel chromotagraphy $\left(2 \% \mathrm{Et}_{2} \mathrm{O}\right.$ in hexanes). The purified product was obtained as a colorless oil (57 $\mathrm{mg}, 0.18 \mathrm{mmol}, 36 \%$ yield). IR (thin film) $3024,2329,1494,1376,1242,739 \mathrm{~cm}^{-1}$; Specific rotation $[\alpha]_{\mathrm{D}}^{23.8}$ $=97.9\left(\mathrm{c}=0.85, \mathrm{CHCl}_{3}\right) ; \quad$ HPLC analysis: Chiralpak OD-H $(\mathrm{Hex} / \mathrm{IPA}=98 / 2,0.6$ $\mathrm{mL} / \mathrm{min}, 230 \mathrm{~nm}, 23^{\circ} \mathrm{C}$ ), $6.7 \mathrm{~min}$ (minor), $7.9 \mathrm{~min}$ (major), $98 \%$ ee. ${ }^{1} \mathbf{H}$ NMR $(400 \mathrm{MHz}$, $\left.\mathrm{CDCl}_{3}\right) \delta 7.50-7.21(\mathrm{~m}, 15 \mathrm{H}), 3.96(\mathrm{q}, 6.9 \mathrm{~Hz}, 1 \mathrm{H}), 3.70(\mathrm{~d}, 13.8 \mathrm{~Hz}, 2 \mathrm{H}), 3.50(\mathrm{~d}, 13.9$ $\mathrm{Hz}, 2 \mathrm{H}), 2.40$ (s, 3H), 1.48 (d, 6.9 Hz, 3H). ${ }^{13} \mathbf{C}$ NMR (100 MHz, $\left.\mathrm{CDCl}_{3}\right) \delta$ 140.7, 139.7, 128.8, 128.8, 128.3, 128.1, 126.8, 56.0, 53.7, 21.2, 14.3. EA Calcd. for $\mathrm{C}_{23} \mathrm{H}_{25} \mathrm{~N}$ : C, 87.57; H, 7.99. Found: C, 87.71; H, 8.10.

\begin{tabular}{|c|c|c|c|}
\hline $\mathbf{R}$ & average er & $\log \left(\mathbf{e r}_{\text {avg }}\right)$ & $\begin{array}{c}\text { standard } \\
\text { deviation }\end{array}$ \\
\hline $\mathrm{H}$ & 80.5 & 1.91 & 0.066 \\
\hline $\mathrm{F}$ & 69.5 & 1.84 & 0.020 \\
\hline $\mathrm{CF}_{3}$ & 41.4 & 1.62 & 0.055 \\
\hline $\mathrm{Me}$ & 87.0 & 1.94 & 0.024 \\
\hline
\end{tabular}

Table S14. Linear free energy relationship of enantiomeric ratio with styrene derivatives

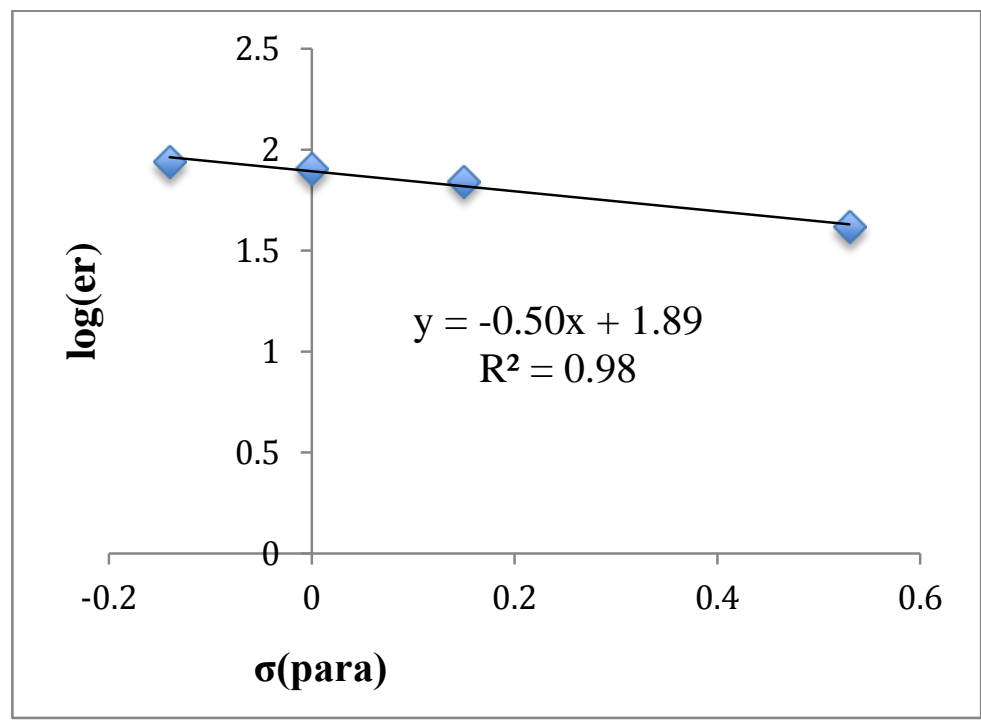

Figure S11. Hammett study with various styrene derivatives

\section{VIIB. Hammett plot for amine electrophile series}




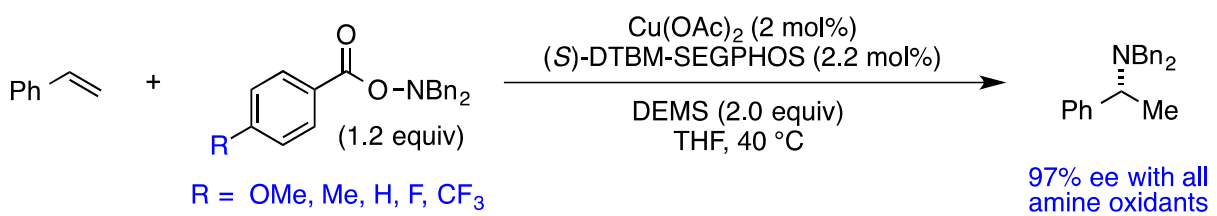

In a nitrogen-filled glove box, a catalyst stock solution was prepared by adding $\mathrm{Cu}(\mathrm{OAc})_{2}$ (3.6 mg, $0.02 \mathrm{mmol}, 0.08$ equiv), (S)-DTBM-SEGPHOS (26 mg, $0.022 \mathrm{mmol}, 0.088$ equiv), and THF (2.0 mL) to an oven-dried $4 \mathrm{~mL}$ vial containing a magnetic stir bar. This mixture was stirred for $10 \mathrm{~min}$ as a homogenous blue solution formed. At this time, diethoxy(methyl)silane $(320 \mu \mathrm{L}, 2.00 \mathrm{mmol}, 8.0$ equiv) was added and the solution was stirred for another $10 \mathrm{~min}$, during which time the solution developed a bright orange color. An aliquot of this solution $(580 \mu \mathrm{L})$ was then transferred to a reaction vial containing styrene $(29 \mu \mathrm{L}, 26.0 \mathrm{mg}, 0.25 \mathrm{mmol}, 1.0$ equiv) and amine electrophile $(0.30$ mmol, 1.2 equiv). The reaction vial was capped, removed from the glove box and placed into an oil bath preheated at $40{ }^{\circ} \mathrm{C}$. After $20 \mathrm{~h}$, the reaction mixture was cooled to ambient temperature and then quenched with sat. $\mathrm{NaHCO}_{3}(2 \mathrm{~mL})$ and extracted with EtOAc $(3 \times 2 \mathrm{~mL})$. The combined organic layers were dried with $\mathrm{Na}_{2} \mathrm{SO}_{4}$, filtered, concentrated in vacuo, and the crude material was purified by silica gel chromatography (2\% EtOAc in hexanes). Enantiomeric excess was determined by chiral HPLC (OD-H column, 98:2 hexanes/IPA, $0.6 \mathrm{~mL} / \mathrm{min}, 6.8 \mathrm{~min}$ (minor) and $7.9 \mathrm{~min}$ (major)). Amine product with $97 \%$ ee was observed for all amine electrophiles shown in the above equation.

Amine electrophiles used in this study: $O$-benzoyl- $N, N$-dibenzylhydroxylamine $(\mathbf{3}, 95$ $\mathrm{mg}, 0.30 \mathrm{mmol}, 1.2$ equiv); $N, N$-dibenzyl- $O$-(4-methoxybenzoyl)hydroxylamine (104 $\mathrm{mg}, 0.30 \mathrm{mmol}, 1.2$ equiv); $\mathrm{N}, \mathrm{N}$-dibenzyl- $O$-(4-methylbenzoyl)hydroxylamine (99 $\mathrm{mg}$, $0.30 \mathrm{mmol}, 1.2$ equiv) $\mathrm{N}, \mathrm{N}$-dibenzyl- $O$-(4-fluorobenzoyl)hydroxylamine (101 $\mathrm{mg}, 0.30$ mmol, 1.2 equiv); $N, N$-dibenzyl- $O$-(4-(trifluoromethyl)benzoyl)hydroxylamine (116 mg, 0.30 mmol, 1.2 equiv). Note: Inconsistent ee values were obtained when using 4(((dibenzylamino)oxy)carbonyl)- $N, N$-diethylaniline (11) as the amine electrophile with styrene $(86-94 \%$ ee).

\section{Isotope labeling studies}

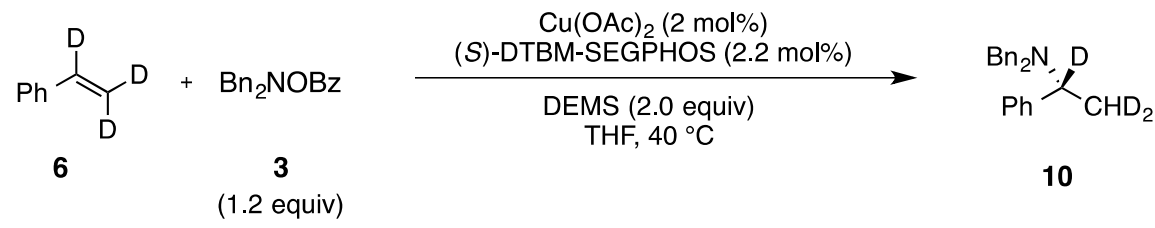

$\mathrm{Bn}_{2} \mathrm{~N}, \mathrm{D} \quad(\boldsymbol{R})-\boldsymbol{N}, \boldsymbol{N}$-Dibenzyl-1-phenylethan-1-amine-1,2,2- $\boldsymbol{d}_{3}$. In a nitrogen-filled glove box, a catalyst solution was prepared with $\mathrm{Cu}(\mathrm{OAc})_{2}(7.2 \mathrm{mg}, 0.04$ mmol, 0.04 equiv) and (S)-DTBM-SEGPHOS (52 mg, $0.044 \mathrm{mmol}, 0.044$ equiv) in THF $(4.0 \mathrm{~mL})$. This mixture was stirred for $10 \mathrm{~min}$ as a homogenous blue solution formed. At this time, diethoxy(methyl)silane $(640 \mu \mathrm{L}, 4.00 \mathrm{mmol}, 4.0$ equiv) was added and the solution was stirred for another $10 \mathrm{~min}$, during which time the solution 
developed a bright orange color. An aliquot of this solution $(2.32 \mathrm{~mL})$ was then transferred to a reaction vial containing styrene- $\alpha, \beta, \beta-\mathrm{d}_{3} 6$ (107 $\mathrm{mg}, 1.0 \mathrm{mmol}, 1.0$ equiv) and $O$-benzoyl- $N, N$-dibenzylhydroxylamine (380 mg, $1.2 \mathrm{mmol}, 1.2$ equiv). The reaction vial was capped, removed from the glove box, and placed in an oil bath preheated to $40{ }^{\circ} \mathrm{C}$. After $20 \mathrm{~h}$, the reaction mixture was cooled to ambient temperature and then quenched with sat. $\mathrm{NaHCO}_{3}(2 \mathrm{~mL})$ and extracted with EtOAc $(3 \times 2 \mathrm{~mL})$. The combined organic layers were dried with $\mathrm{Na}_{2} \mathrm{SO}_{4}$, filtered, concentrated in vacuo and the crude material was purified by silica gel chromotagraphy (2\% EtOAc in hexanes). The purified product was obtained as a white solid (291 mg, $0.95 \mathrm{mmol}, 95 \%$ yield). m.p. 73$74{ }^{\circ} \mathrm{C}$. IR (thin film) 2360, 1493, 1453, 1363, 1027, $731 \mathrm{~cm}^{-1}$. EA Calcd. for $\mathrm{C}_{22} \mathrm{H}_{20} \mathrm{D}_{3} \mathrm{~N}$ : C, 86.79; H, 8.61. Found: C, 87.04; H, 7.62. ${ }^{\mathbf{1}} \mathbf{H}$ NMR $\left(400 \mathrm{MHz}, \mathrm{CDCl}_{3}\right) \delta$ 7.45-7.25 $(\mathrm{m}, 15 \mathrm{H}), 3.67(\mathrm{~d}, 13.8 \mathrm{~Hz}, 2 \mathrm{H}), 3.45(\mathrm{~d}, 13.8 \mathrm{~Hz}, 2 \mathrm{H}), 1.44(\mathrm{~s}, 1 \mathrm{H}) .{ }^{2} \mathbf{H}$ NMR $(400 \mathrm{MHz}$, $\left.\mathrm{CHCl}_{3}\right) \delta 3.79$ (s, 1D), 1.30 (s, 2D). ${ }^{13} \mathbf{C ~ N M R}\left(100 \mathrm{MHz}, \mathrm{CDCl}_{3}\right) \delta 142.7,140.6,128.8$, $128.3,128.2,128.1,126.9,126.8,55.8(\mathrm{t}), 53.7,13.4(\mathrm{qt})$.

In a separate experiment, the above procedure was repeated on a $0.25 \mathrm{mmol}$ scale using degassed THF- $d_{8}$ in place of THF. The reaction solution was transferred to a NMR tube and the tube was capped and sealed with parafilm before removing from the glove box. The NMR tube was placed into an oil bath preheated to $40{ }^{\circ} \mathrm{C}$ and periodically removed in order to perform ${ }^{1} \mathrm{H}$ NMR analysis. At no time were signals attributable to olefinic protons observed.

\section{Preparation of ligated copper precomplex (CuCatMix)}

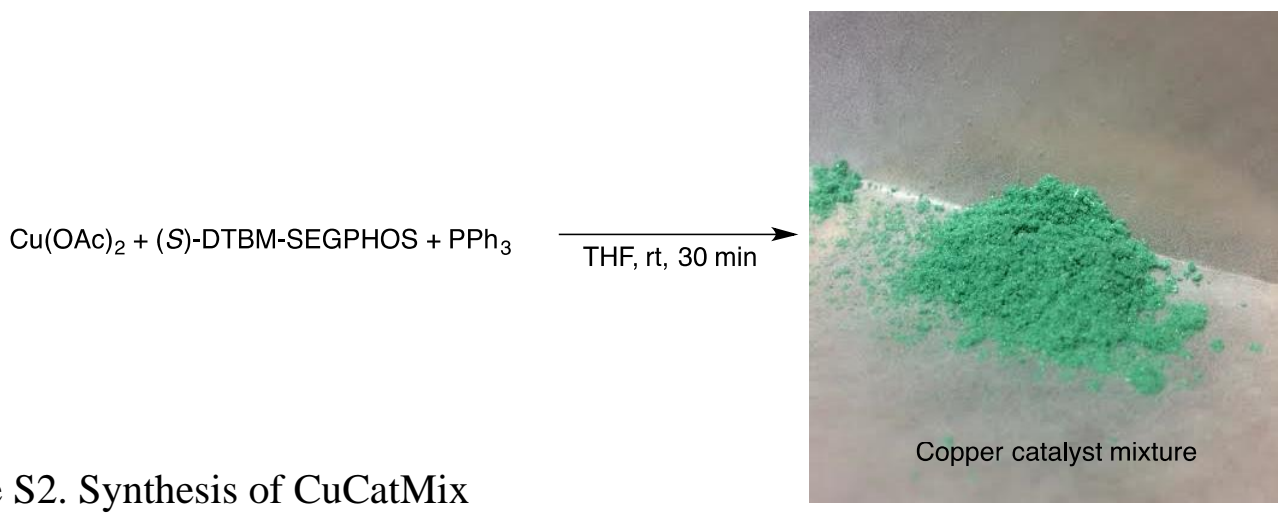

Scheme S2. Synthesis of CuCatMix

In a nitrogen-filled glove box, $\mathrm{Cu}(\mathrm{OAc})_{2}(126 \mathrm{mg}, 0.69 \mathrm{mmol}, 1.0$ equiv), $(S)$-DTBMSEGPHOS (900 mg, $0.76 \mathrm{mmol}, 1.1$ equiv) and $\mathrm{PPh}_{3}$ (200 mg, $0.76 \mathrm{mmol}, 1.1$ equiv) were weighed into a $50 \mathrm{~mL}$ oven-dried round bottom flask. THF $(15 \mathrm{~mL})$ was added and the reaction flask was removed from the glove box and stirred at ambient temperature for $30 \mathrm{~min}$. The reaction mixture became a deep blue homogenous solution during this time. The reaction solution was concentrated in vacuo to give a blue-green oil. Pentane (15 $\mathrm{mL}$ ) was added to the oil and the mixture was stirred for 5 min before concentrated in vacuo. This process was repeated a total of three times to ultimately yield a fine aquacolored powder $(1.23 \mathrm{~g})$. This copper-ligand complex (CuCatMix) was used in the optimized hydroamination processes described below for Table 2. CuCatMix has been 
stored in a desiccator under air for 3 months and shows identical reactivity to when it is recently synthesized.

\section{Optimized hydroamination procedures}

General procedure for Table 2, entries 1, 2, 4, 6, and 7. The entire following procedure was performed open to the atmosphere. To a reaction tube (Fisherbrand, $16 \mathrm{x}$ $125 \mathrm{~mm}$, catalog no. 1495925C) containing a stir bar was added CuCatMix (35.4 mg, 0.02 equiv), $N, N$-dibenzyl- $O$-pivaloylhydroxylamine (357 $\mathrm{mg}, 1.2 \mathrm{mmol}, 1.2$ equiv), alkene or alkyne (1.0 mmol, 1.0 equiv) and THF (1 mL, [1M]). The resulting blue solution was placed in an oil bath preheated to $60{ }^{\circ} \mathrm{C}$ for $5 \mathrm{~min}$ and dimethoxy(methyl)silane ( $247 \mu \mathrm{L}, 2.0 \mathrm{mmol}, 2.0$ equiv) was added. The reaction solution immediately turned a bright orange color. At the time indicated for each substrate, the reaction was cooled to ambient temperature and then quenched with sat. $\mathrm{NaHCO}_{3}(5 \mathrm{~mL})$ and extracted with EtOAc $(3 \times 5 \mathrm{~mL})$. The combined organic layers were dried with $\mathrm{Na}_{2} \mathrm{SO}_{4}$, filtered, concentrated in vacuo, and the resulting crude material was purified by silica gel chromatography. Each reaction was performed in duplicate and two isolated yields were obtained.

Note on THF: The THF used in this procedure was obtained from a solvent system and transferred to a vial that was open to air before being added to the reaction vessel via syringe. We have found that THF from a variety of sources work equally well. For example, THF from Sigma Aldrich Co. (\#360589, $500 \mathrm{~mL}$ bottle) and Macron Fine Chemicals (\#8498-08, 4L bottle) bottles that had been opened and in regular use in our laboratory for one year worked comparably for these reactions.

Note on compatible substrates: For the hydroamination of cis- $\beta$-substituted styrenes and 1,1-disubstituted alkenes, the reactions must be conducted under a nitrogen or argon atmosphere (Table 2, entries 3 and 5, see entries below for details). For internal unactivated alkene substrates, we recommend our previously reported experimental procedure. $^{2}$

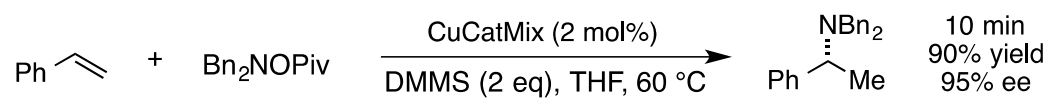

$(\boldsymbol{R})-N, N$-Dibenzyl-1-phenylethan-1-amine (Table 2, entry 1). The general procedure in section $\mathrm{X}$ was performed open to the atmosphere using styrene $(115 \mu \mathrm{L}, 1.0 \mathrm{mmol}, 1.0$ equiv) and a $10 \mathrm{~min}$ reaction time. The desired product was purified by silica gel chromatography (0 to $2 \% \mathrm{Et}_{2} \mathrm{O}$ in hexanes eluent) to give a white solid (Run 1: $271 \mathrm{mg}$, $0.899 \mathrm{mmol}, 90 \%$ yield; Run 2: $269 \mathrm{mg}, 0.892 \mathrm{mmol}, 89 \%$ yield). m.p. $72-73{ }^{\circ} \mathrm{C}$. IR (thin film) 2359, 1493, 1452, 1124, 743, $696 \mathrm{~cm}^{-1} ;{ }^{1} \mathbf{H}$ NMR $\left(400 \mathrm{MHz}, \mathrm{CDCl}_{3}\right) \delta$ 7.50$7.20(\mathrm{~m}, 15 \mathrm{H}), 4.00(\mathrm{q}, 6.9 \mathrm{~Hz}, 1 \mathrm{H}), 3.67$ (d, $13.8 \mathrm{~Hz}, 2 \mathrm{H}), 3.50(\mathrm{~d}, 13.8 \mathrm{~Hz}, 2 \mathrm{H}), 1.48$ (d, $6.9 \mathrm{~Hz}, 3 \mathrm{H}) .{ }^{13} \mathrm{C}$ NMR $\left(100 \mathrm{MHz}, \mathrm{CDCl}_{3}\right) \delta 142.9,140.6,128.8,128.3,128.3,128.2$, 128.2, 126.9, 126.8, 56.3, 53.7, 13.9. EA Calcd. for $\mathrm{C}_{22} \mathrm{H}_{23} \mathrm{~N}$ : C, 87.66; H, 7.69. Found: $\mathrm{C}, 87.73 ; \mathrm{H}, 7.66$. Specific rotation $[\alpha]_{\mathrm{D}}{ }^{24.2}=98.0\left(\mathrm{c}=1.0, \mathrm{CHCl}_{3}\right) ; \mathbf{H P L C}$ analysis: 
Chiralpak OD-H (Hex/IPA = 98/2, $\left.0.6 \mathrm{~mL} / \mathrm{min}, 230 \mathrm{~nm}, 23^{\circ} \mathrm{C}\right), 6.7 \mathrm{~min}(\operatorname{minor}), 7.9 \mathrm{~min}$ (major), $95 \%$ ee.

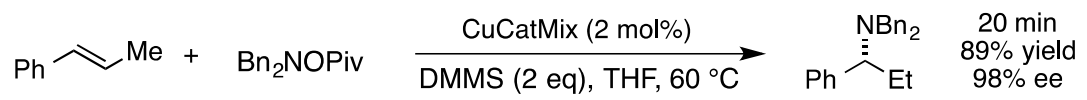

( $R$ )- $N, N$-Dibenzyl-1-phenylpropan-1-amine (Table 2, entry 2). The general procedure in section $\mathrm{X}$ was performed open to the atmosphere using trans- $\beta$-methylstyrene $(130 \mu \mathrm{L}$, $1.0 \mathrm{mmol}, 1.0$ equiv) and a $20 \mathrm{~min}$ reaction time. The desired product was purified by silica gel chromatography ( 0 to $4 \% \mathrm{Et}_{2} \mathrm{O}$ in hexanes eluent) to give a colorless oil (Run 1: $300 \mathrm{mg}, 0.951 \mathrm{mmol}, 95 \%$ yield; Run 2: $260 \mathrm{mg}, 0.824 \mathrm{mmol}, 82 \%$ yield). IR (thin film) 2960, 1493, 1452, 1027, 862, $740 \mathrm{~cm}^{-1}$; ${ }^{1} \mathbf{H}$ NMR (400 MHz, $\left.\mathrm{CDCl}_{3}\right) \delta$ 7.50-7.20 (m, 15 H), $3.80(\mathrm{~d}, 13.9 \mathrm{~Hz}, 2 \mathrm{H}), 3.68(\mathrm{t}, 7.5 \mathrm{~Hz}, 1 \mathrm{H}), 3.23(\mathrm{~d}, 13.8 \mathrm{~Hz}, 2 \mathrm{H}), 2.18(\mathrm{~m}, 1 \mathrm{H}), 1.85$ $(\mathrm{m}, 1 \mathrm{H}), 1.00(\mathrm{t}, 7.3 \mathrm{~Hz}, 3 \mathrm{H}) .{ }^{13} \mathbf{C}$ NMR $\left(100 \mathrm{MHz}, \mathrm{CDCl}_{3}\right) \delta 140.6,139.1,129.1,128.9$, 128.3, 128.0, 127.1, 126.8, 63.9, 53.8, 24.4, 11.9. EA Calcd. for $\mathrm{C}_{23} \mathrm{H}_{25} \mathrm{~N}$ : C, 87.57; H, 7.99. Found: $\mathrm{C}, 87.62 ; \mathrm{H}, 7.95$. Specific rotation $[\alpha]_{\mathrm{D}}^{23.9}=114.2\left(\mathrm{c}=1.0, \mathrm{CHCl}_{3}\right)$; HPLC analysis: Chiralpak OD-H (Hex/IPA = 96/4, $\left.0.6 \mathrm{~mL} / \mathrm{min}, 230 \mathrm{~nm}, 23^{\circ} \mathrm{C}\right), 6.6 \mathrm{~min}$ (minor), 7.9 min (major), $98 \%$ ee.

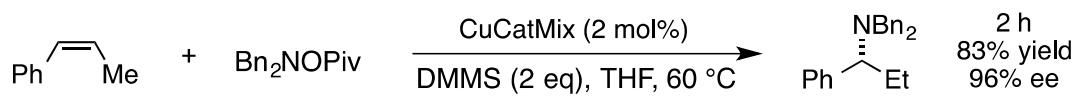

$(R)-N, N$-Dibenzyl-1-phenylpropan-1-amine (Table 2, entry 3). To a reaction tube (Fisherbrand, $16 \times 125 \mathrm{~mm}$, catalog no. 1495925C) containing a stir bar was added CuCatMix (35.4 mg, 0.02 equiv) and $\mathrm{N}, \mathrm{N}$-dibenzyl- $O$-pivaloylhydroxylamine $(357 \mathrm{mg}$, $1.2 \mathrm{mmol}, 1.2$ equiv). The reaction tube was capped, put under vacuum, and backfilled with argon. This process was repeated a total of three times. THF $(1 \mathrm{~mL})$ from a solvent still was then added via syringe and cis- $\beta$-methylstyrene (130 $\mu \mathrm{L} 1.0 \mathrm{mmol}, 1.0$ equiv) was added before the resulting blue solution was placed in an oil bath preheated to $60{ }^{\circ} \mathrm{C}$ for $5 \mathrm{~min}$. Dimethoxy(methyl)silane $(247 \mu \mathrm{L}, 2.0 \mathrm{mmol}, 2.0$ equiv) was added, and the reaction solution was stirred for a further $2 \mathrm{~h}$. The reaction solution was cooled to ambient temperature and then quenched with sat. $\mathrm{NaHCO}_{3}(5 \mathrm{~mL})$ and extracted with EtOAc $(3 \times 5 \mathrm{~mL})$. The combined organic layers were dried with $\mathrm{Na}_{2} \mathrm{SO}_{4}$, filtered, concentrated in vacuo, and the resulting crude material was purified by silica gel chromatography ( 0 to $4 \% \mathrm{Et}_{2} \mathrm{O}$ in hexanes eluent) to give a colorless oil (Run 1: $243 \mathrm{mg}$, $0.770 \mathrm{mmol}, 77 \%$ yield; Run 2: $282 \mathrm{mg}, 0.894 \mathrm{mmol}, 89 \%$ yield). ${ }^{1} \mathbf{H}$ NMR (400 MHz, $\left.\mathrm{CDCl}_{3}\right) \delta$ 7.50-7.20 (m, $\left.15 \mathrm{H}\right), 3.80(\mathrm{~d}, 13.9 \mathrm{~Hz}, 2 \mathrm{H}), 3.68(\mathrm{t}, 7.5 \mathrm{~Hz}, 1 \mathrm{H}), 3.23(\mathrm{~d}, 13.8$ $\mathrm{Hz}, 2 \mathrm{H}), 2.18(\mathrm{~m}, 1 \mathrm{H}), 1.85(\mathrm{~m}, 1 \mathrm{H}), 1.00(\mathrm{t}, 7.3 \mathrm{~Hz}, 3 \mathrm{H})$. HPLC analysis: Chiralpak OD-H $\left(\mathrm{Hex} / \mathrm{IPA}=96 / 4,0.6 \mathrm{~mL} / \mathrm{min}, 230 \mathrm{~nm}, 23^{\circ} \mathrm{C}\right.$ ), $6.6 \mathrm{~min}$ (minor), $7.9 \mathrm{~min}$ (major), $96 \%$ ee. 


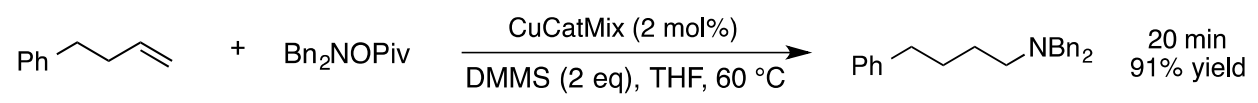

$\boldsymbol{N}, \boldsymbol{N}$-Dibenzyl-4-phenylbutan-1-amine (Table 2 , entry 4). ${ }^{1}$ The general procedure in section $X$ was performed open to the atmosphere using 4-phenyl-1-butene $(150 \mu \mathrm{L}, 1.0$ mmol, 1.0 equiv) and a 20 min reaction time. For this substrate, $0.5 \mathrm{~mL}$ of THF was used. The desired product was purified by silica gel chromatography ( 0 to $4 \% \mathrm{Et}_{2} \mathrm{O}$ in hexanes eluent) to give a colorless oil (Run 1: $296 \mathrm{mg}, 0.898 \mathrm{mmol}, 90 \%$ yield; Run 2: $303 \mathrm{mg}$, $0.920 \mathrm{mmol}, 92 \%$ yield). ${ }^{1} \mathbf{H}$ NMR $\left(400 \mathrm{MHz}, \mathrm{CDCl}_{3}\right) \delta 7.41-7.14(\mathrm{~m}, 15 \mathrm{H}), 3.57$ (s, 4H), $2.57(\mathrm{t}, 7.4 \mathrm{~Hz}, 2 \mathrm{H}), 2.46(\mathrm{t}, 6.9 \mathrm{~Hz}, 2 \mathrm{H}), 1.70-1.55(\mathrm{~m}, 4 \mathrm{H}) .{ }^{13} \mathbf{C}$ NMR $(100 \mathrm{MHz}$, $\left.\mathrm{CDCl}_{3}\right) \delta 142.8,140.1,128.9,128.5,128.3,128.3,126.9,125.7,58.5,53.2,35.8,29.0$, 26.7 .

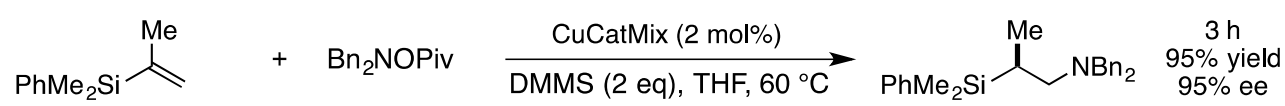

(S)-N,N-Dibenzyl-2-(dimethyl(phenyl)silyl)propan-1-amine (Table 2, entry 5). To a reaction tube (Fisherbrand, $16 \times 125 \mathrm{~mm}$, catalog no. 1495925C) containing a stir bar was added CuCatMix (35.4 mg, 0.02 equiv) and $N, N$-dibenzyl- $O$-pivaloylhydroxylamine (357 mg, $1.2 \mathrm{mmol}, 1.2$ equiv). The reaction tube was capped, put under vacuum, and backfilled with argon. This process was repeated a total of three times. THF (1 mL) from a solvent still was then added via syringe and dimethyl(phenyl)(prop-1-en-2-yl)silane (176 mg, $1.0 \mathrm{mmol}, 1.0$ equiv) was added before the resulting blue solution was placed in an oil bath preheated to $60{ }^{\circ} \mathrm{C}$ for $5 \mathrm{~min}$. Dimethoxy(methyl)silane $(247 \mu \mathrm{L}, 2.0 \mathrm{mmol}$, 2.0 equiv) was added, and the reaction solution was stirred for a further $3 \mathrm{~h}$. The reaction solution was cooled to ambient temperature and then quenched with sat. $\mathrm{NaHCO}_{3}(5 \mathrm{~mL})$ and extracted with EtOAc $(3 \times 5 \mathrm{~mL})$. The combined organic layers were dried with $\mathrm{Na}_{2} \mathrm{SO}_{4}$, filtered, concentrated in vacuo, and the resulting crude material was purified by silica gel chromatography ( 0 to $5 \% \mathrm{Et}_{2} \mathrm{O}$ in hexanes eluent) to give a colorless oil (Run 1: $361 \mathrm{mg}, 0.97 \mathrm{mmol}, 97 \%$ yield; Run 2: $347 \mathrm{mg}, 0.93 \mathrm{mmol}, 93 \%$ yield). IR (thin film) 2951, 1494, 1427, 1111, 731, $571 \mathrm{~cm}^{-1}$; Specific rotation $[\alpha]_{\mathrm{D}}^{23.8}=-74.2(\mathrm{c}=1.0$, $\mathrm{CHCl}_{3}$ ); EA Calcd. for $\mathrm{C}_{23} \mathrm{H}_{31} \mathrm{NSi}$ : C, 80.37; H, 8.36. Found: C, 80.56; H, 8.50. ${ }^{1} \mathbf{H}$ NMR $\left(400 \mathrm{MHz}, \mathrm{CDCl}_{3}\right) \delta$ 7.51-7.35 (m, 15H), $3.80(\mathrm{~d}, 13.6 \mathrm{~Hz}, 2 \mathrm{H}), 3.32(\mathrm{~d}, 13.6 \mathrm{~Hz}, 2 \mathrm{H})$, $2.45(\mathrm{~m}, 2 \mathrm{H}), 1.40(\mathrm{~m}, 1 \mathrm{H}), 1.10(\mathrm{~d}, 7.2 \mathrm{~Hz}, 3 \mathrm{H}), 0.27(\mathrm{~s}, 6 \mathrm{H}) .{ }^{13} \mathbf{C}$ NMR $(100 \mathrm{MHz}$, $\left.\mathrm{CDCl}_{3}\right) \delta 139.9,138.5,134.0,129.1,128.9,128.2,127.8,126.8,58.2,56.1,18.1,13.2$. HPLC analysis: Chiralcel OJ (Hex/EtOH = 85/15, $\left.1.0 \mathrm{~mL} / \mathrm{min}, 210 \mathrm{~nm}, 23^{\circ} \mathrm{C}\right), 4.2 \mathrm{~min}$ (minor), 22.3 min (major), 95\% ee.

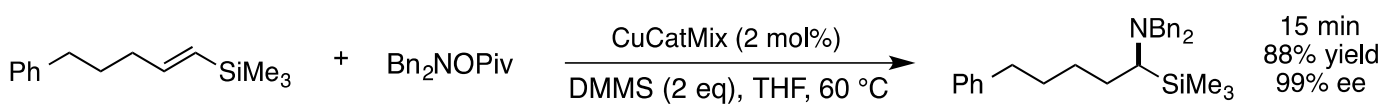

(S)-N,N-Dibenzyl-5-phenyl-1-(trimethylsilyl)pentan-1-amine (Table 2, entry 6). The general procedure in section $\mathrm{X}$ was performed open to the atmosphere using $(E)$ - 
trimethyl(5-phenylpent-1-en-1-yl)silane (218 mg, $1.0 \mathrm{mmol}, 1.0$ equiv) and a $15 \mathrm{~min}$ reaction time. The desired product was purified by silica gel chromatography ( 0 to $4 \%$ $\mathrm{Et}_{2} \mathrm{O}$ in hexanes eluent) to give a colorless oil (Run 1: $365 \mathrm{mg}, 0.878 \mathrm{mmol}, 88 \%$ yield; Run 2: $365 \mathrm{mg}, 0.878 \mathrm{mmol}, 88 \%$ yield). IR (thin film) 2929, 1494, 1453, 1360, 1247 , $743 \mathrm{~cm}^{-1} ;{ }^{1} \mathbf{H}$ NMR $\left(400 \mathrm{MHz}, \mathrm{CDCl}_{3}\right) \delta$ 7.40-7.15 (m, 15H), $3.69(\mathrm{~s}, 4 \mathrm{H}), 2.63(\mathrm{~m}, 2 \mathrm{H})$, $2.20(\mathrm{dd}, 7.6$ and $5.7 \mathrm{~Hz}, 1 \mathrm{H}), 1.81(\mathrm{~m}, 1 \mathrm{H}), 1.60-1.30(\mathrm{~m}, 5 \mathrm{H}), 0.12(\mathrm{~s}, 9 \mathrm{H}) .{ }^{13} \mathbf{C ~ N M R}$ $\left(100 \mathrm{MHz}, \mathrm{CDCl}_{3}\right) \delta 142.9,140.9,129.0,128.6,128.3,128.2,126.8,125.7,56.5,49.8$, 36.0, 31.8, 28.7, 26.1. EA Calcd. for $\mathrm{C}_{28} \mathrm{H}_{37} \mathrm{NSi}$ : C, 80.90; H, 8.97. Found: C, 81.01; H, 8.95. Specific rotation $[\alpha]_{\mathrm{D}}^{23.8}=2.0\left(\mathrm{c}=1.0, \mathrm{CHCl}_{3}\right)$; HPLC analysis: Chiralpak OD-H $\left(\mathrm{Hex} / \mathrm{IPA}=99 / 1,0.6 \mathrm{~mL} / \mathrm{min}, 230 \mathrm{~nm}, 23^{\circ} \mathrm{C}\right.$ ), $6.8 \mathrm{~min}$ (major), $7.4 \mathrm{~min}$ (minor) 99\% ee.

$$
\left.\mathrm{Ph}=\mathrm{Ph}+\mathrm{Bn}_{2} \text { NOPiv } \frac{\text { CuCatMix (2 mol\%) }}{\mathrm{DMMS}(2 \mathrm{eq}), \mathrm{THF}, 60^{\circ} \mathrm{C}} \stackrel{\mathrm{Ph}}{\longrightarrow}\right\rangle_{\mathrm{Ph}} \stackrel{\mathrm{Bn}_{2} \mathrm{~N}}{91 \% \mathrm{NMR} \text { yield }}
$$

$(E)-N, N$-dibenzyl-1,2-diphenylethen-1-amine (Table 2 , entry 7 ). ${ }^{3}$ The general procedure in section $\mathrm{X}$ was performed open to the atmosphere using diphenylacetylene (178 $\mathrm{mg}, 1.0 \mathrm{mmol}, 1.0$ equiv) and a $15 \mathrm{~min}$ reaction time. The desired product was quantified by ${ }^{1} \mathrm{H}$ NMR of the crude reaction mixture using 1,1,2,2-tetrachloroethane as an internal standard. (Run 1: 90\% yield; Run 2: $92 \%$ yield).

\section{Hydroamination with low loadings of DTBM-SEGPHOS}

General procedure. In a nitrogen-filled glove box, a reaction tube (Fisherbrand, $16 \mathrm{x}$ $125 \mathrm{~mm}$, catalog no. $1495925 \mathrm{C})$ containing a stir bar was charged with $\mathrm{Cu}(\mathrm{OAc})_{2}(3.6$ mg, 0.02 mmol, 0.02 equiv), $\mathrm{PPh}_{3}(5.2 \mathrm{mg}, 0.02 \mathrm{mmol}, 0.02$ equiv), $N, N$-dibenzyl- $O$ pivaloylhydroxylamine ( $357 \mathrm{mg}, 1.2 \mathrm{mmol}, 1.2$ equiv), and alkene (1.0 mmol, 1.0 equiv). In a separate $8 \mathrm{~mL}$ scintillation vial $(S)$-DTBM-SEGPHOS $(4.7 \mathrm{mg}, 0.004 \mathrm{mmol}, 0.0004$ equiv) and THF (4 mL) was added and stirred to homogeneity. An aliquot from the stock solution of DTBM-SEGPHOS (1 mL) was added to the reaction tube and was stirred until homogeneity was reached. Dimethoxy(methyl)silane ( $247 \mu \mathrm{L}, 2.0 \mathrm{mmol}, 2.0$ equiv) was added to the resultant blue solution. The reaction vessel was capped and removed from the glove box, and immersed in an oil bath preheated to $60{ }^{\circ} \mathrm{C}$ and stirred for $24 \mathrm{~h}$. After cooling to ambient temperature, the reaction was quenched with a saturated solution of $\mathrm{NaHCO}_{3}(5 \mathrm{~mL})$ and extracted with EtOAc $(3 \times 5 \mathrm{~mL})$. The combined organic layers were concentrated in vасио and the resulting crude material was purified by silica gel chromatography. Each reaction was performed in duplicate and the two obtained isolated yields are given below.

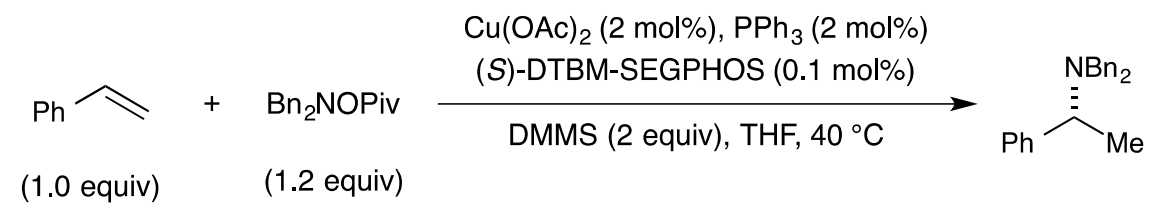

(R)-N,N-Dibenzyl-1-phenylethan-1-amine (Table 3, entry 1). The general procedure 
from section XI was followed using styrene $(115 \mu \mathrm{L}, 1.0 \mathrm{mmol}, 1.0$ equiv). The desired product was purified by silica gel chromatography (0 to $5 \% \mathrm{Et}_{2} \mathrm{O}$ in hexanes eluent) to give a white solid (Run 1: $259 \mathrm{mg}, 0.86 \mathrm{mmol}, 86 \%$ yield; Run 2: $268 \mathrm{mg}, 0.89 \mathrm{mmol}$, $89 \%$ yield). HPLC analysis: Chiralpak OD-H (Hex/IPA = 98/2, $0.6 \mathrm{~mL} / \mathrm{min}, 230 \mathrm{~nm}$, $23^{\circ} \mathrm{C}$ ), $6.7 \mathrm{~min}$ (minor), $7.9 \mathrm{~min}$ (major), $92 \%$ ee.

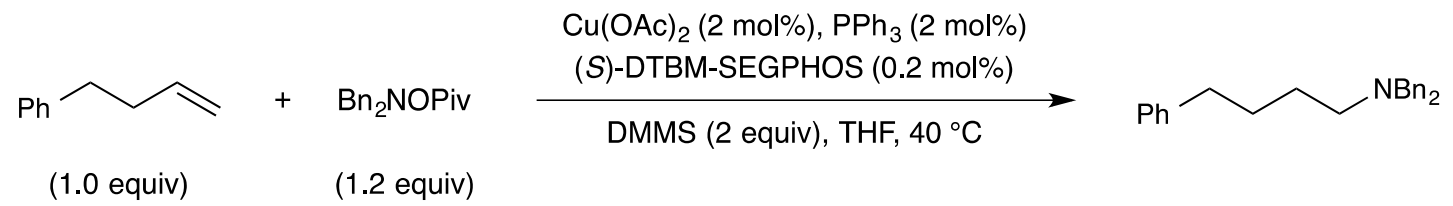

$\boldsymbol{N}, \boldsymbol{N}$-Dibenzyl-4-phenylbutan-1-amine (Table 3, entry 2). In a nitrogen-filled glove box, a reaction tube (Fisherbrand, $16 \times 125 \mathrm{~mm}$, catalog no. 1495925C) containing a stir bar was charged with $\mathrm{Cu}(\mathrm{OAc})_{2}\left(3.6 \mathrm{mg}, 0.02 \mathrm{mmol}, 0.02\right.$ equiv), $\mathrm{PPh}_{3}(5.2 \mathrm{mg}, 0.02$ mmol, 0.02 equiv), $N, N$-dibenzyl- $O$-pivaloylhydroxylamine $(357 \mathrm{mg}, 1.2 \mathrm{mmol}, 1.2$ equiv), and alkene (1.0 mmol, 1.0 equiv). In a separate $8 \mathrm{~mL}$ scintillation vial $(S)$-DTBMSEGPHOS (9.4 mg, $0.008 \mathrm{mmol}, 0.0008$ equiv) and THF (4 mL) was added and stirred to homogeneity. An aliquot from the stock solution of DTBM-SEGPHOS (1 mL) was added to the reaction tube and was stirred until homogeneity was reached. Dimethoxy(methyl)silane ( $247 \mu \mathrm{L}, 2.0 \mathrm{mmol}, 2.0$ equiv) was added to the resultant blue solution. The reaction vessel was capped and removed from the glove box, and immersed in an oil bath preheated to $60{ }^{\circ} \mathrm{C}$ and stirred for $24 \mathrm{~h}$. After cooling to ambient temperature, the reaction was quenched with a saturated solution of $\mathrm{NaHCO}_{3}(5 \mathrm{~mL})$ and extracted with EtOAc $(3 \times 5 \mathrm{~mL})$. The combined organic layers were concentrated in vасио and the resulting crude material was purified by silica gel chromatography ( 0 to $5 \% \mathrm{Et}_{2} \mathrm{O}$ in hexanes eluent) to give a colorless oil (Run 1: $276 \mathrm{mg}, 0.84 \mathrm{mmol}, 84 \%$ yield; Run 2: $283 \mathrm{mg}, 0.86 \mathrm{mmol}, 86 \%$ yield).

\section{Preparation of amine electrophiles}

Amine electrophiles 3, 11, 12 and 14 are known compounds and were prepared according to previously reported literature procedures. $^{2} \quad \mathrm{~N}, \mathrm{~N}$-dibenzyl-O-(4fluorobenzoyl)hydroxylamine and $\quad N, N$-dibenzyl-O-(4-(trifluoromethyl)benzoyl)hydroxylamine were prepared in a similar manner. ${ }^{4}$

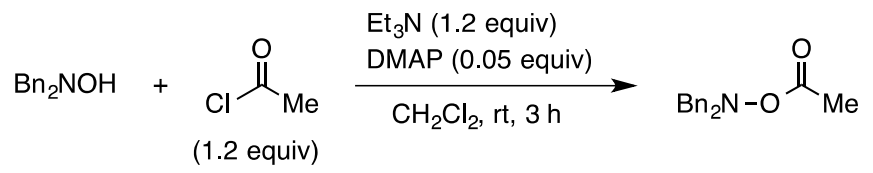

$\mathrm{Bn}_{2} \mathrm{~N}-\mathrm{O}$ 觉 $\mathrm{O}$-Acetyl- $\mathrm{N}, \boldsymbol{N}$-dibenzylhydroxylamine (13). $\mathrm{N}, \mathrm{N}$-dibenzylhydroxylamine (2.00 g, $9.40 \mathrm{mmol}, 1.0$ equiv), triethylamine (1.56 $\mathrm{mL}, 11.3 \mathrm{mmol}, 1.2$ equiv) and 4-dimethylaminopyridine (57 mg, $0.47 \mathrm{mmol}, 0.05$ equiv) were dissolved in $\mathrm{CH}_{2} \mathrm{Cl}_{2}(20 \mathrm{~mL})$ in a $100 \mathrm{~mL}$ round bottom flask. Acetyl chloride $(812 \mu \mathrm{l}$, $11.3 \mathrm{mmol}, 1.2$ equiv) was then added slowly and the resulting solution was stirred at room temperature for $3 \mathrm{~h}$. The final reaction mixture was directly concentrated in vacuo 
and the crude material was purified by silica gel column chromatography (10\% EtOAc in hexanes eluent). The purified product was isolated as a colorless oil $(2.40 \mathrm{~g}, 9.40 \mathrm{mmol}$, $100 \%$ yield). IR (thin film) 1756, 1454, 1362, 1194, 998, $738 \mathrm{~cm}^{-1} ;{ }^{1} \mathbf{H}$ NMR $(400 \mathrm{MHz}$, $\left.\mathrm{CDCl}_{3}\right) \delta 7.50-7.20(\mathrm{~m}, 10 \mathrm{H}), 4.11(\mathrm{~s}, 4 \mathrm{H}), 1.81(\mathrm{~s}, 3 \mathrm{H}) .{ }^{13} \mathbf{C ~ N M R}\left(100 \mathrm{MHz}, \mathrm{CDCl}_{3}\right) \delta$ 169.8, 135.9, 129.5, 128.3, 127.7, 62.5, 19.4. EA Calcd. for $\mathrm{C}_{16} \mathrm{H}_{17} \mathrm{NO}_{2}$ : C, 75.27; $\mathrm{H}$, 6.71. Found: C, 74.88; H, 6.67.

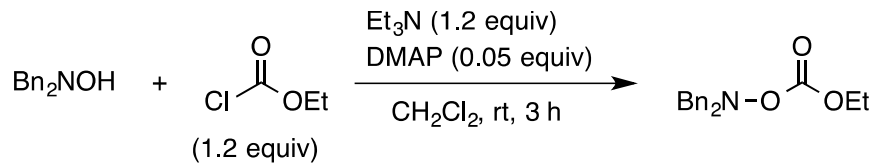

$\mathrm{Bn}_{\mathrm{B}_{2} \mathrm{~N}-\mathrm{O}} \mathrm{ll}_{\mathrm{OEt}} \quad \boldsymbol{N}, \boldsymbol{N}$-Dibenzyl-O-(ethoxycarbonyl)hydroxylamine (15). $\mathrm{N}, \mathrm{N}$-dibenzyl$11.3 \mathrm{mmol}, 1.2$ equiv) and 4-dimethylaminopyridine (57 $\mathrm{mg}, 0.47 \mathrm{mmol}$, 0.05 equiv) were dissolved in $\mathrm{CH}_{2} \mathrm{Cl}_{2}(20 \mathrm{~mL})$ in a $100 \mathrm{~mL}$ round bottom flask. Ethyl chloroformate (1.08 mL, $11.3 \mathrm{mmol}, 1.2$ equiv) was then added slowly and the resulting solution was stirred at room temperature for $3 \mathrm{~h}$. The final reaction mixture was directly concentrated in vacuo and the crude material was purified by silica gel column chromatography (10\% EtOAc in hexanes eluent). The purified product was isolated as a colorless oil (2.60 g, $9.12 \mathrm{mmol}, 97 \%$ yield). IR (thin film) 1765, 1455, 1215, 814, 779, $697 \mathrm{~cm}^{-1} ;{ }^{1} \mathbf{H}$ NMR $\left(400 \mathrm{MHz}, \mathrm{CDCl}_{3}\right) \delta$ 7.45-7.20 (m, 10H), $4.11(\mathrm{~s}, 4 \mathrm{H}), 4.06(\mathrm{q}, 7.1$ $\mathrm{Hz}, 2 \mathrm{H}), 1.16(\mathrm{t}, 7.1 \mathrm{~Hz}, 3 \mathrm{H}) .{ }^{13} \mathbf{C}$ NMR $\left(100 \mathrm{MHz}, \mathrm{CDCl}_{3}\right) \delta 154.5,135.8,129.4,128.3$, 127.7, 64.1, 62.5, 14.1. EA Calcd. for $\mathrm{C}_{17} \mathrm{H}_{19} \mathrm{NO}_{3}$ : C, 71.56; H, 6.71. Found: C, 71.59; H, 6.85 .
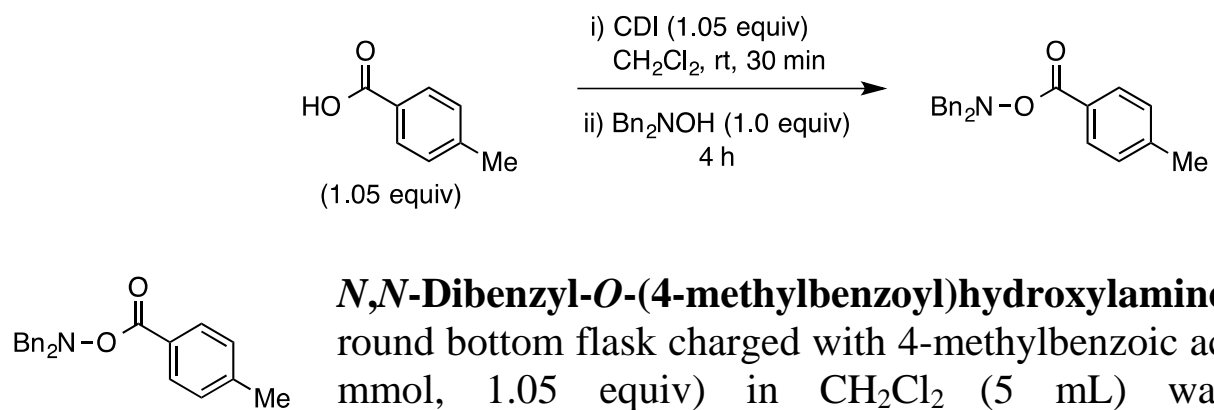

$\boldsymbol{N}, \boldsymbol{N}$-Dibenzyl- $\boldsymbol{O}$-(4-methylbenzoyl)hydroxylamine. To a $25 \mathrm{~mL}$ round bottom flask charged with 4-methylbenzoic acid $(670 \mathrm{mg}, 4.92$ mmol, 1.05 equiv) in $\mathrm{CH}_{2} \mathrm{Cl}_{2}(5 \mathrm{~mL})$ was added $N, N^{\prime}-$ carbonyldiimidazole (800 $\mathrm{mg}, 4.92 \mathrm{mmol}, 1.05$ equiv) and the solution was stirred at room temperature for $30 \mathrm{~min}$. A solution of $\mathrm{N}, \mathrm{N}$ dibenzylhydroxylamine (1.00 g, $4.69 \mathrm{mmol}, 1.0$ equiv) in $\mathrm{CH}_{2} \mathrm{Cl}_{2}$ (3 ml) was then slowly added and the reaction solution was stirred for an additional $4 \mathrm{~h}$. The reaction solution was directly concentrated in vасио and the crude material was purified by silica gel column chromatography (5\% EtOAc in hexanes eluent). The purified product was isolated as a white solid (1.34 g, $4.04 \mathrm{mmol}, 86 \%$ yield). m.p. $95-97{ }^{\circ} \mathrm{C}$. IR (thin film) 2360, 1734, 1259, 1176, 1069, $746 \mathrm{~cm}^{-1} ;{ }^{1} \mathbf{H} \mathbf{~ N M R}\left(400 \mathrm{MHz}, \mathrm{CDCl}_{3}\right) \delta 7.81(\mathrm{dd}, 8.2$ and $1.8 \mathrm{~Hz}, 2 \mathrm{H}), 7.52(\mathrm{~m}, 4 \mathrm{H}), 7.45-7.20(\mathrm{~m}, 6 \mathrm{H}), 7.20(\mathrm{~d}, 8.0 \mathrm{~Hz}, 2 \mathrm{H}), 4.26(\mathrm{~s}, 4 \mathrm{H}), 2.41(\mathrm{~s}$, $3 \mathrm{H}) .{ }^{13} \mathrm{C}$ NMR $\left(100 \mathrm{MHz}, \mathrm{CDCl}_{3}\right) \delta$ 165.0, 143.6, 136.1, 129.5, 129.4, 129.1, 128.4, 
127.7, 126.6, 62.1, 21.7. EA Calcd. for $\mathrm{C}_{22} \mathrm{H}_{21} \mathrm{NO}_{2}: \mathrm{C}, 79.73 ; \mathrm{H}, 6.39$. Found: C, 79.83; H, 6.25 .

\section{XIII. ${ }^{31}$ P-NMR Studies}

\section{XIIIA. Monitoring of the CuH solution by ${ }^{31} \mathrm{P}-\mathrm{NMR}$}

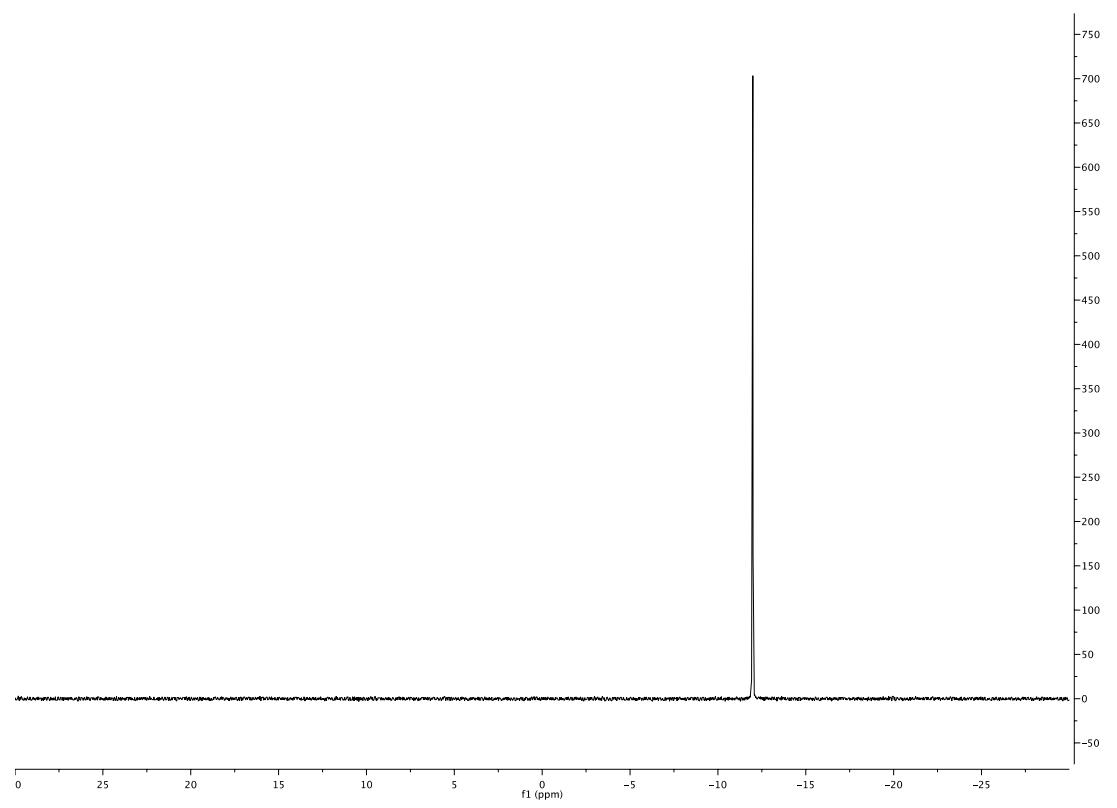

Figure S12. ${ }^{31} \mathrm{P}-\mathrm{NMR}$ spectrum of (S)-DTBM-SEGPHOS.

In a nitrogen-filled glove box, $\mathrm{CuOAc}(26 \mathrm{mg}, 0.14 \mathrm{mmol}, 1.1 \mathrm{equiv})$ and $(S)$-DTBMSEGPHOS (150 mg, $0.13 \mathrm{mmol}, 1.0$ equiv) were weighed into an $8 \mathrm{~mL}$ scintillation vial. toluene $(1 \mathrm{~mL})$ was added and the solution was stirred in the glove box for $24 \mathrm{~h}$. The solution was filtered through a plug of celite, concentrated in vacuo, redissolved in THF $(10 \mathrm{~mL})$ and analyzed by ${ }^{31}$ P-NMR (solution A, Figure S13). 


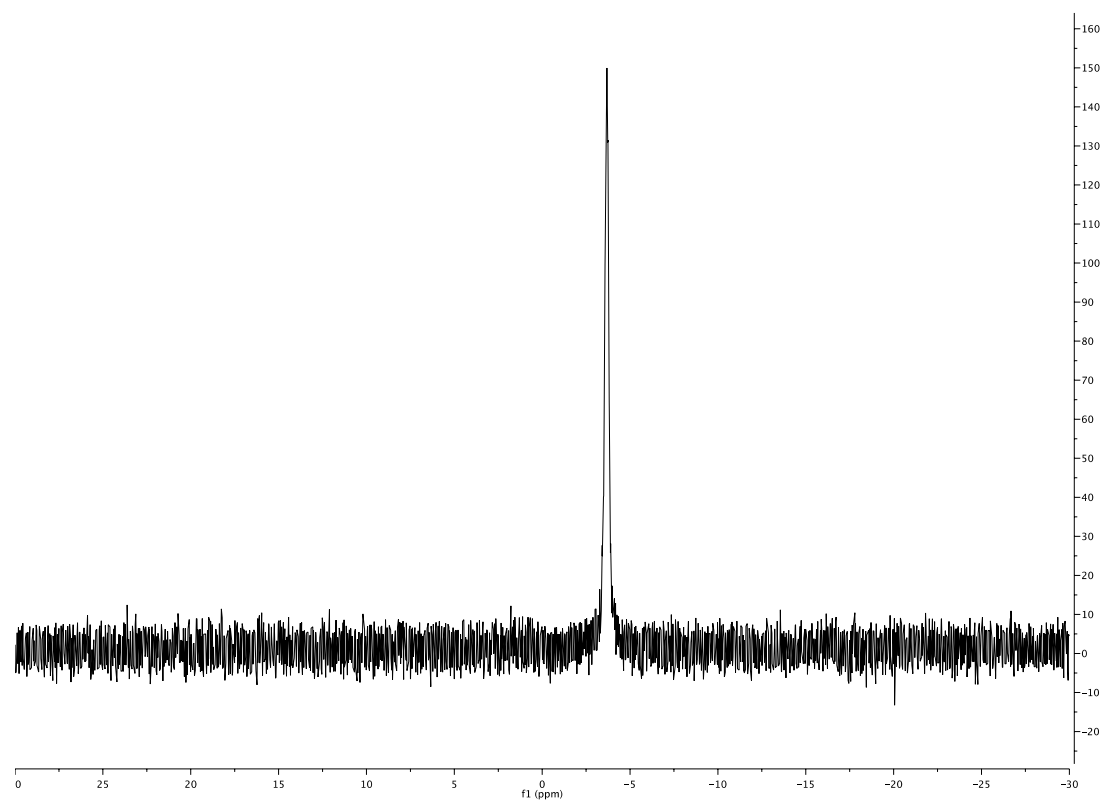

Figure S13. ${ }^{31} \mathrm{P}-\mathrm{NMR}$ spectrum of a solution of CuOAc and $(S)$-DTBM-SEGPHOS.

An aliquot of solution A (from section XIIA) was transferred to a separate $8 \mathrm{~mL}$ scintillation vial $(1 \mathrm{~mL})$. Diethoxy(methyl)silane (DEMS, $80 \mu \mathrm{L}, 0.50 \mathrm{mmol}$ ) was added to this vial, and was stirred for $15 \mathrm{~min}$ and transferred to a separate NMR tube. The NMR tube was capped and wrapped with parafilm. Study of this sample by ${ }^{31} \mathrm{P}-\mathrm{NMR}$ revealed a substantial amount of unbound DTBM-SEGPHOS with a new series of peaks at +5.0 ppm (Figure S14).

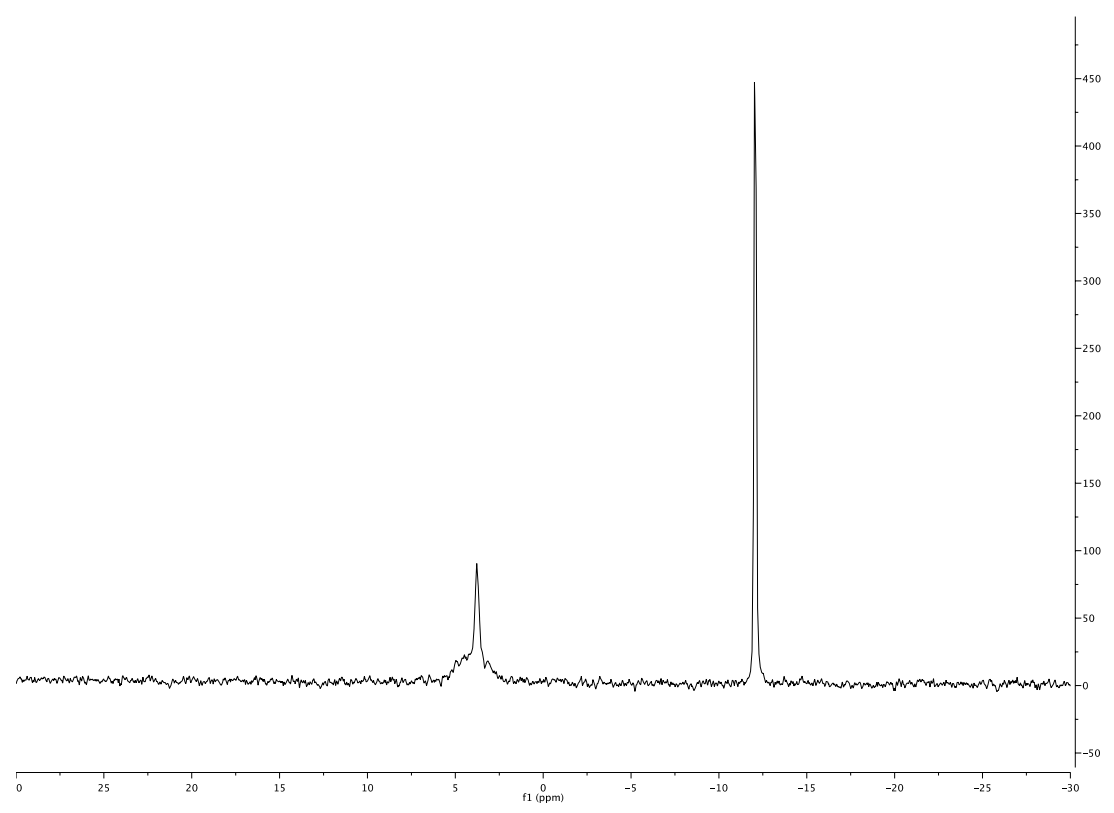

Figure S14. ${ }^{31} \mathrm{P}-\mathrm{NMR}$ spectrum of DEMS CuH solution. 
${ }^{31} \mathrm{P}\left\{{ }^{1} \mathrm{H}\right\}-\mathrm{NMR}$ studies of the $\mathrm{CuH}$ solution were conducted by charging an $8 \mathrm{~mL}$ scintillation vial with $\mathrm{Cu}(\mathrm{OAc})_{2}(0.91 \mathrm{mg}, 0.005 \mathrm{mmol}, 1$ equiv $),(S)$-DTBM-SEGPHOS (6.5 $\mathrm{mg}, 0.0055 \mathrm{mmol}, 1.1$ equiv), and THF $(0.5 \mathrm{~mL})$. The reaction mixture was stirred to homogeneity, and diethoxymethylsilane ( $80 \mu \mathrm{L}, 0.50 \mathrm{mmol}, 100$ equiv) was added. Once a color change to orange occurred (15 min), the solution was transferred to a NMR tube, capped, wrapped with parafilm, and taken out of the glove box.

${ }^{31} \mathrm{P}\left\{{ }^{1} \mathrm{H}\right\}-\mathrm{NMR}$ studies were run with a relaxation delay set to $5 \mathrm{~s}$. The ${ }^{31} \mathrm{P}\left\{{ }^{1} \mathrm{H}\right\}-\mathrm{NMR}$ spectrum reveals that there is $35 \%$ of a new series of peaks around $+5.0 \mathrm{ppm}$ and $65 \%$ of the unbound DTBM-SEGPHOS ligand remaining (Figure S15). This sample is similar to the one observed in Figure S14.

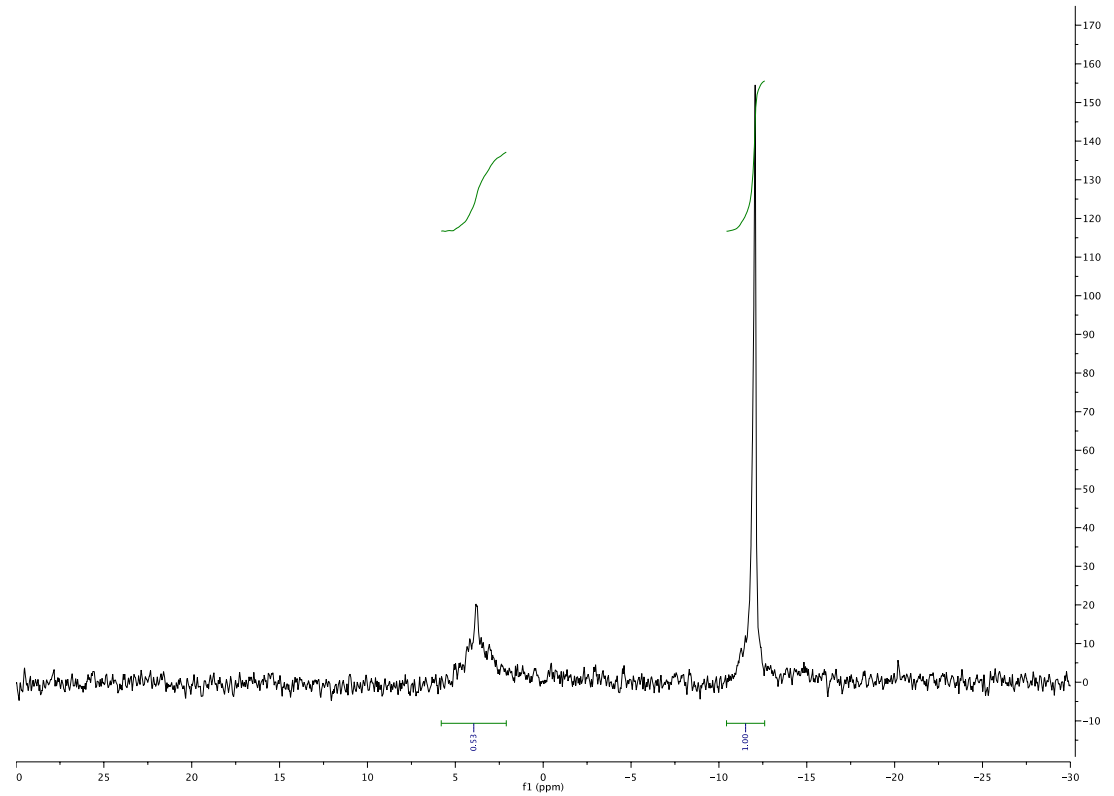

Figure $\mathrm{S} 15 .{ }^{31} \mathrm{P}\left\{{ }^{1} \mathrm{H}\right\}$-NMR spectrum of the $\mathrm{CuH}$ solution with DEMS as the silane.

\section{XIIIB. Monitoring of the Hydroamination of Styrene by ${ }^{31} \mathrm{P}\left\{{ }^{1} \mathrm{H}\right\}$-NMR}

In situ ${ }^{31} \mathrm{P}\left\{{ }^{1} \mathrm{H}\right\}$-NMR studies were conducted at $40{ }^{\circ} \mathrm{C}$, which was established before the sample was inserted into the spectrometer. A pad array experiment was used to collect the data. A total number of 75 experiments were collected with a relaxation delay of $5 \mathrm{~s}$, an acquisition time of $3 \mathrm{~s}$, and 24 scans for each individual experiment in the pad array. Data was collected for an experiment every $600 \mathrm{~s}$.

In a nitrogen-filled glove box, an $8 \mathrm{~mL}$ scintillation vial was charged with $\mathrm{Cu}(\mathrm{OAc})_{2}(3.6$ $\mathrm{mg}, 0.02 \mathrm{mmol}, 0.08$ equiv), (S)-DTBM-SEGPHOS (26.0 mg, $0.022 \mathrm{mmol}, 0.088$ equiv), and THF $(2.0 \mathrm{~mL})$, and this vial was stirred to homogeneity. Once homogeneity was reached, diethoxymethylsilane $(240 \mu \mathrm{L}, 1.5 \mathrm{mmol}, 6.0$ equiv) was added to each vial and stirred until a color change to orange occurred $(15 \mathrm{~min})$. An aliquot of the $\mathrm{CuH}$ solution $(580 \mu \mathrm{L})$ was added to a separate 8 -mL scintillation vial containing styrene $(29 \mu \mathrm{L}, 0.25$ mmol, 1.0 equiv) and $O$-benzoyl- $N, N$-dibenzylhydroxylamine $(95 \mathrm{mg}, 0.30 \mathrm{mmol}, 1.2$ 
equiv). The contents of this vial were transferred to a NMR tube, and the NMR tube was capped and sealed with parafilm. The sample was run in the Varian Inova $500 \mathrm{MHz}$ spectrometer as explained above. A representative spectrum is displayed in Figure S16, and the reaction progress over time is plotted in Figure S17.

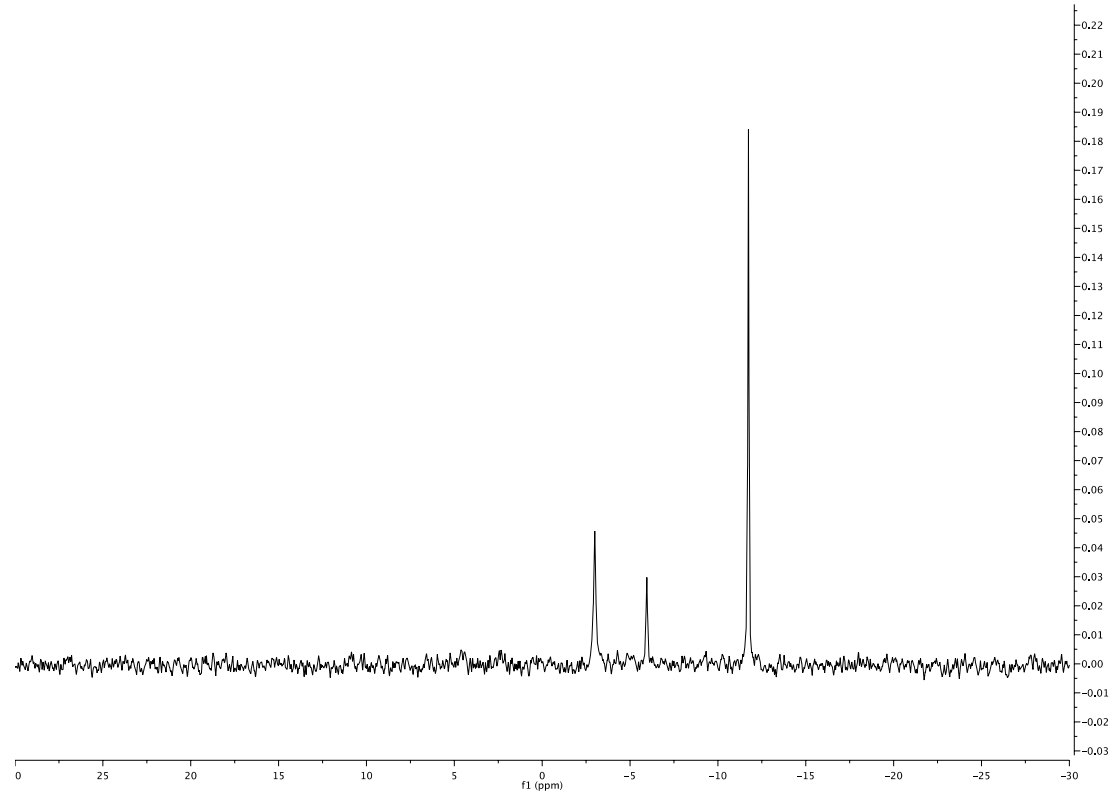

Figure S16. Representative ${ }^{31} \mathrm{P}\left\{{ }^{1} \mathrm{H}\right\}$-NMR spectrum of CuH-catalyzed hydroamination of styrene.

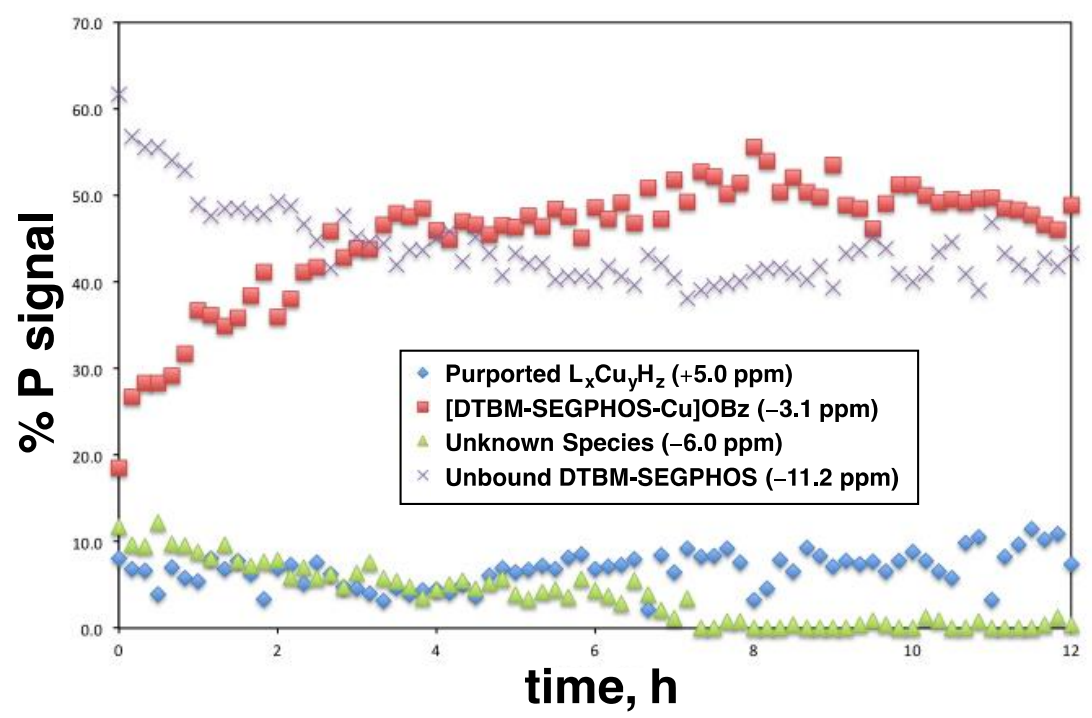

Figure S17. Reaction progress of CuH-catalyzed hydroamination of styrene by ${ }^{31} \mathrm{P}\left\{{ }^{1} \mathrm{H}\right\}$ NMR. 


\section{XIIIC. Evidence for a DTBM-SEGPHOS-bound copper benzoate species}

In a nitrogen-filled glove box, (S)-DTBM-SEGPHOS (98 mg, $0.08 \mathrm{mmol}, 1$ equiv), copper(I) triflate benzene complex $\left((\mathrm{CuOTf})_{2}\right.$ benzene complex, $22 \mathrm{mg}, 0.044 \mathrm{mmol}, 1.1$ equiv), and toluene were added to an $8-\mathrm{mL}$ scintillation vial. The reaction mixture was stirred for $24 \mathrm{~h}$, and then filtered through a plug of celite. Analysis of this solution (solution B) by ${ }^{31} \mathrm{P}-\mathrm{NMR}$ gave a new broad peak at $+2.0 \mathrm{ppm}$ (Figure S18).

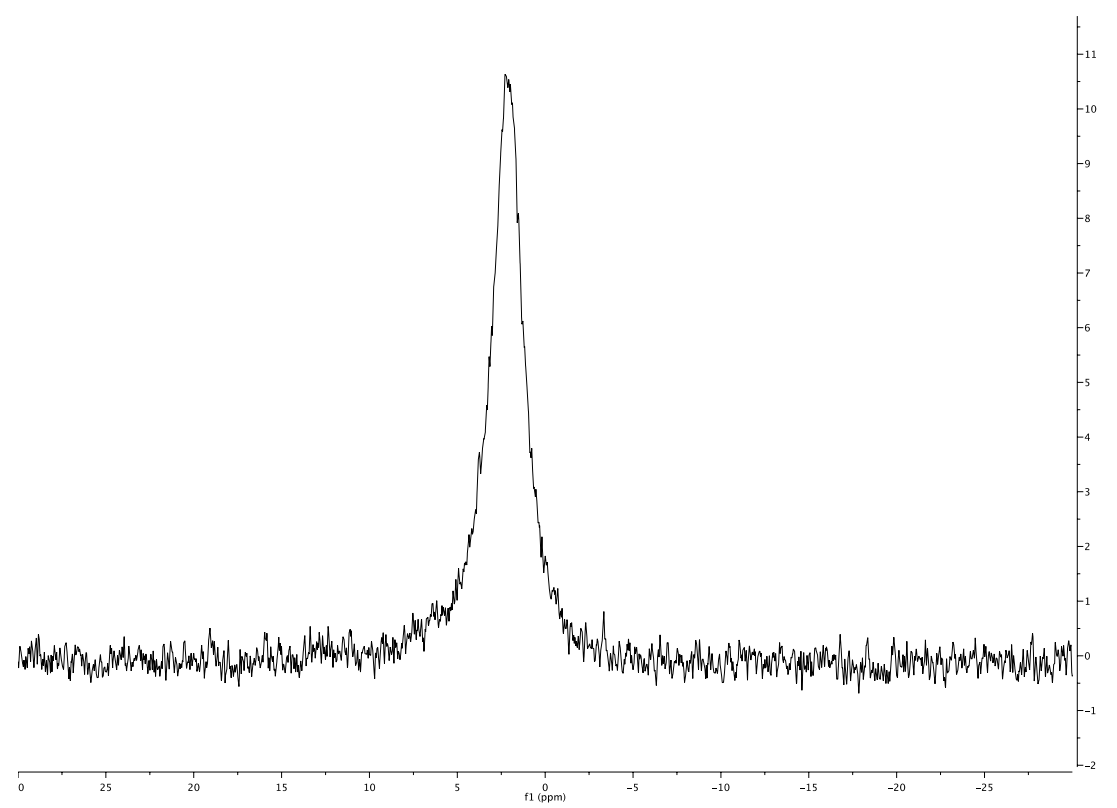

Figure S18. ${ }^{31} \mathrm{P}-\mathrm{NMR}$ spectrum of mixture of $(\mathrm{CuOTf})_{2}$ benzene complex and $(S)$ DTBM-SEGPHOS in THF.

An aliquot of solution B (from section XIIIC) $(0.5 \mathrm{~mL})$ was transferred to an $8 \mathrm{~mL}$ scintillation vial and diluted with THF $(0.5 \mathrm{~mL})$. Potassium benzoate $(\mathrm{KOBz}, 13 \mathrm{mg}, 0.08$ mmol) was added to this solution, and the solution was stirred for $24 \mathrm{~h}$. The reaction mixture was then filtered through a plug of celite and transferred to a NMR tube. The NMR tube was capped, wrapped with parafilm, and analyzed by ${ }^{31} \mathrm{P}-\mathrm{NMR}$. Complete conversion to a new peak was observed $(-2.9 \mathrm{ppm})$, which has a similar shift to the dominant peak observed in the ${ }^{31} \mathrm{P}-\mathrm{NMR}$ spectrum of the $\mathrm{CuH}$-catalyzed hydroamination of styrene (Figure S19). 


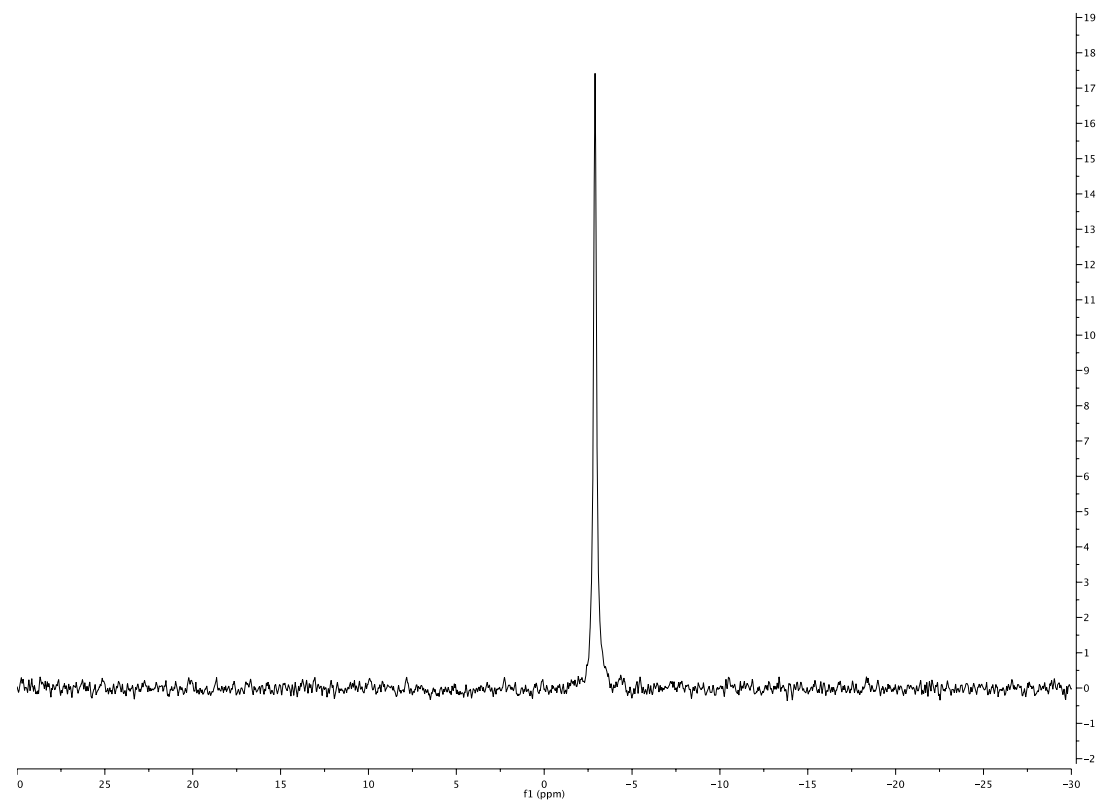

Figure S19. ${ }^{31} \mathrm{P}-\mathrm{NMR}$ spectrum of the mixture from Figure S18 with the addition of $\mathrm{KOBz}$.

\section{Electrospray ionization mass spectrometry (ESI-MS) studies}

In a nitrogen-filled glove box, $\mathrm{Cu}(\mathrm{OAc})_{2}(1.8 \mathrm{mg}, 0.01 \mathrm{mmol}, 0.04$ equiv), $(S)$-DTBMSEGPHOS (13.0 mg, $0.011 \mathrm{mmol}, 0.044$ equiv), and THF $(1.0 \mathrm{~mL})$ were transferred to an $8 \mathrm{~mL}$ scintillation vial. Diethoxymethylsilane $(160 \mu \mathrm{L}, 1.0 \mathrm{mmol}, 4.0$ equiv) was added and the reaction mixture was stirred until a color change to orange was observed (15 min). An aliquot of this solution $(580 \mu \mathrm{L})$ was transferred to a separate $8 \mathrm{~mL}$ scintillation vial with styrene $(29 \mu \mathrm{L}, 0.25 \mathrm{mmol}, 1$ equiv) and $O$-benzoyl- $N, N$ dibenzylhydroxylamine ( $95 \mathrm{mg}, 0.30 \mathrm{mmol}, 1.2$ equiv).

Another aliquot of the $\mathrm{CuH}$ solution $(10 \mu \mathrm{L})$ was added to an $8 \mathrm{~mL}$ scintillation vial and diluted with THF $(200 \mu \mathrm{L})$. An aliquot from the hydroamination solution $(10 \mu \mathrm{L})$ was also transferred to an $8 \mathrm{~mL}$ scintillation vial and diluted with THF $(200 \mu \mathrm{L})$. These vials were capped, wrapped with parafilm, and taken out of the glove box for analysis by ESIMS.

In both spectra, a peak at $709 \mathrm{~m} / \mathrm{z}$ is observed, which is associated with DTBMSEGPHOS (DTBM-SEGPHOS - PAr $_{2}$ ). An additional peak is observed at $1242 \mathrm{~m} / \mathrm{z}$, which is attributable to a monomeric [DTBM-SEGPHOS]Cu species. An additional peak at $1560 \mathrm{~m} / \mathrm{z}$ is observed in the hydroamination aliquot, which is ascribed to [DTBM$\mathrm{SEGPHOS}] \mathrm{Cu}+\mathrm{Bn}_{2} \mathrm{NOBz}$. 


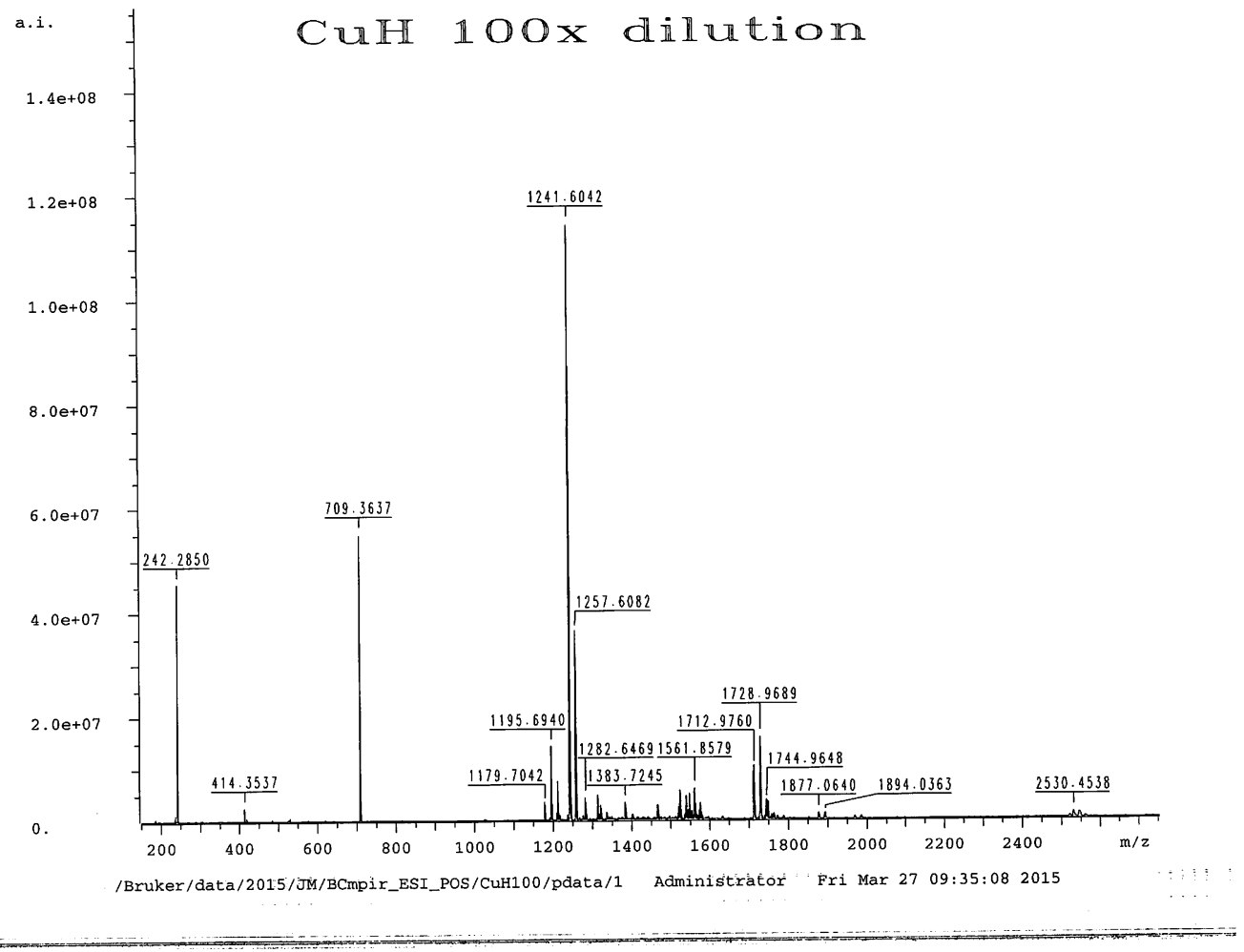

Figure S20. ESI-MS spectrum of the CuH solution. 


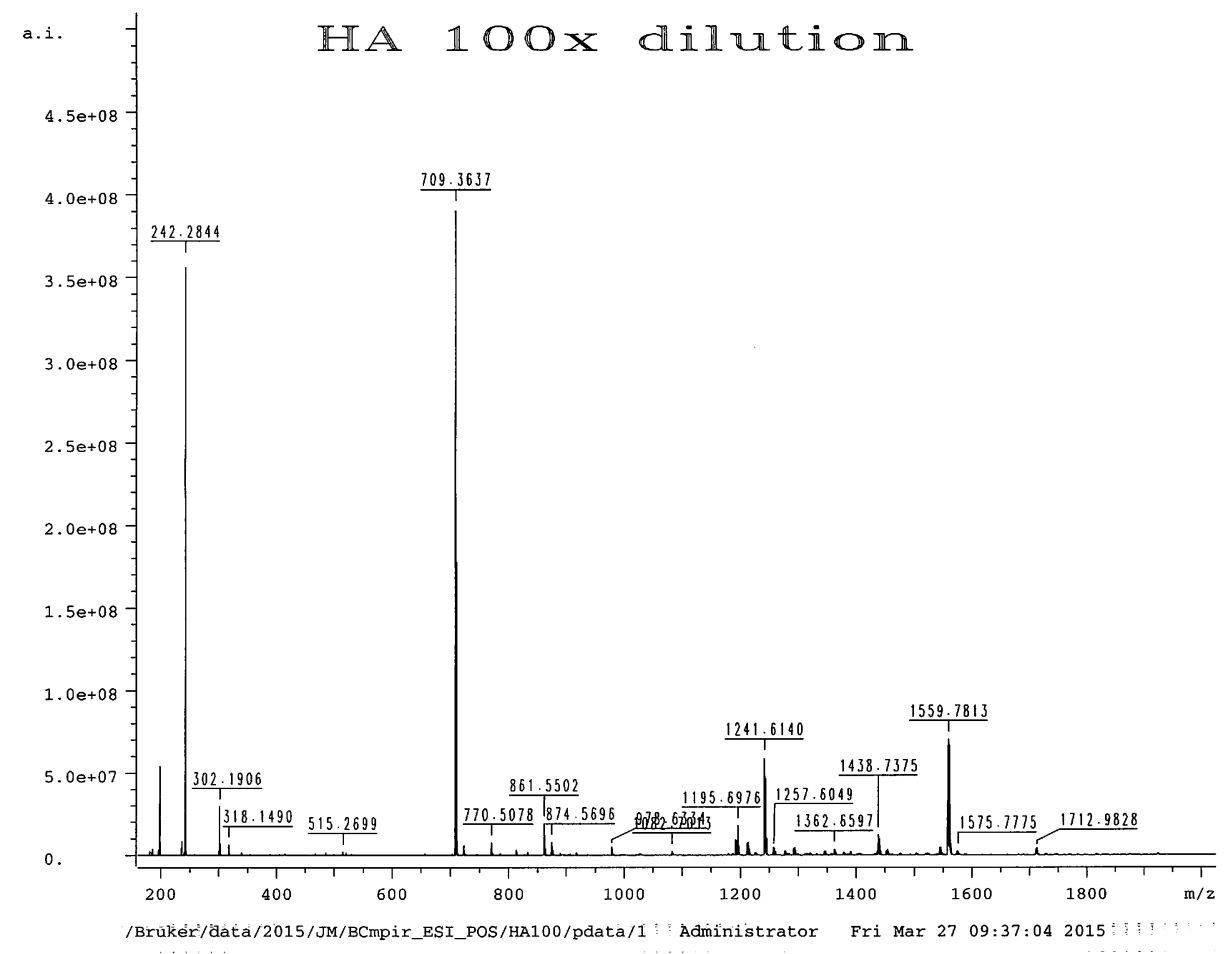

Figure S21. ESI-MS spectrum of the hydroamination of styrene solution.

\section{ESI-MS studies with $\mathbf{P P h}_{3}$}

In a nitrogen-filled glove box, $\mathrm{Cu}(\mathrm{OAc})_{2}(1.8 \mathrm{mg}, 0.01 \mathrm{mmol}, 0.04$ equiv), $(S)$-DTBMSEGPHOS (13.0 mg, $0.011 \mathrm{mmol}, 0.044$ equiv), $\mathrm{PPh}_{3}$ (2.9 mg, $0.011 \mathrm{mmol}, 0.044$ equiv) and THF $(1.0 \mathrm{~mL})$ were transferred to an $8 \mathrm{~mL}$ scintillation vial. Diethoxymethylsilane (160 $\mu \mathrm{L}, 1.0 \mathrm{mmol}, 4.0$ equiv) was added and the reaction mixture was stirred until a color change to orange was observed $(15 \mathrm{~min})$. An aliquot of this solution $(580 \mu \mathrm{L})$ was transferred to another $8 \mathrm{~mL}$ scintillation vial with styrene $(29 \mu \mathrm{L}, 0.25 \mathrm{mmol}, 1$ equiv) and $O$-benzoyl- $N, N$-dibenzylhydroxylamine ( $95 \mathrm{mg}, 0.30 \mathrm{mmol}, 1.2$ equiv).

Another aliquot of the $\mathrm{CuH}$ solution $(10 \mu \mathrm{L})$ was added to an $8 \mathrm{~mL}$ scintillation vial and diluted with THF $(200 \mu \mathrm{L})$. An aliquot from the hydroamination solution $(10 \mu \mathrm{L})$ was also transferred to an $8 \mathrm{~mL}$ scintillation vial and diluted with THF $(200 \mu \mathrm{L})$. These vials were capped, wrapped with parafilm, and taken out of the glove box for analysis by ESIMS.

In both spectra, a major peak at $\sim 1504 \mathrm{~m} / \mathrm{z}$ is observed, which is ascribed to [DTBM$\mathrm{SEGPHOS]CuPPh}$. These experiments suggest that the secondary ligand may bind to the monomeric active DTBM-SEGPHOS-ligated copper(I) catalyst; however, further work is required to provide a specific rationale for the observed rate enhancement. In the hydroamination of styrene solution, an additional major peak is observed at $709 \mathrm{~m} / \mathrm{z}$, which is again ascribed to the unbound DTBM-SEGPHOS. 


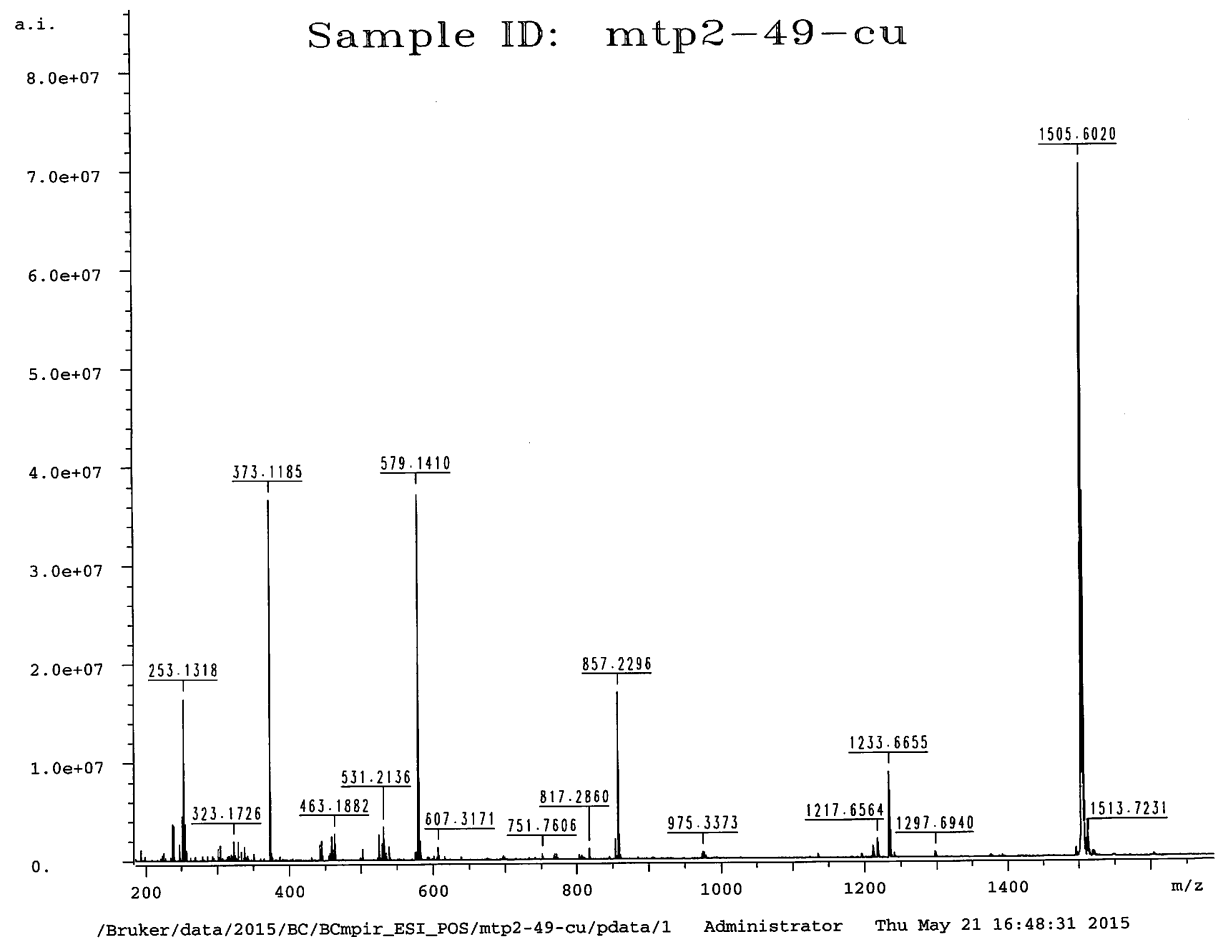

Figure S22. ESI-MS spectrum of the CuH solution with $\mathrm{PPh}_{3}$. 


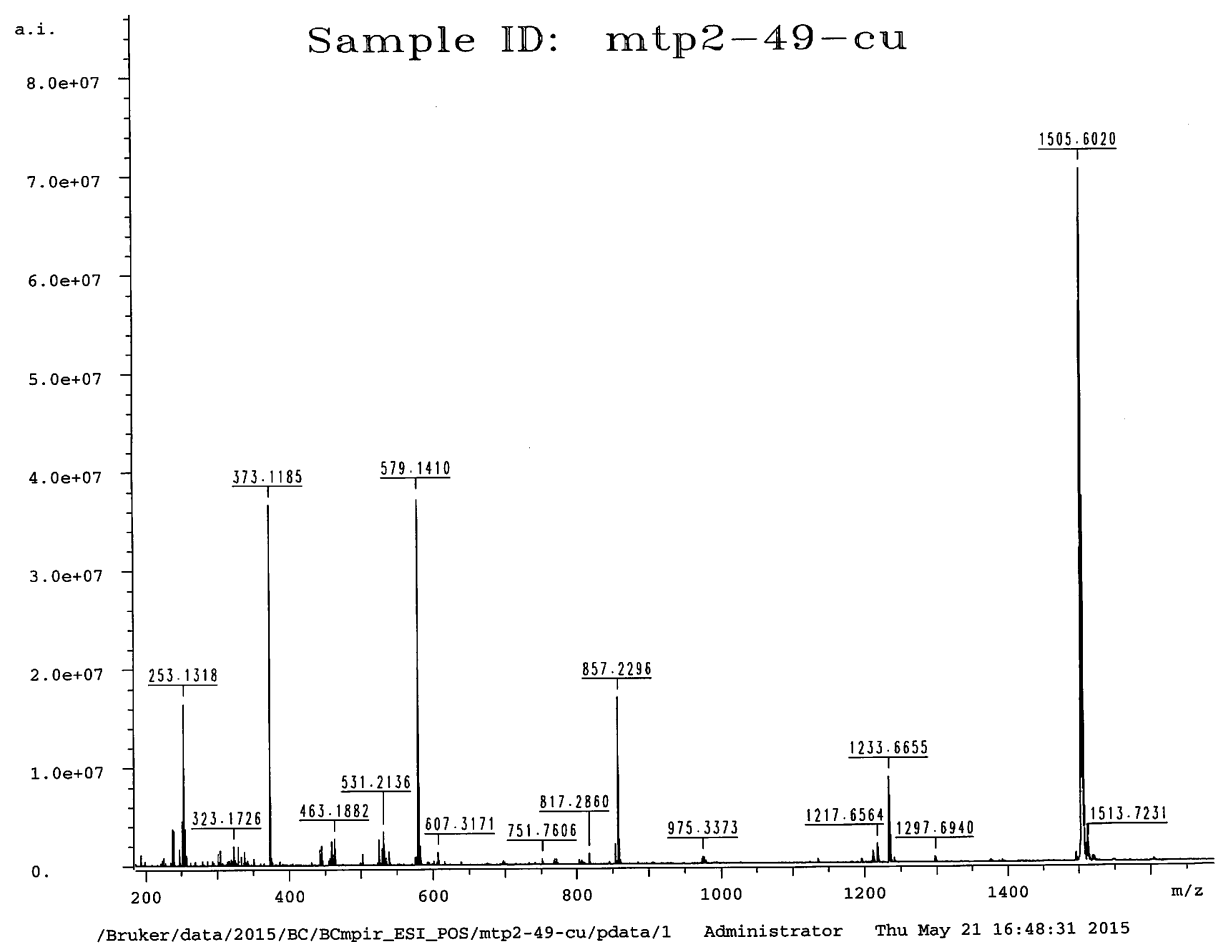

Figure S23. ESI-MS spectrum of the hydroamination of styrene solution with $\mathrm{PPh}_{3}$.

\section{References}

1. Zhu, S.; Niljianskul, N.; Buchwald, S. L. J. Am. Chem. Soc. 2013, 135, 15746.

2. Yang, Y.; Shi, S.-L.; Liu, P.; Buchwald, S. L. Science 2015, 349, 62.

3. Shi, S.-L.; Buchwald, S. L. Nature Chem. 2015, 7, 38.

4. Sakurai, T.; Mizuno, H.; Kubota, T.; Inoue, H. Bull. Chem. Soc. Jpn. 1991, 64, 2140. 


\section{Chiral HPLC traces}

Note: For each entry, the top HPLC trace is a racemic sample that was prepared using standard conditions and rac-DTBM-SEGPHOS ligand.

(R)- $\boldsymbol{N}, \boldsymbol{N}$-Dibenzyl-1-( $\boldsymbol{p}$-tolyl)ethan-1-amine, used for Scheme 6. Hexanes/iPrOH, 98/2, $0.6 \mathrm{~mL} / \mathrm{min}, 230 \mathrm{~nm}, \mathrm{OD}-\mathrm{H}$.

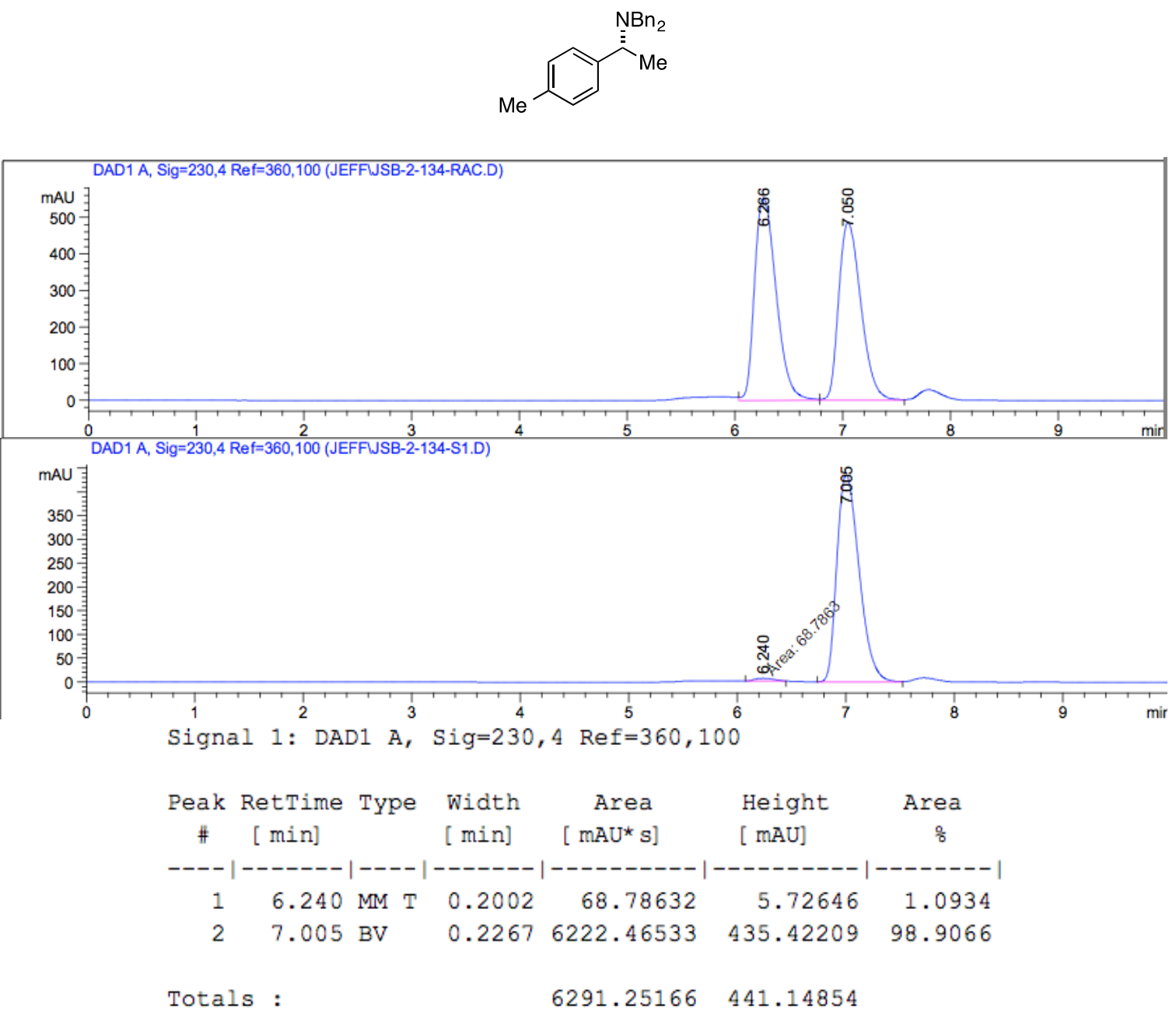


Equation 1, 4. Hexanes/iPrOH 98/2, 0.6 mL/min, 230 nm, OD-H.
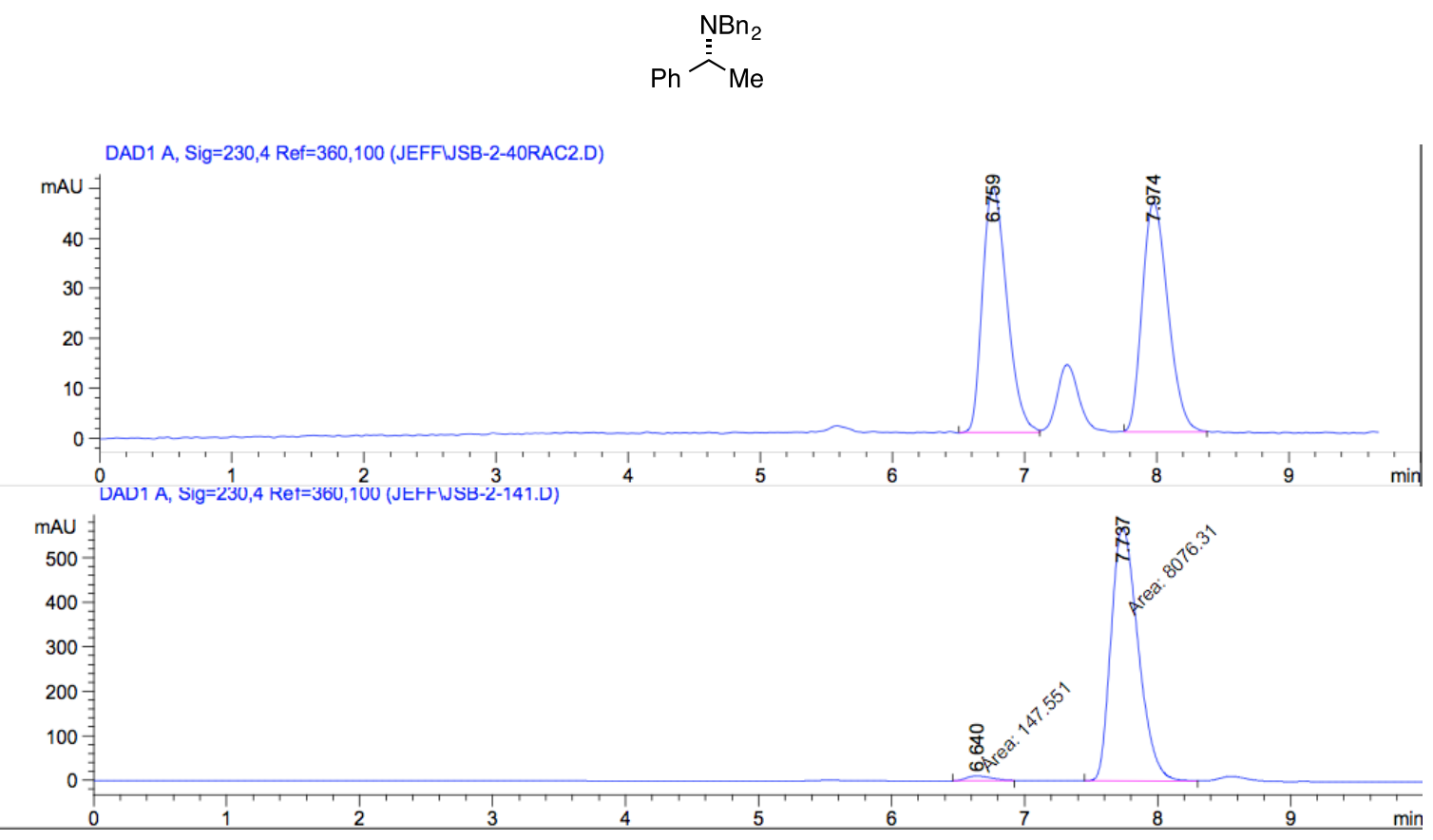

Signal 1: DAD1 A, Sig=230, 4 Ref $=360,100$

\begin{tabular}{|c|c|c|c|c|c|c|}
\hline $\begin{array}{c}\text { Peak } \\
\#\end{array}$ & $\begin{array}{c}\text { RetTime } \\
\text { [ min] }\end{array}$ & Type & $\begin{array}{l}\text { Width } \\
\text { [ } \mathrm{min}]\end{array}$ & $\begin{array}{c}\text { Area } \\
{\left[\mathrm{mAU}^{\star} \mathrm{s}\right]}\end{array}$ & $\begin{array}{l}\text { Height } \\
\text { [ mAU] }\end{array}$ & $\begin{array}{c}\text { Area } \\
\%\end{array}$ \\
\hline - & - & & ----- & ---------- & -------- & $-------\mid$ \\
\hline 1 & 6.640 & MM T & 0.2274 & 147.55089 & 10.81209 & 1.7942 \\
\hline 2 & 7.737 & $\mathrm{MM} \mathrm{T}$ & 0.2363 & 8076.31152 & 569.55078 & 98.2058 \\
\hline Tota & : & & & 8223.86241 & 580.36287 & \\
\hline
\end{tabular}


Table 2, entry 1. Hexanes/iPrOH 98/2, 0.6 mL/min, 230 nm, OD-H.

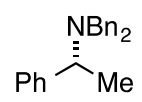
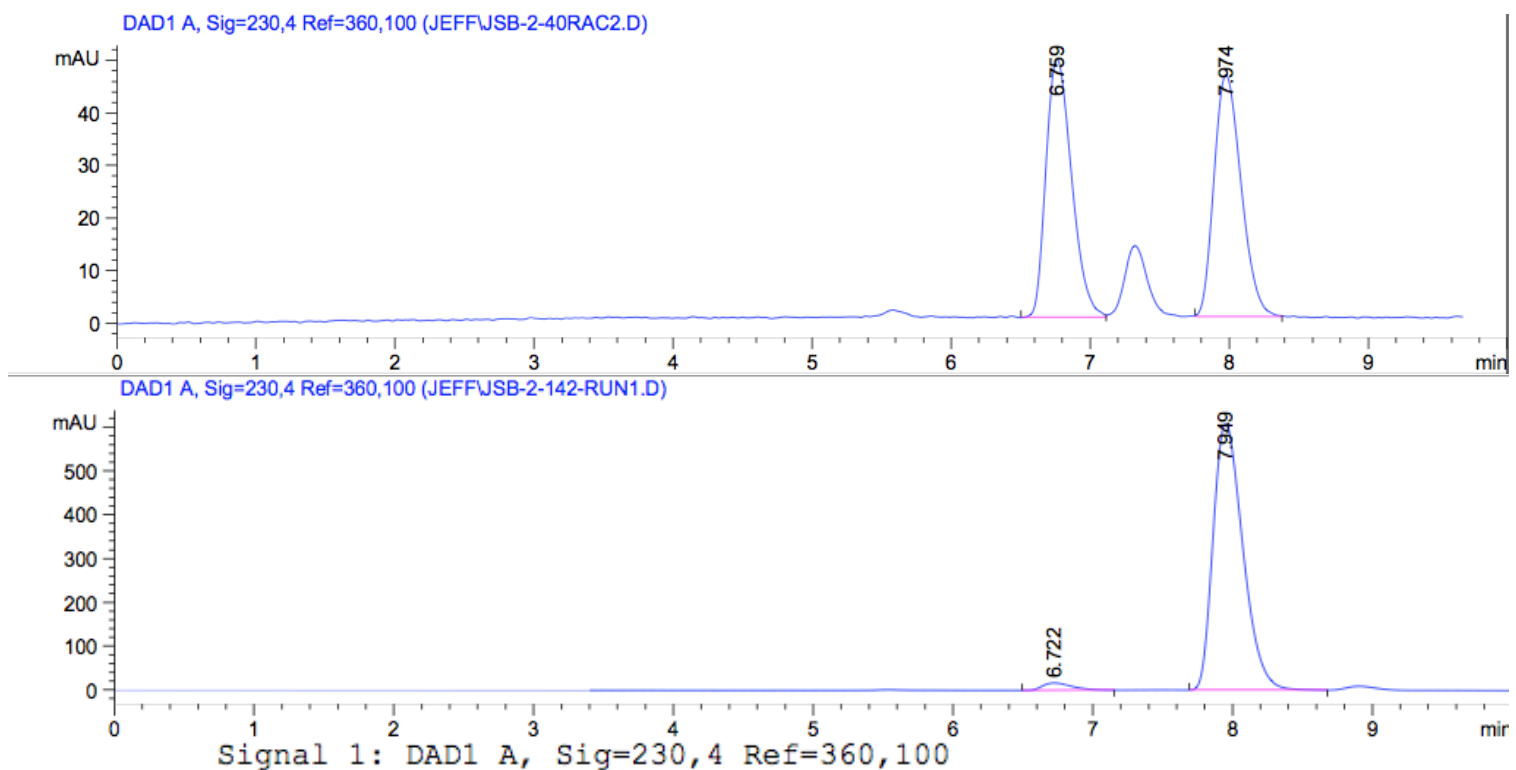

Signal 1: DAD1 A, Sig $=230,4$ Ref $=360,100$

\begin{tabular}{|c|c|c|c|c|c|c|}
\hline $\begin{array}{c}\text { Peak } \\
\text { \# }\end{array}$ & $\begin{array}{c}\text { RetTime } \\
\text { [min] }\end{array}$ & Type & $\begin{array}{l}\text { Width } \\
\text { [min] }\end{array}$ & $\begin{array}{c}\text { Area } \\
{\left[\mathrm{mAU}^{\star} \mathrm{s}\right]}\end{array}$ & $\begin{array}{l}\text { Height } \\
{[\mathrm{mAU}]}\end{array}$ & $\begin{array}{c}\text { Area } \\
\%\end{array}$ \\
\hline & 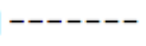 & & & |---------- & ----------- & -------- \\
\hline 1 & 6.722 & $\mathrm{BB}$ & 0.2293 & 245.44460 & 16.71216 & 2.6535 \\
\hline 2 & 7.949 & $\mathrm{BB}$ & 0.2325 & 9004.55078 & 608.88434 & 97.3465 \\
\hline otal & Ls : & & & 9249.99538 & 625.59650 & \\
\hline
\end{tabular}


Table 2, entry 2. Hexanes/iPrOH 96/4, 0.6 mL/min, 230 nm, OD-H.
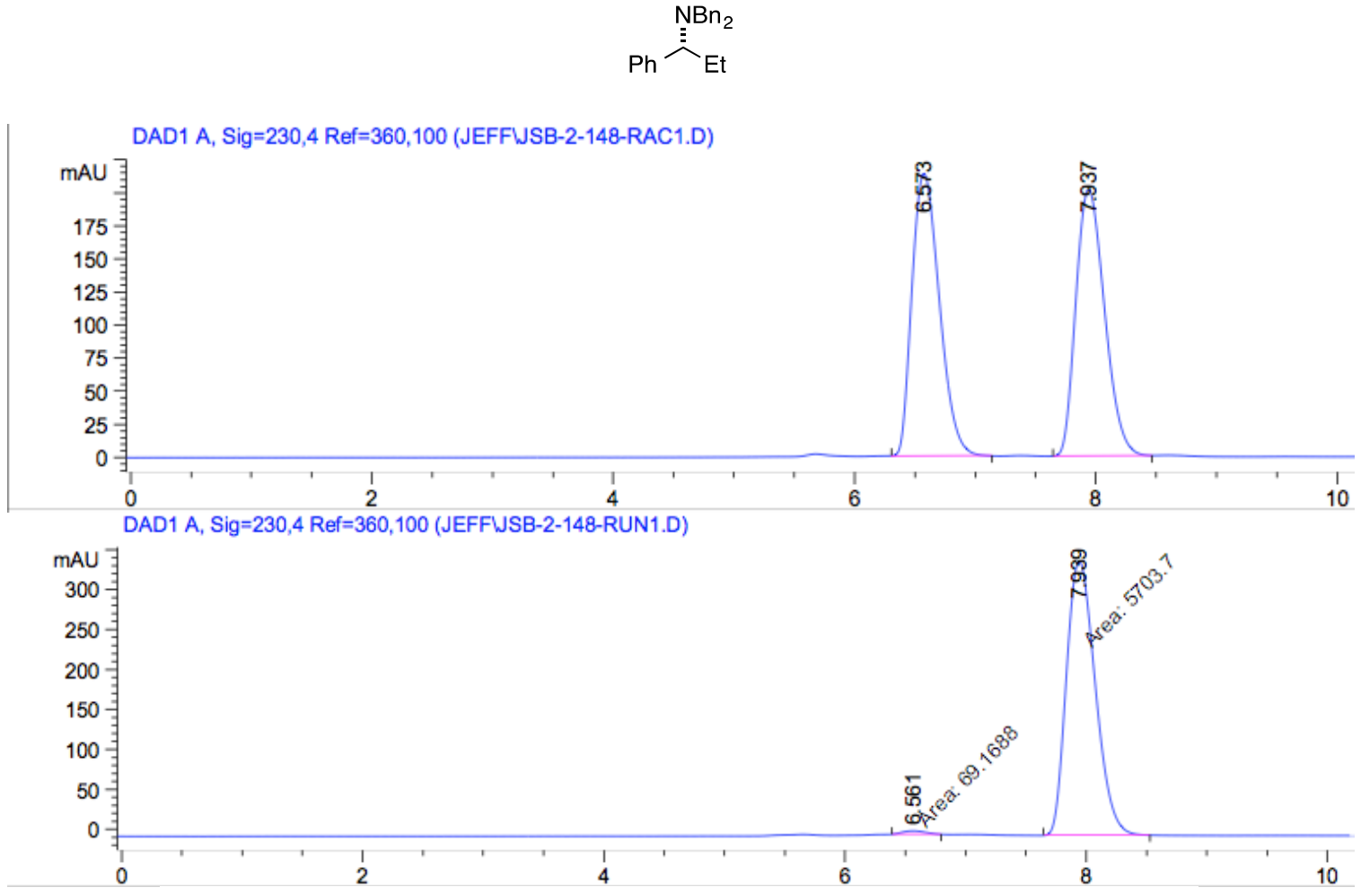

Signal 1: DAD1 A, Sig=230, 4 Ref $=360,100$

\begin{tabular}{|c|c|c|c|c|c|c|}
\hline $\begin{array}{c}\text { Peak } \\
\quad \#\end{array}$ & $\begin{array}{c}\text { RetTime } \\
\text { [min] }\end{array}$ & Type & $\begin{array}{l}\text { Width } \\
\text { [min] }\end{array}$ & $\begin{array}{c}\text { Area } \\
{\left[\mathrm{mAU}^{\star} \mathrm{s}\right]}\end{array}$ & $\begin{array}{l}\text { Height } \\
\text { [mAU] }\end{array}$ & $\begin{array}{c}\text { Area } \\
\%\end{array}$ \\
\hline \multicolumn{7}{|c|}{$----|-------|----|-------|----------|----------|--------$} \\
\hline 1 & 6.561 & MM T & 0.2409 & 69.16875 & 4.78611 & 1.1982 \\
\hline 2 & 7.939 & MM T & 0.2770 & 5703.70215 & 343.20840 & 98.8018 \\
\hline Total & : & & & 5772.87090 & 347.99451 & \\
\hline
\end{tabular}


Table 2, entry 3. Hexanes/iPrOH 96/4, 0.6 mL/min, 230 nm, OD-H.

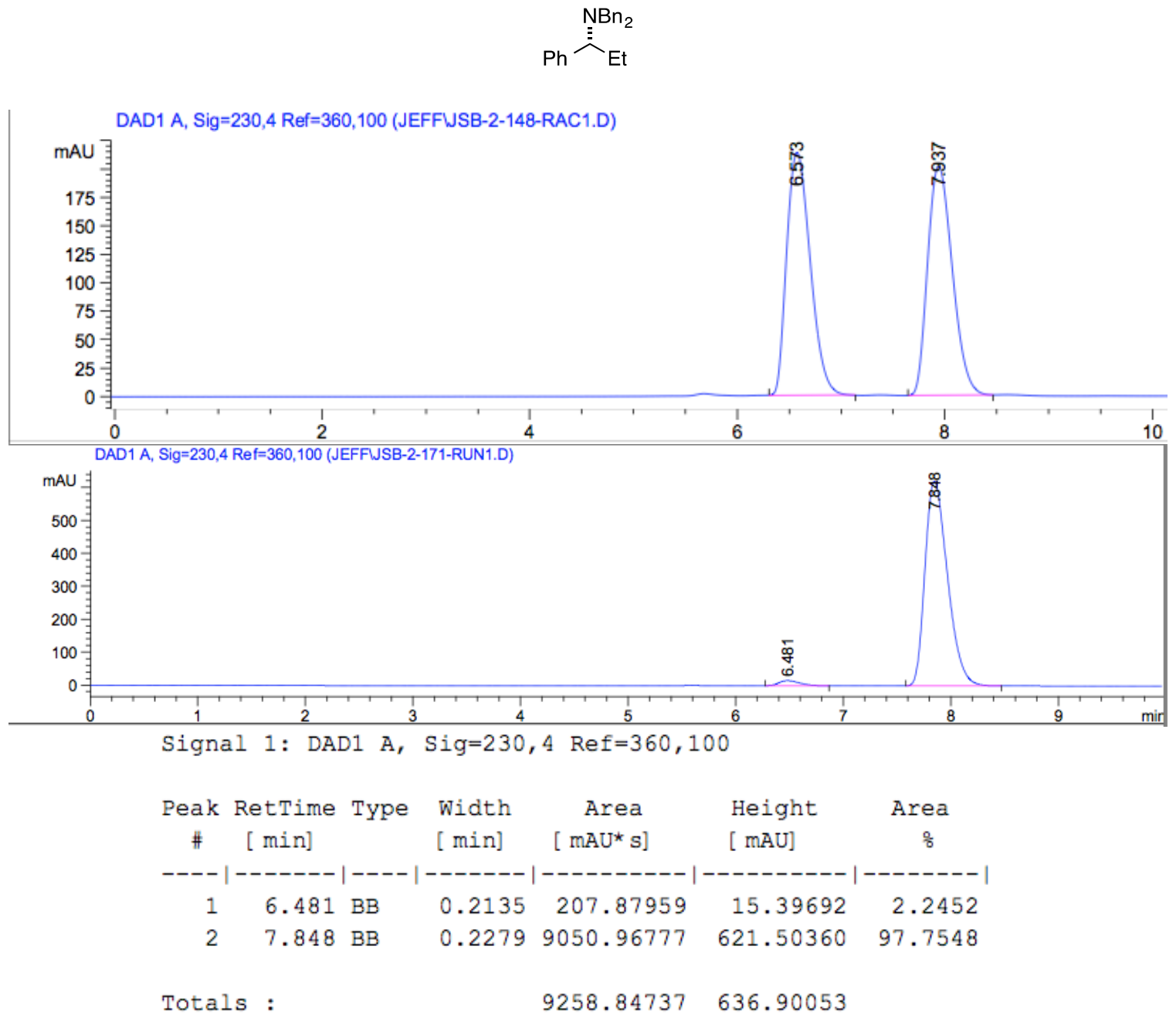


Table 2, entry 5. Hexanes/EtOH 85/15, 1.0 mL/min, 210 nm, OJ.

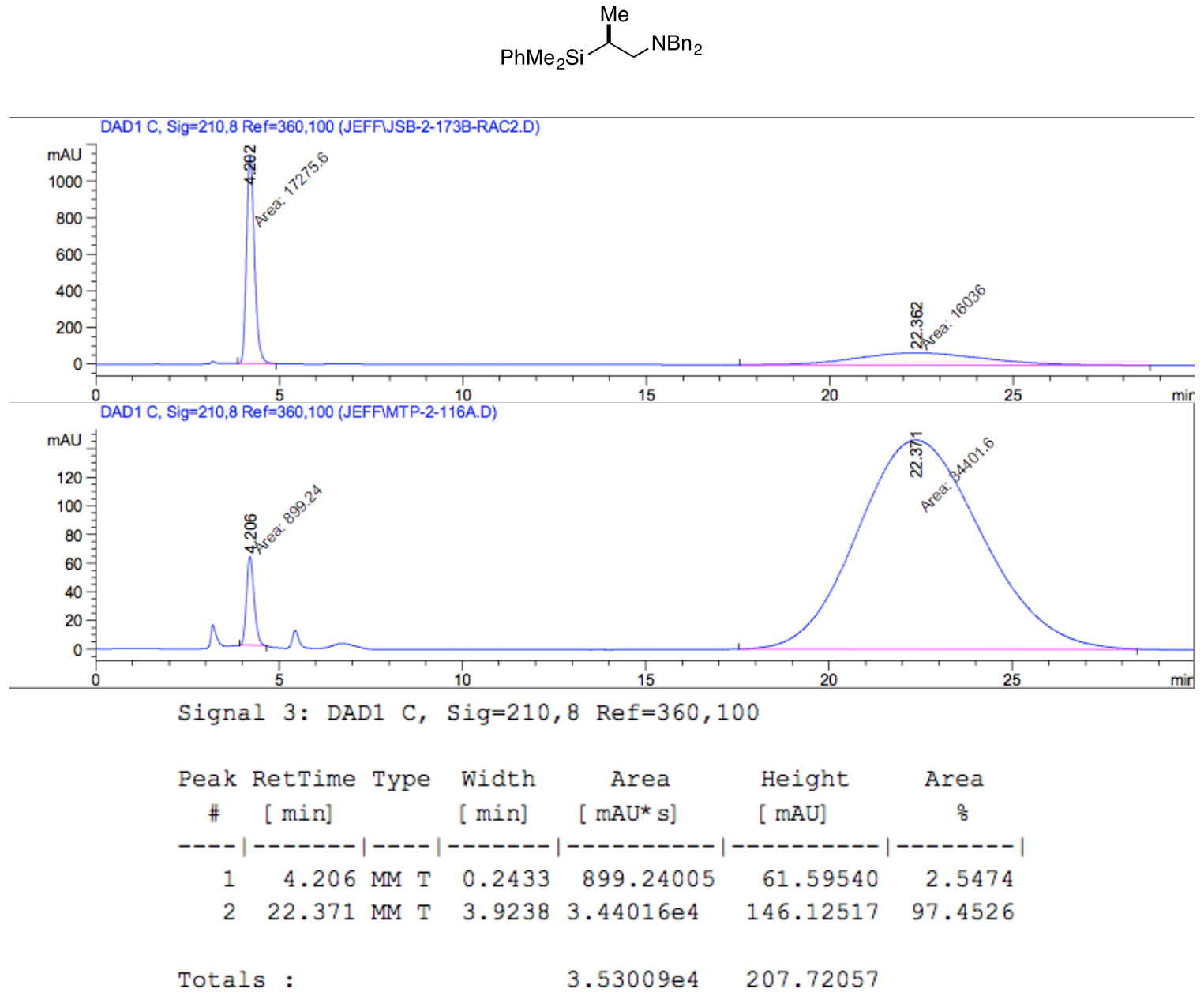


Table 2, entry 6. Hexanes/iPrOH 99/1, 0.6 mL/min, 230 nm, OD-H.
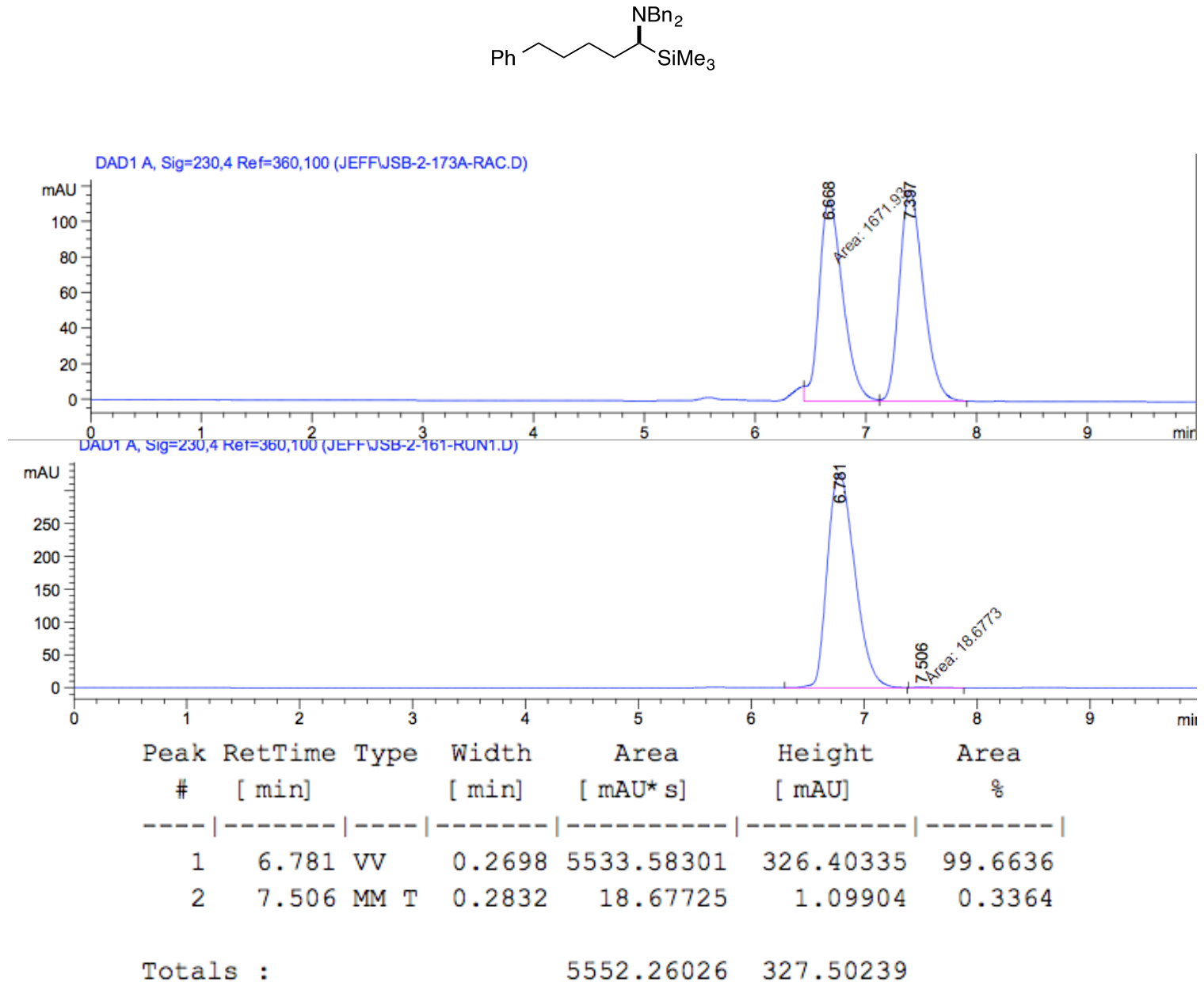
Table 3, entry 1. Hexanes/iPrOH 98/2, 0.6 mL/min, 230 nm, OD-H.<smiles>CC(C)(C)c1ccccc1</smiles>
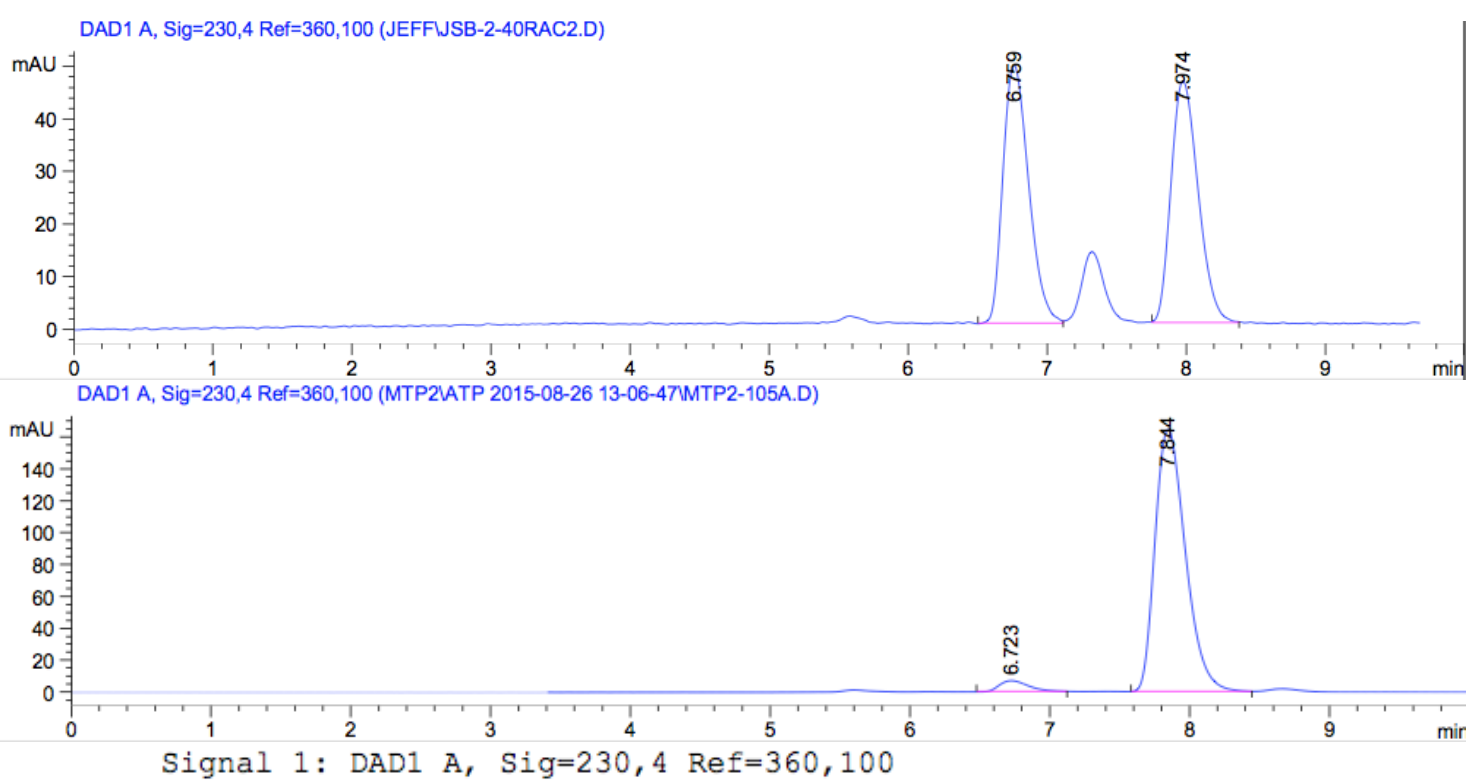

Signal 1: DAD1 A, Sig=230,4 Ref $=360,100$

\begin{tabular}{|c|c|c|c|c|c|c|}
\hline $\begin{array}{c}\text { Peak } \\
\text { \# }\end{array}$ & $\begin{array}{c}\text { RetTime } \\
\text { [min] }\end{array}$ & Type & $\begin{array}{l}\text { Width } \\
\text { [min] }\end{array}$ & $\begin{array}{c}\text { Area } \\
{\left[\mathrm{mAU}^{\star} \mathrm{s}\right]}\end{array}$ & $\begin{array}{l}\text { Height } \\
\text { [mAU] }\end{array}$ & $\begin{array}{c}\text { Area } \\
\%\end{array}$ \\
\hline & ------ & & & |---------- & ---------- & -------- \\
\hline 1 & & & & 102.41685 & 6.93351 & 3.9495 \\
\hline 2 & 7.844 & $\mathrm{BB}$ & 363 & 2490.72314 & 164.80060 & 96.0505 \\
\hline
\end{tabular}

Totals : $\quad 2593.14000 \quad 171.73411$ 
XVII. NMR spectra<smiles>CCCCCC(C)c1ccc(C)cc1</smiles>
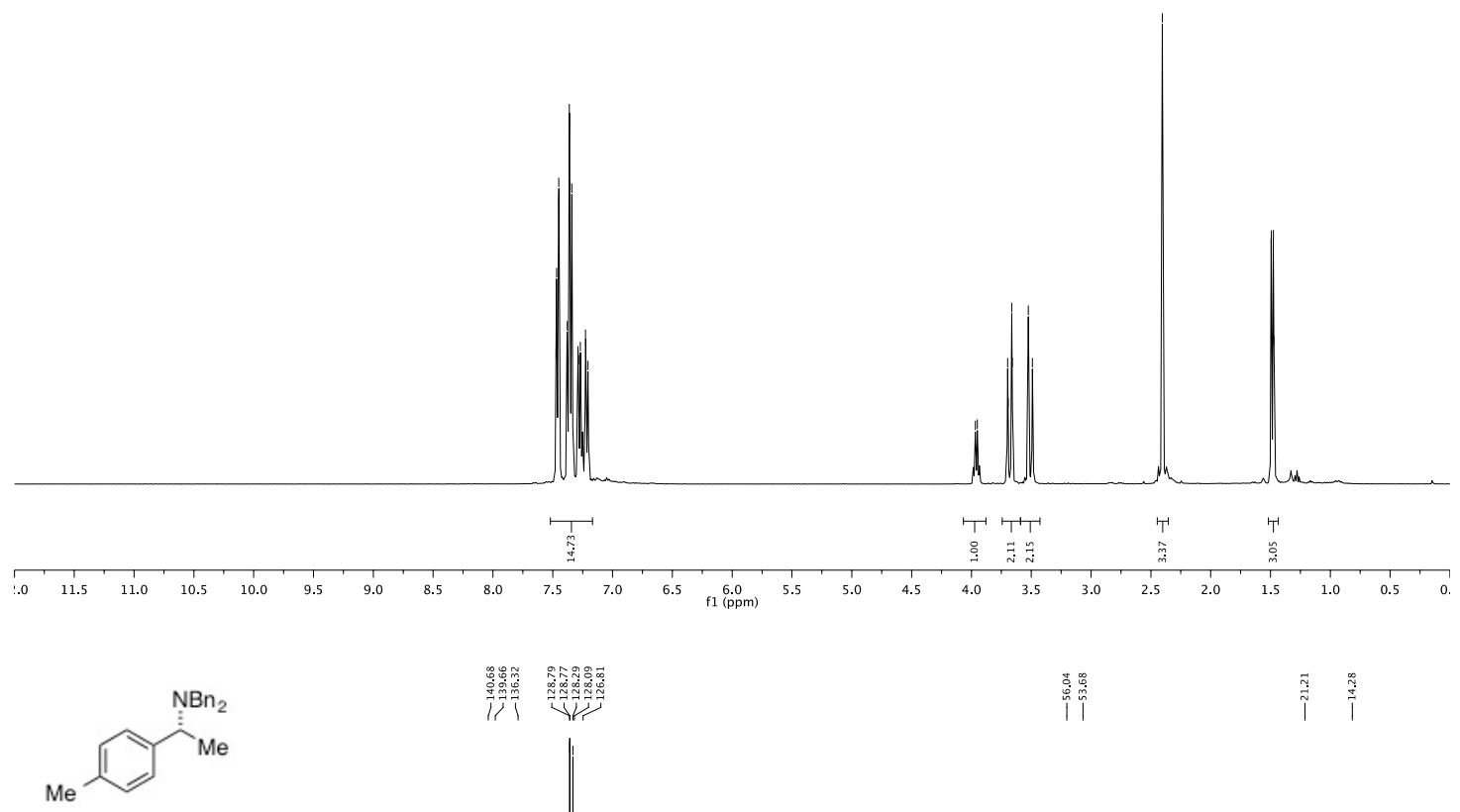

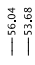
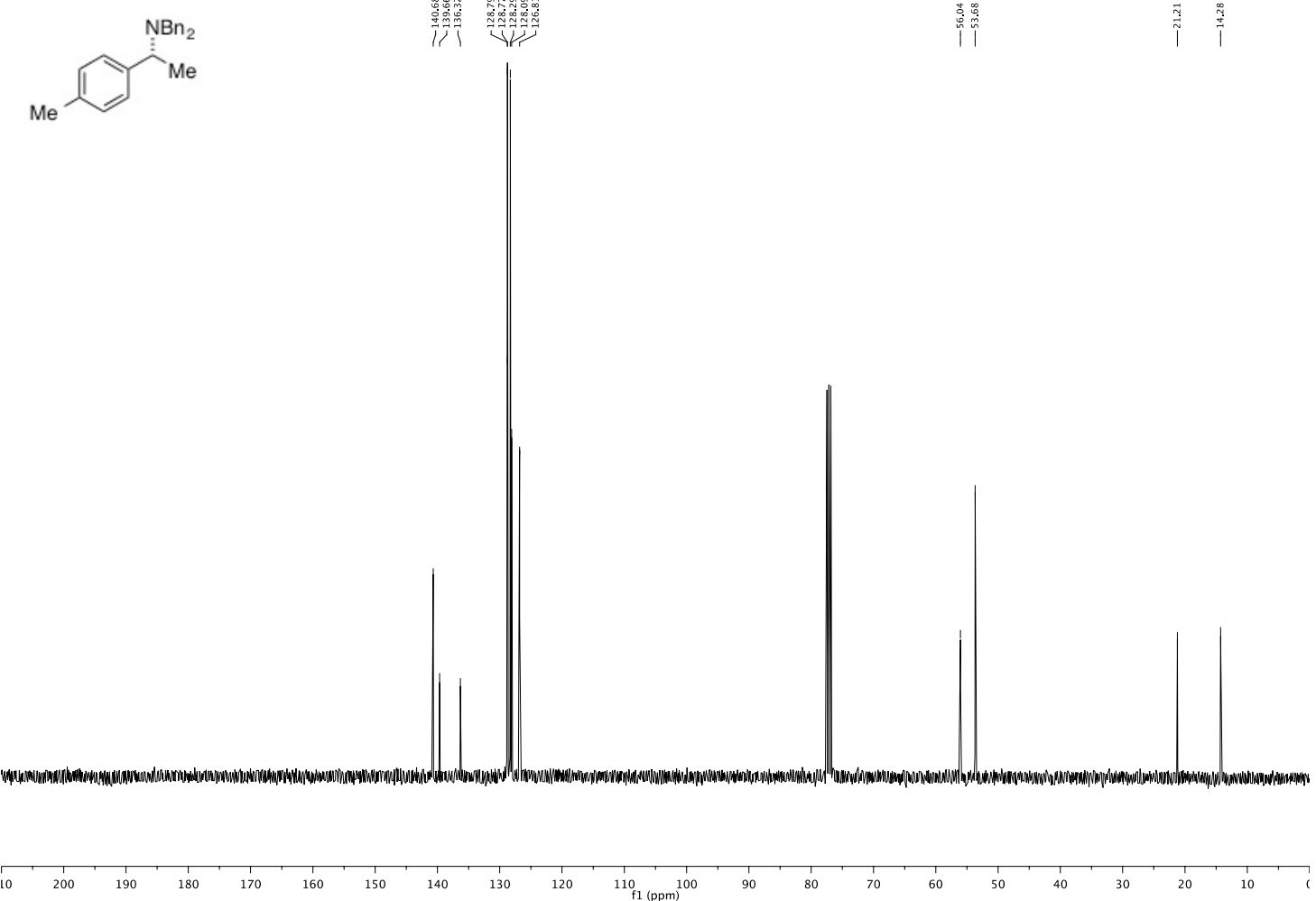

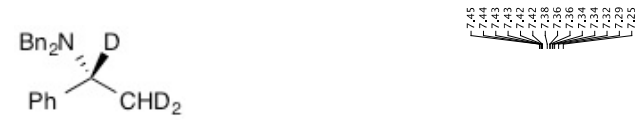

$\mathrm{Ph} \quad \mathrm{CHD}_{2}$
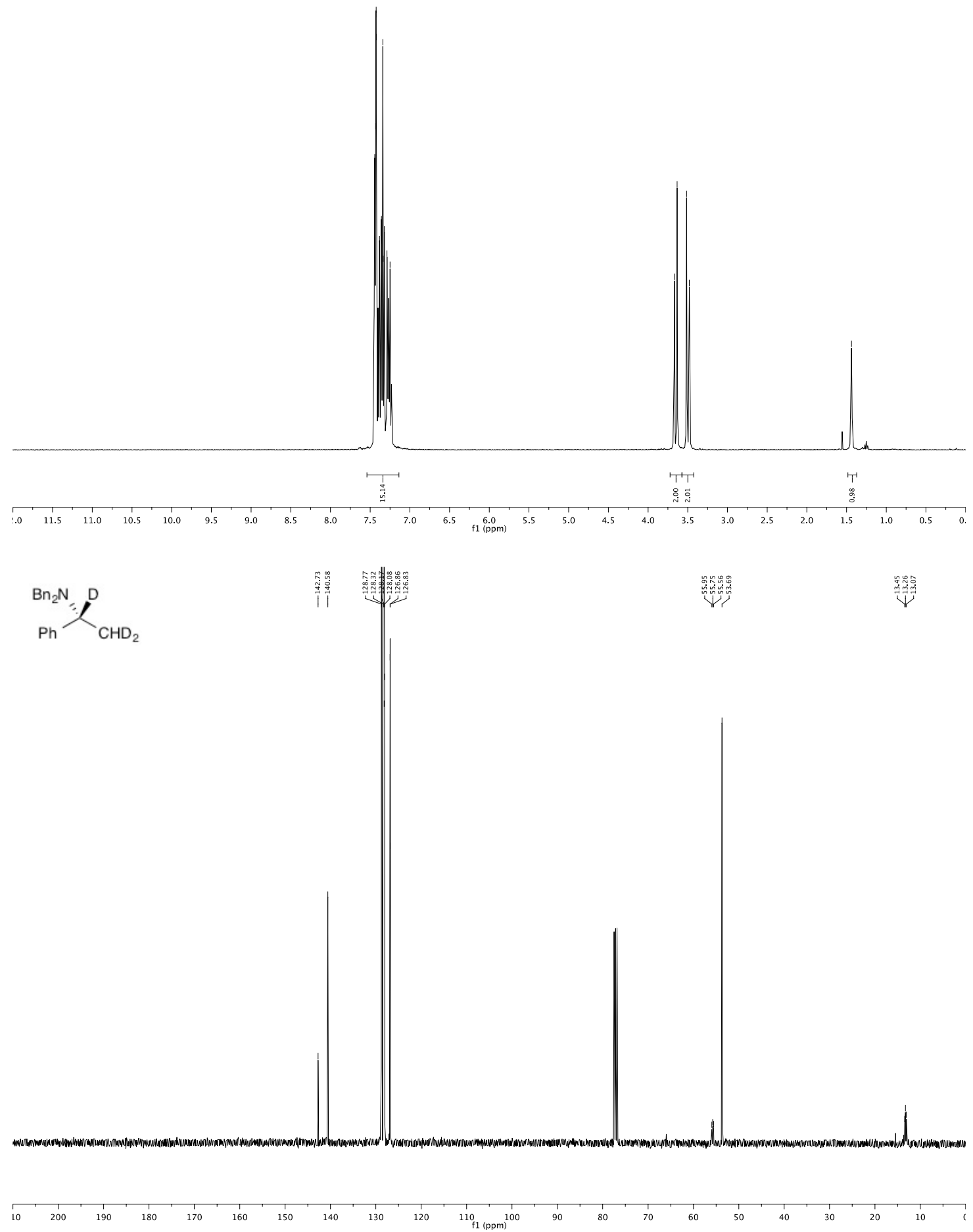


$$
\mathrm{Ph} \stackrel{\mathrm{NBn}_{2}}{\overbrace{\mathrm{Me}}}
$$
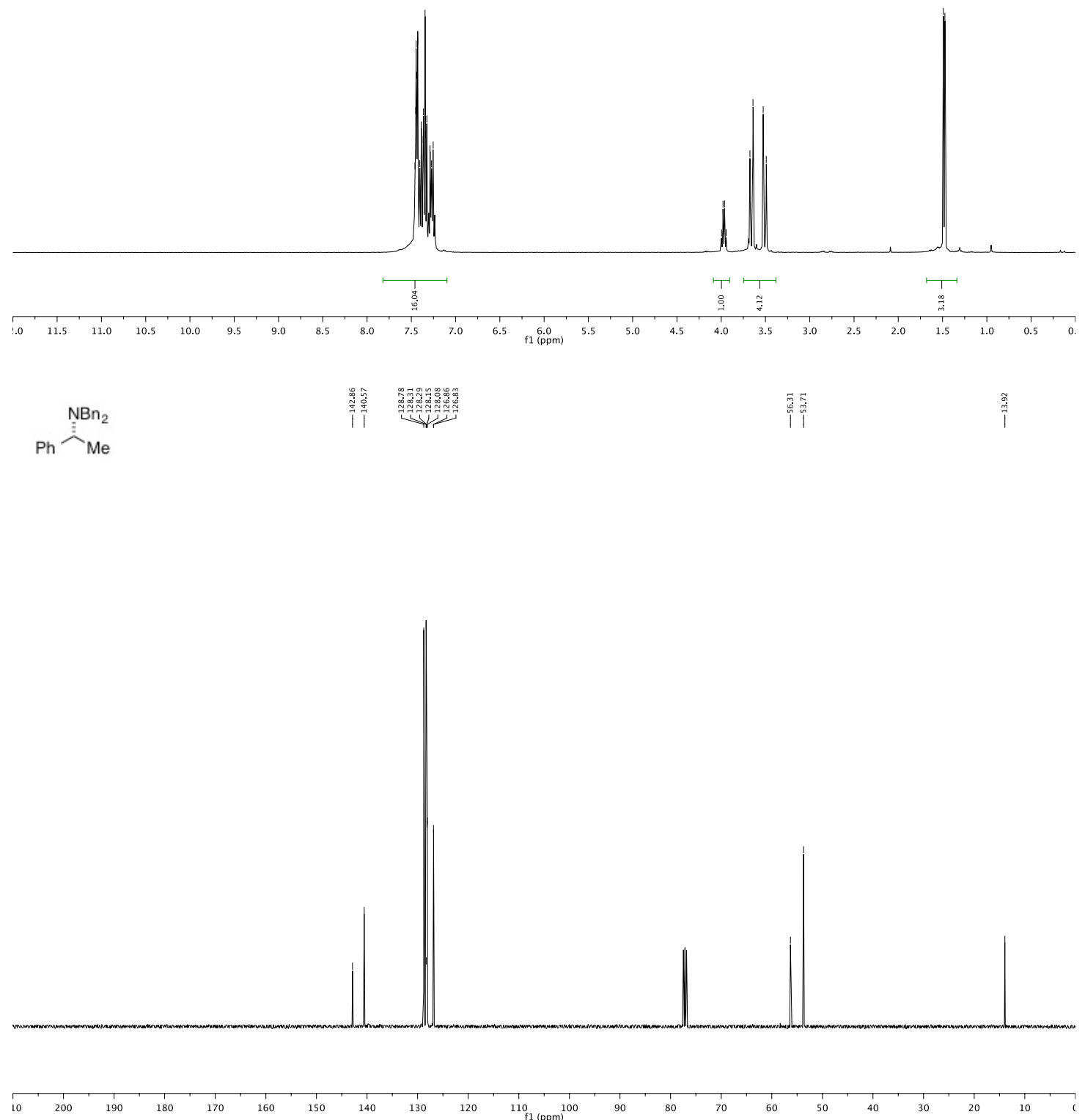


$$
\mathrm{Ph} \stackrel{\stackrel{\mathrm{NBn}}{\Xi}_{\mathrm{Et}}}{\mathrm{Et}}
$$

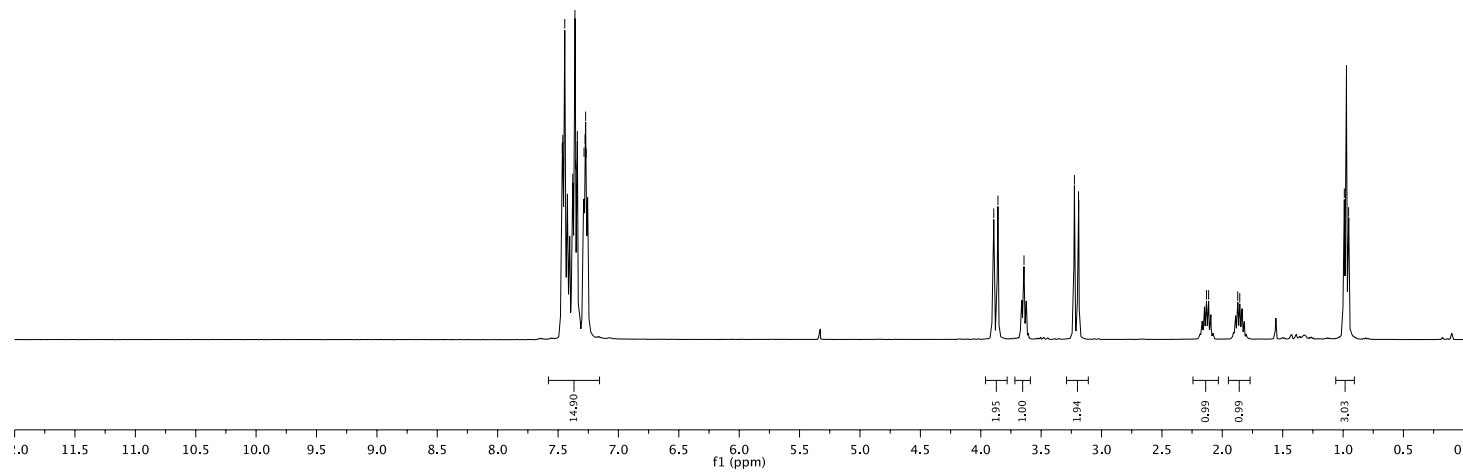

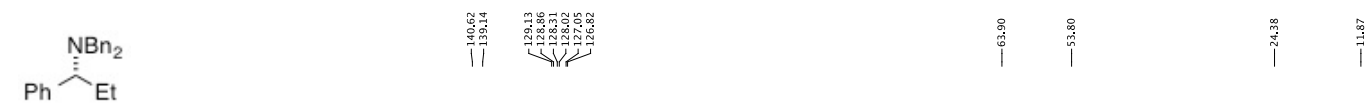
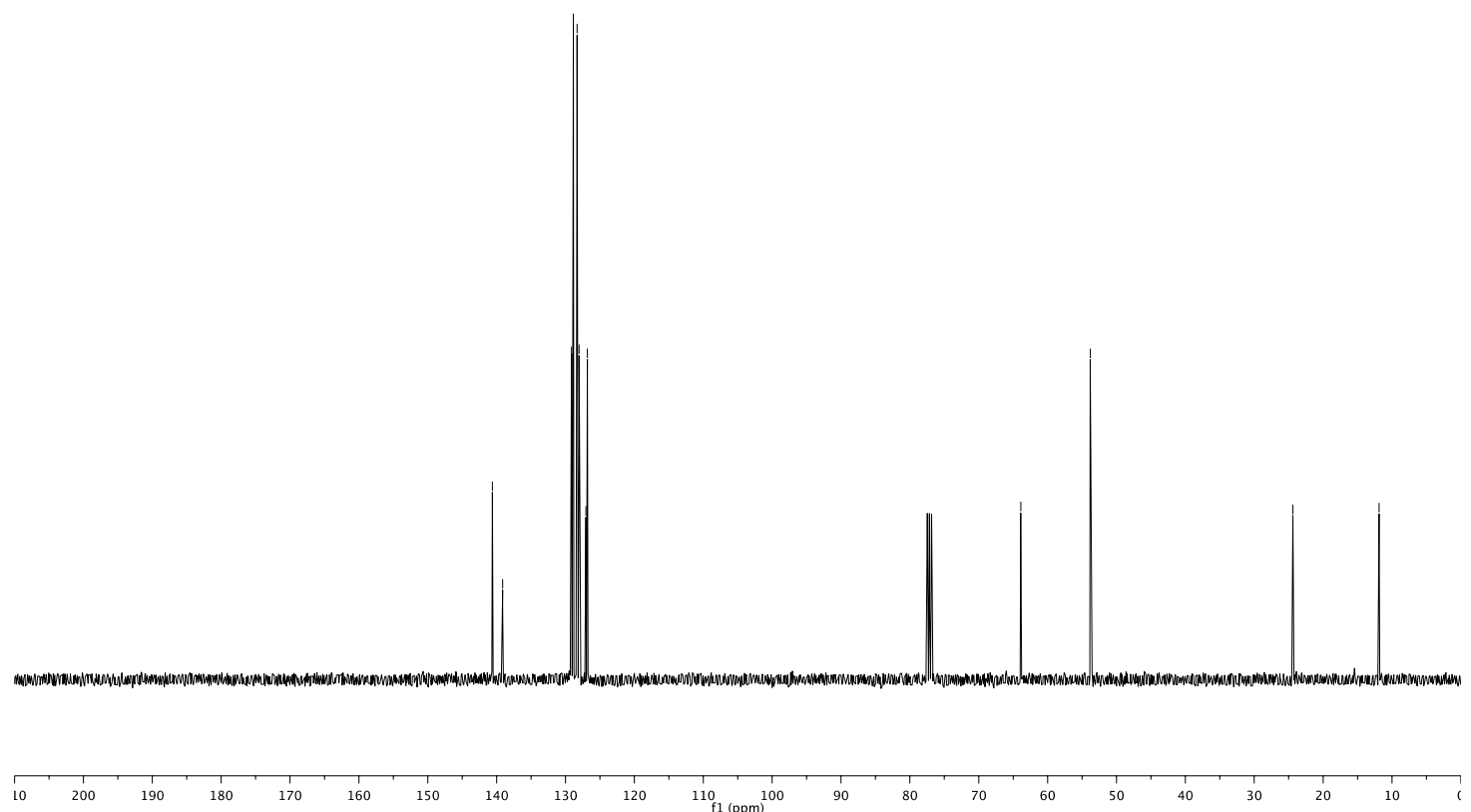

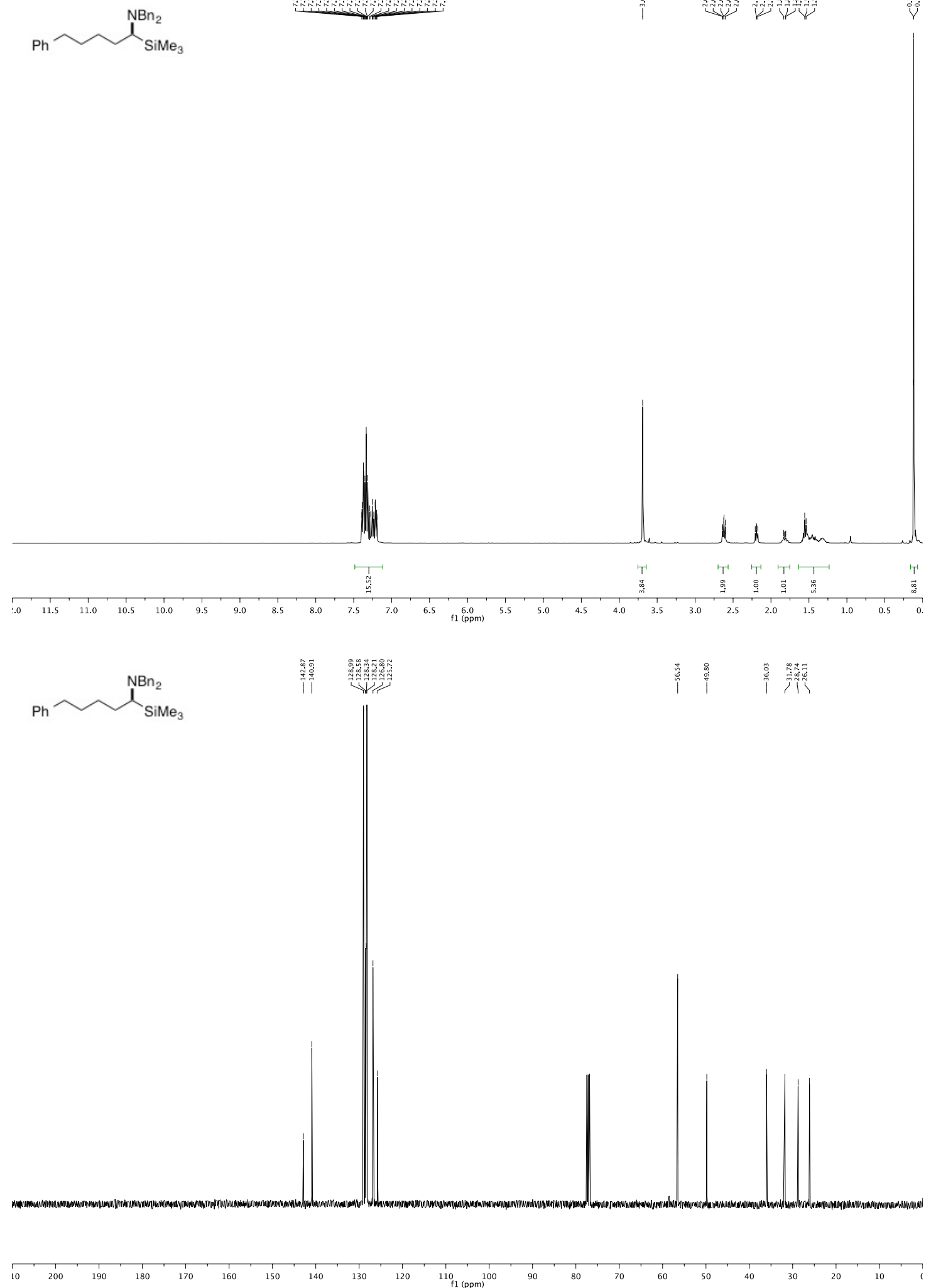

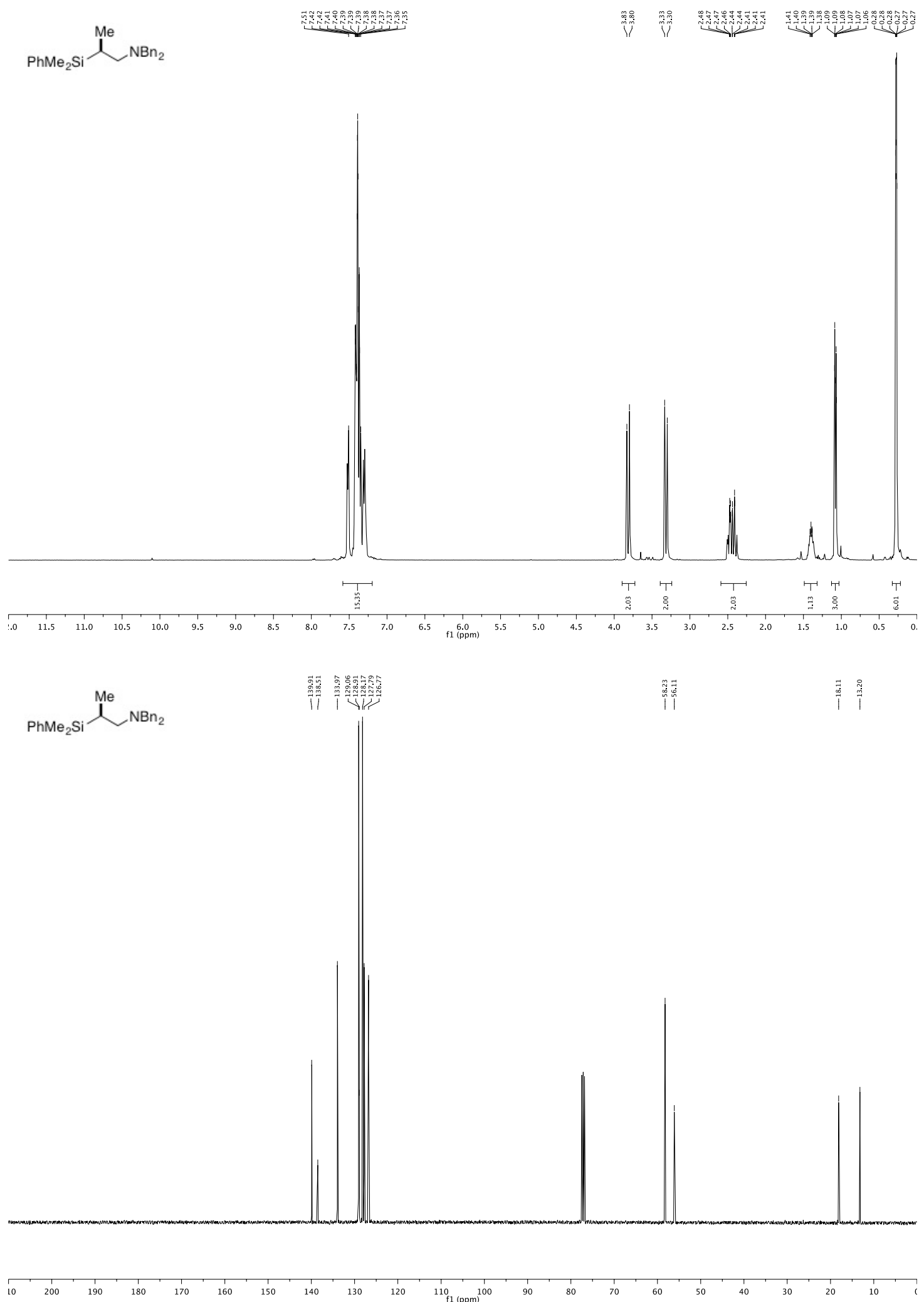
$\mathrm{Ph} \sim \mathrm{NBn}_{2}$
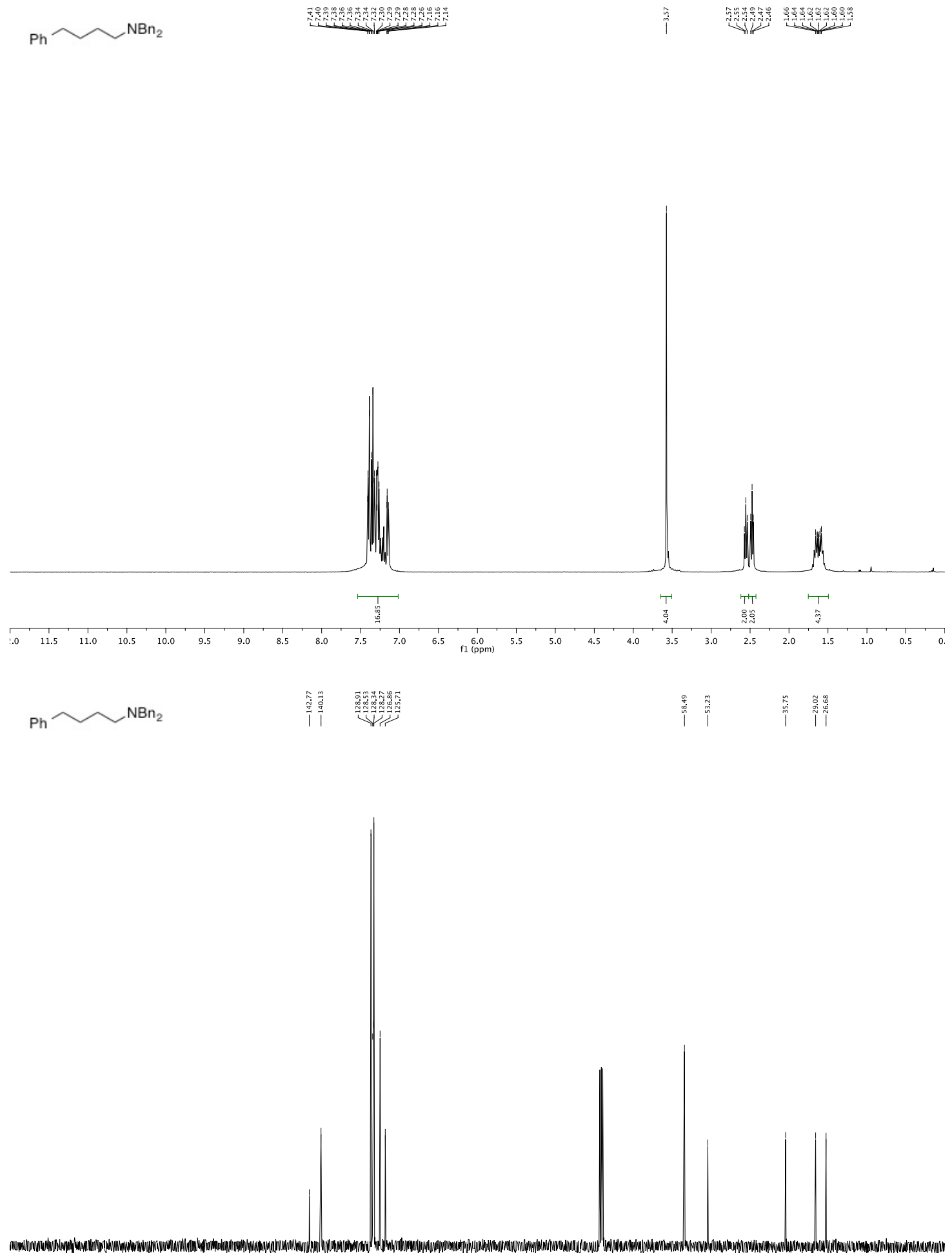

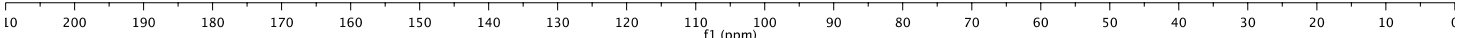




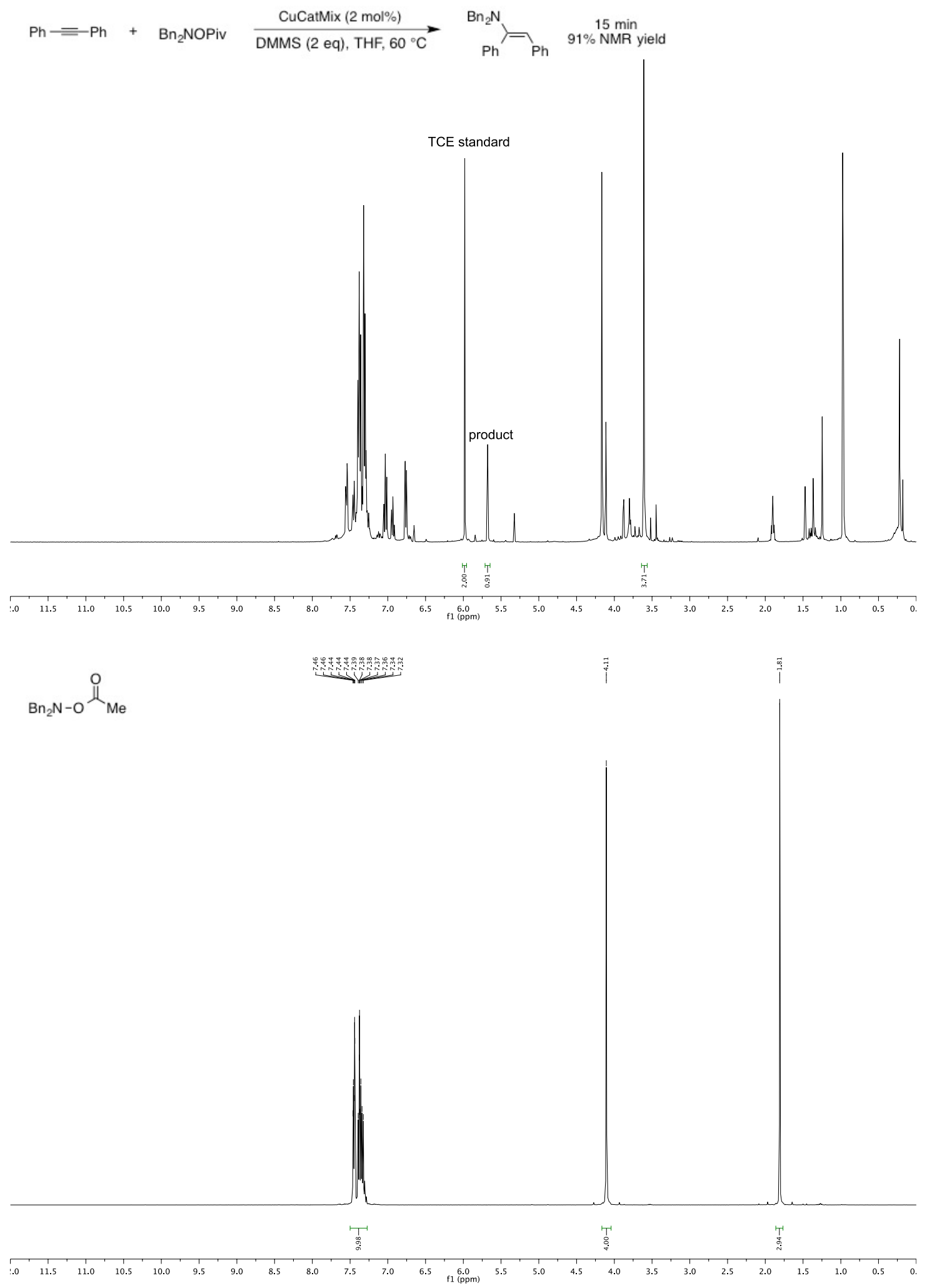



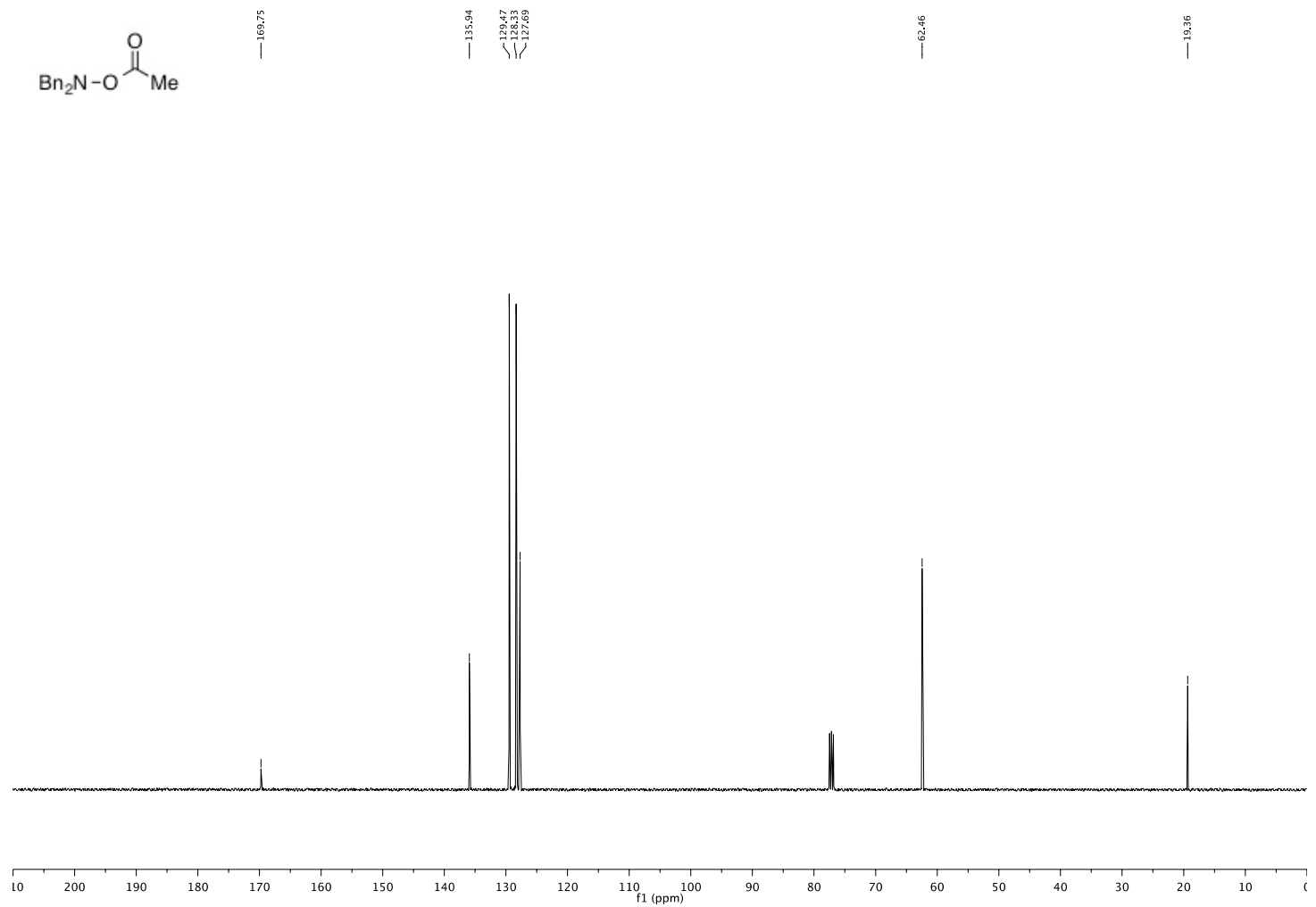

$$
\mathrm{Bn}_{2} \mathrm{~N}-\mathrm{O} \stackrel{\mathrm{O}}{\mathrm{I}} \mathrm{Bu}^{\mathrm{B}}
$$

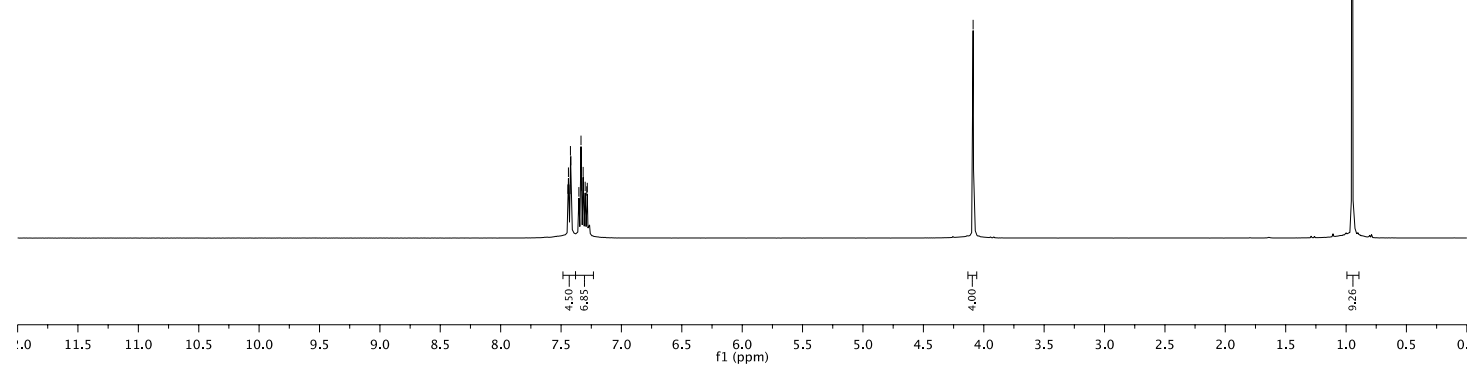



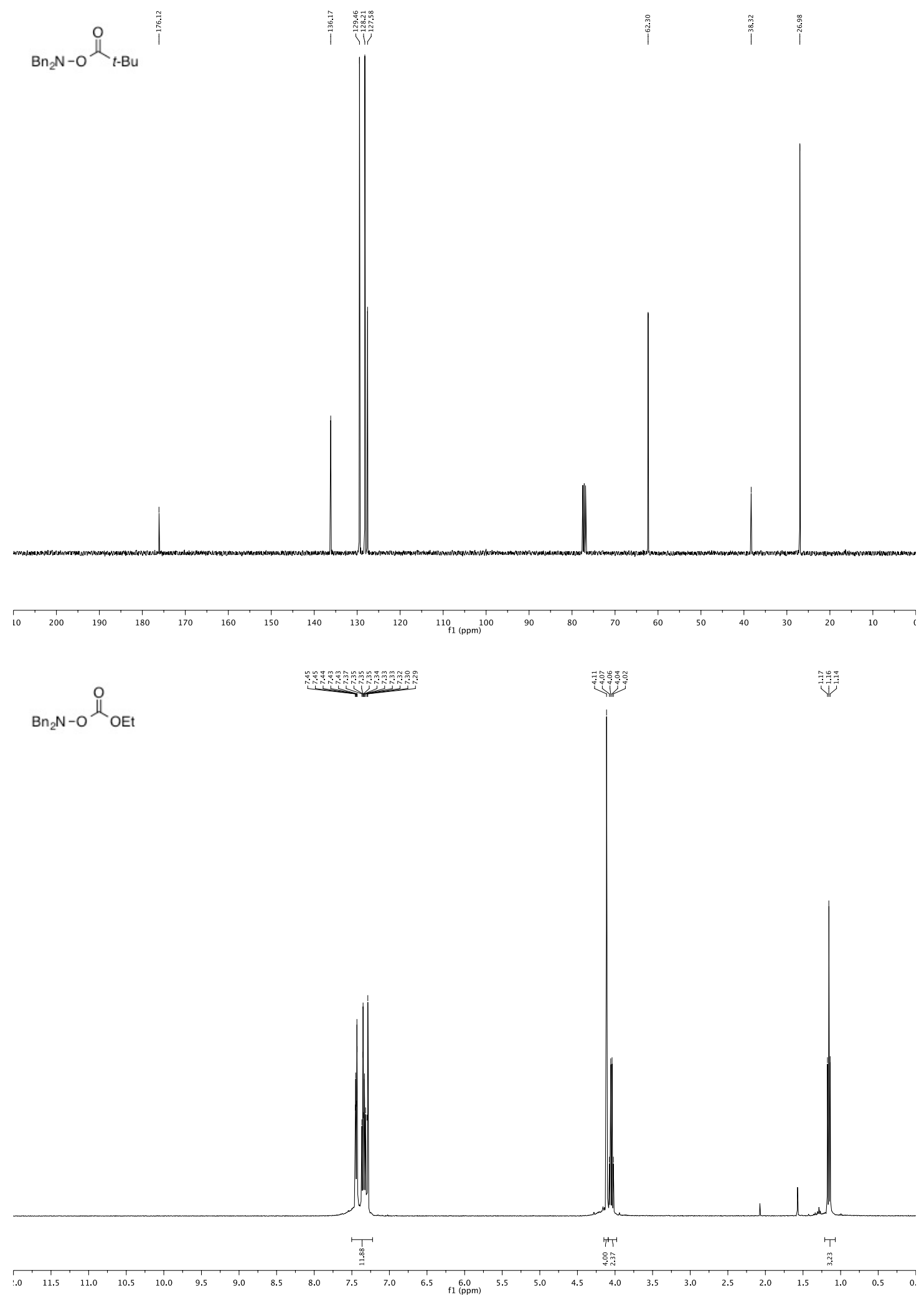

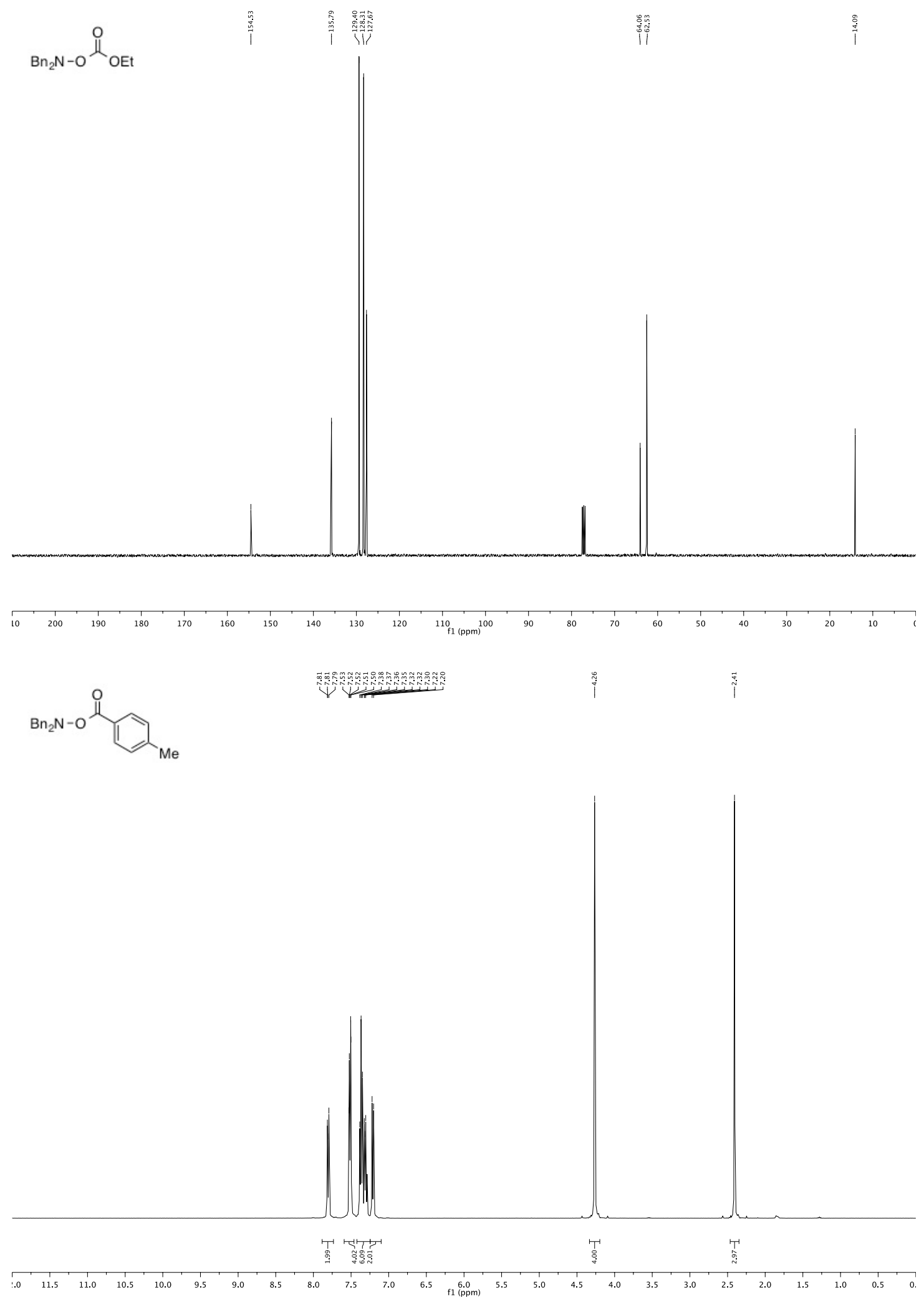

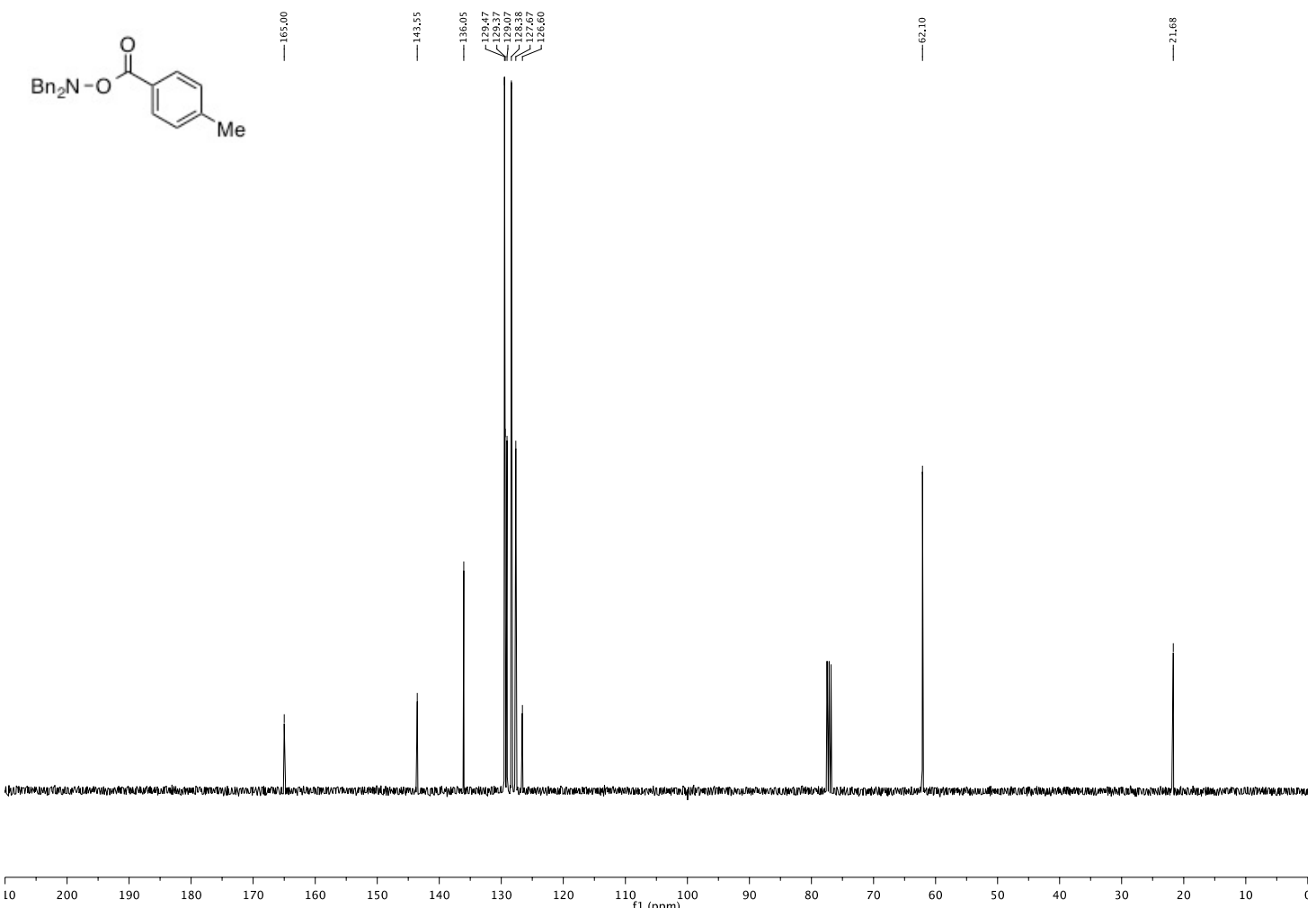